\title{
MEASURING LIQUEFIED RESIDUAL STRENGTH USING FULL-SCALE SHAKE TABLE CYCLIC SIMPLE SHEAR TESTS
}

\author{
A Thesis \\ Presented to \\ The Faculty of California Polytechnic State University, \\ San Luis Obispo \\ In Partial Fulfillment \\ Of the Requirements for the Degree \\ Master of Science in Civil and Environmental Engineering
}

By

Taylor Ryan Honnette

November 2018 
(C) 2018

Taylor Ryan Honnette

ALL RIGHTS RESERVED 
TITLE: Measuring Liquefied Residual Strength Using Full-Scale Shake Table Cyclic Simple Shear Tests

AUTHOR: Taylor Ryan Honnette

DATE SUBMITTED: November 2018

COMMITTEE CHAIR: Dr. Robb Moss, Ph.D., PE, F.ASCE

Professor of Civil Engineering

COMMITTEE MEMBER: Mr. Nephi Derbidge

Lecturer of Civil Engineering

COMMITTEE MEMBER: Dr. Gregg Fiegel, Ph.D., PE, GE

Professor of Civil Engineering 


\begin{abstract}
Measuring Liquefied Residual Strength Using Full-Scale Shake Table Cyclic Simple Shear Tests

Taylor Ryan Honnette
\end{abstract}

This research consists of full-scale cyclic shake table tests to investigate liquefied residual strength of \#2/16 Monterey Sand. A simple shear testing apparatus was mounted to a full-scale one-dimensional shake table to mimic a confined layer of saturated sand subjected to strong ground motions. Testing was performed at the Parson's Geotechnical and Earthquake Laboratory at California Polytechnic State University, San Luis Obispo. T-bar penetrometer pullout tests were used to measure residual strength of the liquefied soil during cyclic testing. Cone Penetration Testing (CPT) was performed on the soil specimen throughout testing to relate the laboratory specimen to field index test data and to compare CPT results of the \#2/16 Monterey sand before and after liquefaction. The generation and dissipation of excess pore pressures during cyclic motion are measured and discussed. The effects of liquefied soil on seismic ground motion are investigated. Measured residual strengths are compared to previous correlations comparing liquefied residual strength ratios and CPT tip resistance. 


\section{ACKNOWLEDGMENTS}

Foremost, I would like to thank my advisor, Dr. Robb Moss, for his constant guidance and input throughout this research. His thoughtful recommendations and analyses proved invaluable to this project. I am truly appreciative for all the extra time and support Dr. Moss invested into my education.

Mr. Derbidge's expertise in geotechnical laboratory testing was heavily utilized throughout this process. His ability to quickly and thoughtfully answer my constant inquiries regarding laboratory testing and soil mechanics were vital to this investigation.

Dr. Fiegel's commitment to educational and engineering excellence is evident in his courses and feedback. His courses provided me with a strong understanding of the fundamentals of geotechnical engineering.

The Cal Poly Civil Engineering Department faculty and staff provided the necessary materials to complete this research. Special consideration given to: Ron Leverett, Amy Sinclair, Dr. Charles Chadwell, and Xi Shen.

Lastly, I would like to thank my fellow students for their assistance in transporting and constructing materials and equipment used in this research: Brock Andrew, Cory Wallace, Austin Della, and Kyle Kao.

Thank you all for your dedication and support. 


\section{TABLE OF CONTENTS}

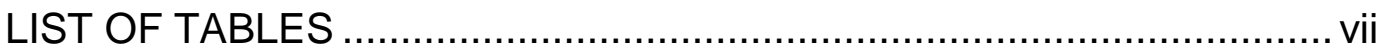

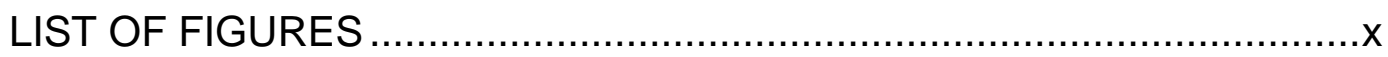

\section{CHAPTER}

1. LITERATURE REVIEW ....................................................... 1

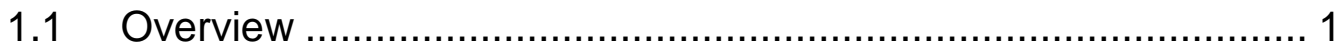

1.2 Seismically-induced liquefaction mechanics............................. 2

1.3 Liquefaction Triggering ........................................................ 3

1.4 Residual Strength Estimation ............................................. 9

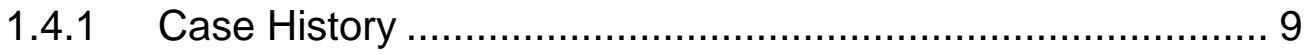

1.4.2 Laboratory Testing ...................................................... 14

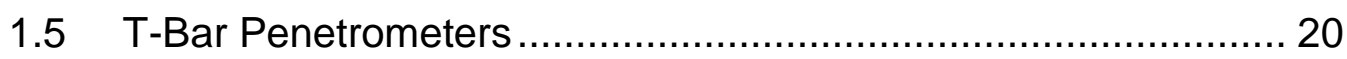

1.6 Full-Scale Shake Table Testing ............................................ 22

2. EQUIPMENT AND INSTRUMENTATION ...................................... 25

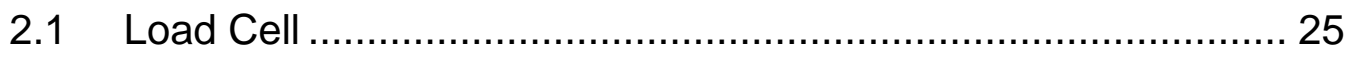

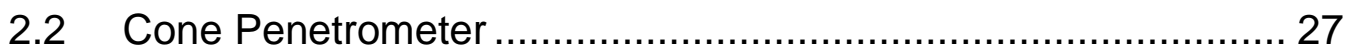

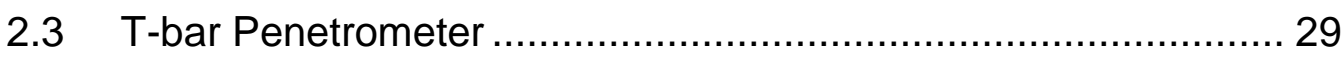

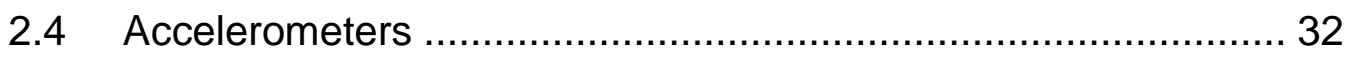

2.5 Pore Pressure Transducers................................................... 33

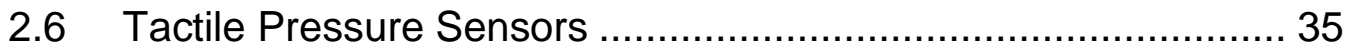

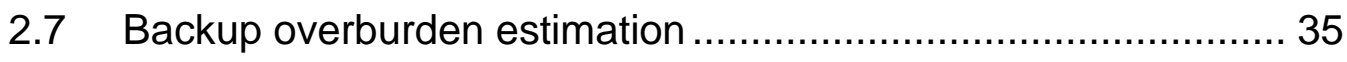

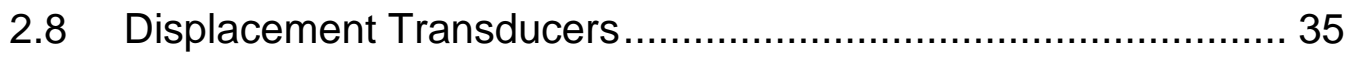

2.9 Flexible Walled Testing Apparatus ......................................... 36

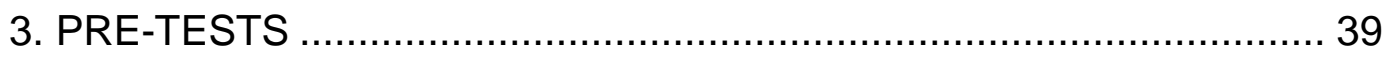

3.1 Dry Pluviated Trash Can Test .................................................. 39

3.2 Wet Pluviated Trash Can Test 1 .............................................. 46

3.3 Wet Pluviated Trash Can Test 2 ........................................... 51

3.4 Shake Table Transfer Function ............................................. 52 


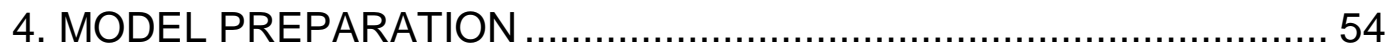

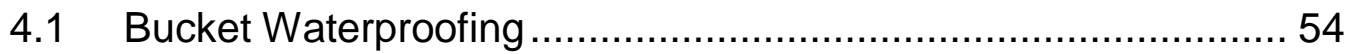

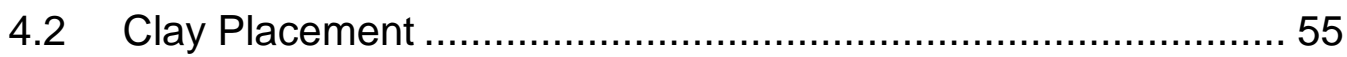

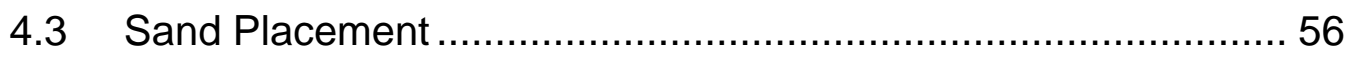

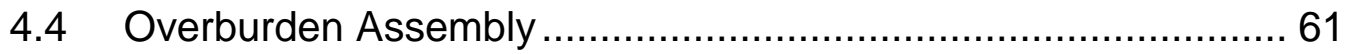

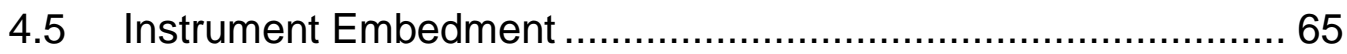

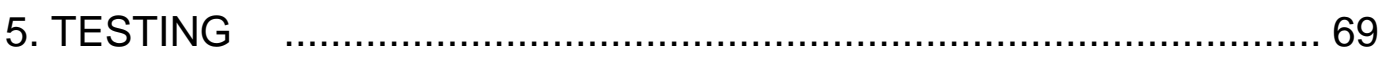

5.1.1 Pre-Liquefaction Shear Wave Velocity............................... 69

5.1.2 Initial Cone Penetration Test Sounding (CPT_1.1) .............. 71

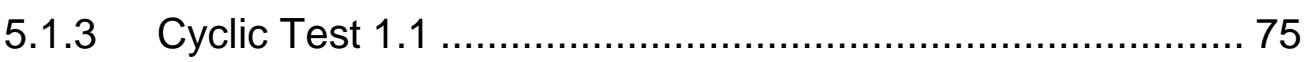

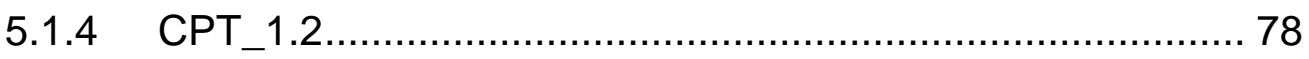

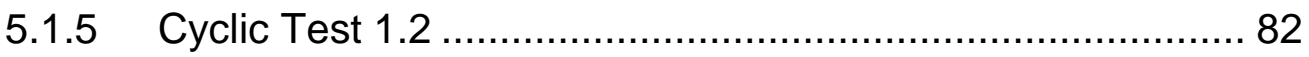

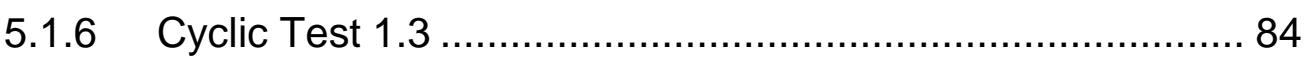

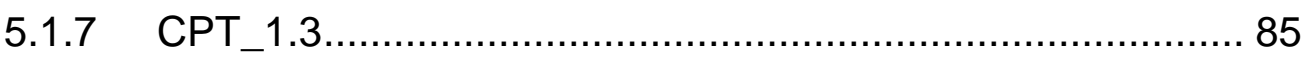

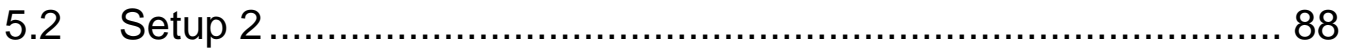

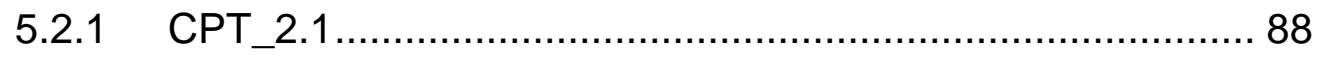

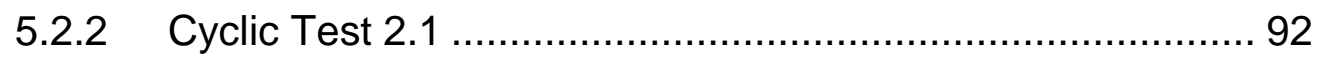

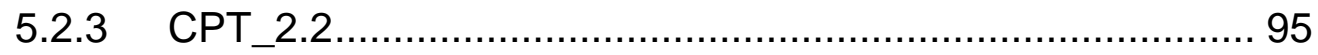

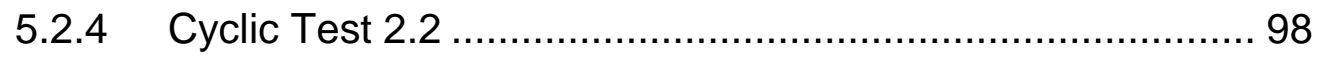

5.2 .5 CPT_2.3................................................................ 100

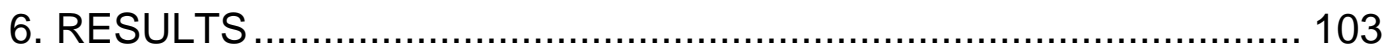

6.1 Data Acquisition ............................................................... 103

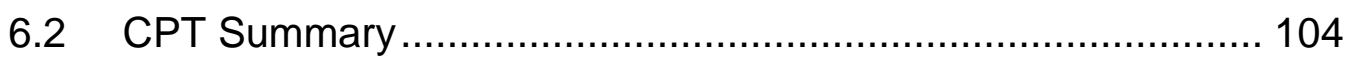

6.3 T-Bar Penetrometer Summary .......................................... 105

6.4 Pore Pressure Dissipation ................................................. 108

6.5 Liquefied Soil Effects on Motion .......................................... 109

6.6 Liquefied Residual Strength Estimation................................. 112

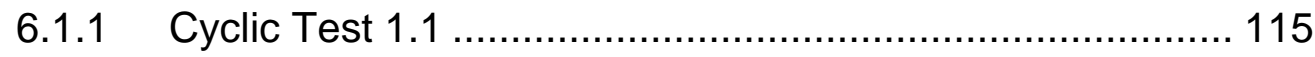

6.1.2 Cyclic Test 2.1 ..................................................... 117 
7. CONCLUSIONS AND RECOMMENDATIONS FOR FUTURE

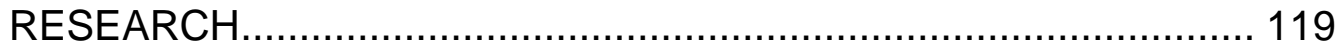

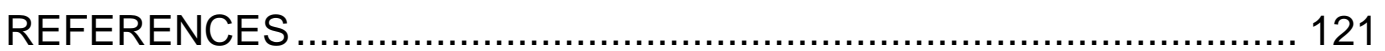

\section{APPENDICES}

A. T-bar Penetrometer Testing .............................................. 128 


\section{LIST OF TABLES}

Table

Page

1. Accelerometer Calibration Values ................................................. 33

2. Pore Pressure Transducer Calibration Values.................................. 34

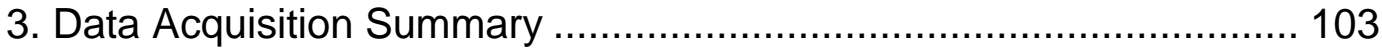




\section{LIST OF FIGURES}

$\begin{array}{lll}\text { Figure Page } & \end{array}$

1. Key Elements of Soil Liquefaction Engineering (Seed et al., 2003) ....... 2

2. Evaluation of Liquefaction Potential for Fine Sands (Seed and Idriss, 1970)

3. Relationship Between Stress Ratios Causing Liquefaction and N1values for Clean Sands for $M=7.5$ Earthquakes (Seed and Idriss, 1971) 6

4. Vs Curves Recommended at Various Fines (Andrus and Stokoe,

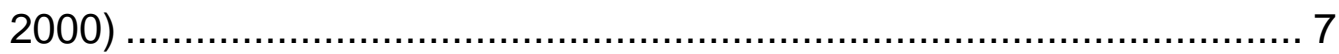

5. Contours of Probability of Liquefaction (Moss et al., 2006) 8

6. Prefailure Vertical Effective Stress Contours and Critical Failure Surface used for Yield Strength Analysis of Mochi-Koshi Tailings Dam No.1 (Olson and Stark, 2002)

7. Comparison of Liquefied Strength Ratios and Normalized CPT Tip Resistance for Liquefaction Flow Failures (Olson and Stark, 2003) .... 11

8. Median Residual Strengths Predicted by Model (Kramer and Wang, 2015)

9. Predicted Variation of Residual Strength with Initial Vertical Effective Strength (Kramer and Wang, 2015).

10. Comparison Between Olson and Stark (2002) and Weber et al. (2015)

11. Static Liquefaction Test, 1. Sphere Displacement, 2. Apparent Drag, 3. Pore Pressure Ratio (de Alba and Ballestero, 2006)

12. Plan and Sectional View of Typical Centrifuge Test Model Configuration (Dewoolkar et al., 2016)

13. Typical Coupon Force and Excess Pore Pressure Measurements from Centrifuge Tests (Dewoolkar et al., 2016)

14. Comparison of Measured Residual Strength and Residual Strength Ratios with SPT-based Correlations (Dewoolkar et al., 2016) 
15. Field T-Bar Penetrometer (Stewart and Randolph, 1994) 21

16. Model Sand Container and Embedded Pipe (Towhata et al., 1999) .. 22

17. Time Histories of Surface Ground Displacement in Front of Pile Group (Motamad and Towhata, 2010) ........................................... 24

18. Tovey Engineering SSC-500 Load Cell ......................................... 26

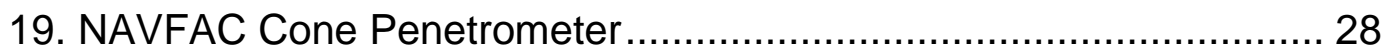

20. CPT Data Acquisition Interface.................................................. 29

21. T-Bar Penetrometer (from Crosariol, 2010) ...................................... 30

22. Eyelet Connector for T-Bar Penetrometer ...................................... 31

23. Pore Pressure Transducer and Accelerometer Instrument Package (From Jacobs, 2016) ................................................................ 34

24. Calibration of Cable Extension Position Sensors............................... 36

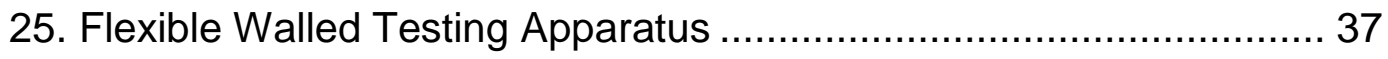

26. Site Response (solid) vs Predicted Response (dashed) Spectra

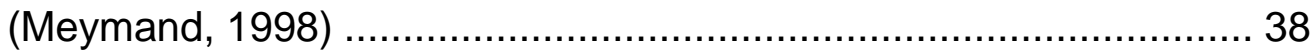

27. Dry Pluviated 44 Gallon Test Sample ............................................. 40

28. Average Dry Pluviated T-bar Pullout Pressure ................................ 41

29. Dry Trash CPT 1.2 Corrected CPT Tip Resistance ........................ 43

30. Dry Trash CPT 1.2 Sleeve Friction ............................................... 44

31. Dry Trash CPT 1.2 Friction Ratio................................................. 45

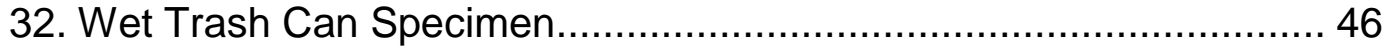

33. Average Wet Pluviated Trash 1 T-bar Pullout Pressure ................... 47

34. Wet Trash CPT 1.1 Corrected CPT Tip Resistance ....................... 48

35. Wet Trash CPT 1.1 Sleeve Friction ............................................... 49

36. Wet Trash CPT 1.1 Friction Ratio ................................................... 50

37. Wet Trash 2 T-bar Pullout Pressures ............................................. 51

38. Sine Sweep Fast Fourier Transformation of the Uppermost Accelerometer (From Jacobs, 2016) ............................................ 53

39. Flexible Walled Testing Apparatus ................................................ 54

40. Clay Mixture and Filter Fabric at Base of Specimen ......................... 56 
41. Approximate Grain Size Distribution of \#2/16 Monterey Sand

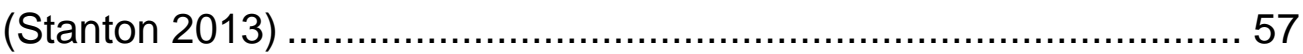

42. Large-Scale Pluviation Device ................................................... 58

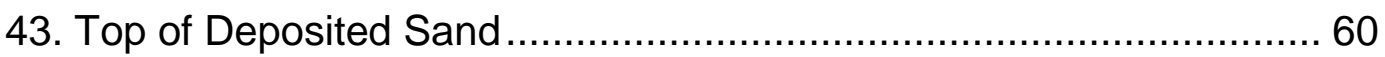

44. Bottom Plates of Overburden Assembly ......................................... 62

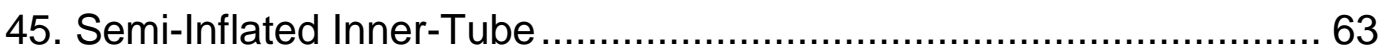

46. Completed Overburden Assembly .................................................. 64

47. Accelerometer Embedment in Sand ..................................................6 66

48. Top View of Completed Specimen ................................................ 67

49. Schematic Section of Completed Specimen ..................................... 68

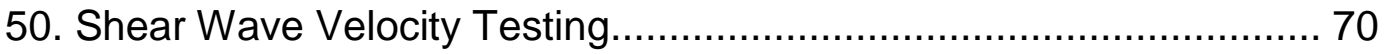

51. CPT 1.1 Corrected Tip Resistance …........................................... 72

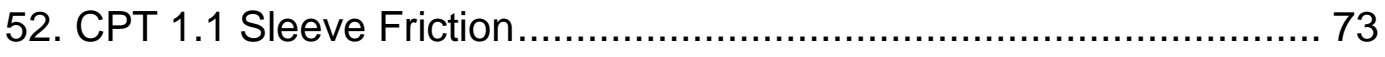

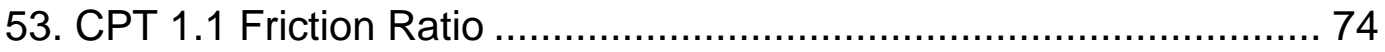

54. Shake Table Control Output ........................................................ 75

55. Cyclic Test 1.1 T-bar Pullout Pressure .......................................... 76

56. Displaced Bucket After Cyclic Test 1.1 ......................................... 77

57. CPT 1.2 Corrected Tip Resistance ….............................................. 79

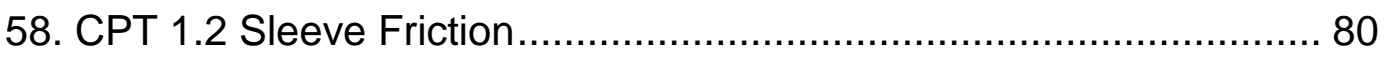

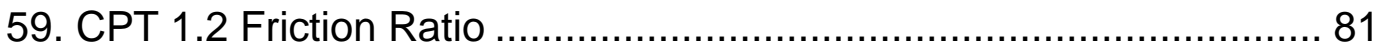

60. Cyclic Test 1.2 Excess Pore Pressures ........................................... 83

61. Cyclic Test 1.3 T-Bar Pullout Pressure ........................................... 84

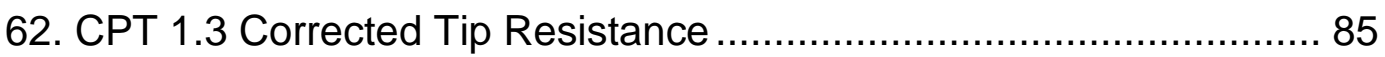

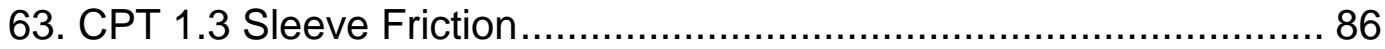

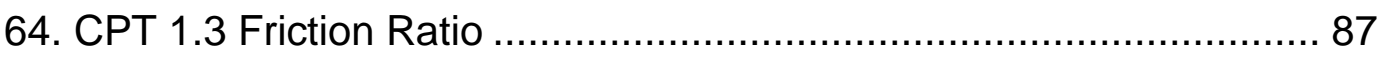

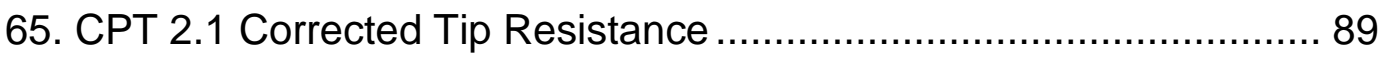

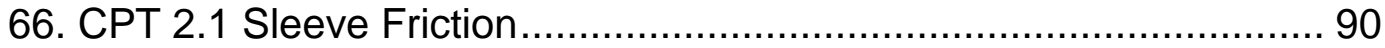

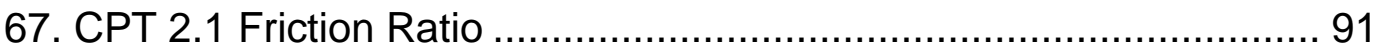

68. Cyclic Test 2.1 T-bar Pullout Pressure .......................................... 92

69. Cyclic Test 2.1 Excess Pore Pressures .......................................... 93

70. Displaced Bucket After Cyclic Test 2.1 ......................................... 94 
71. CPT 2.2 Corrected Tip Resistance …............................................ 95

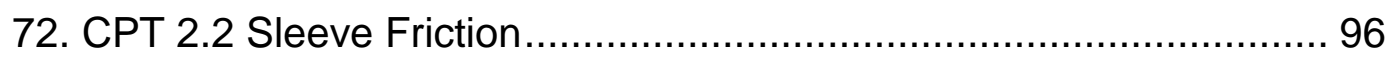

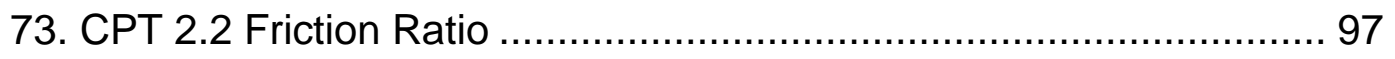

74. Cyclic Test 2.2 T-bar Pullout Pressure ............................................. 99

75. CPT 2.3 Corrected Tip Resistance .................................................. 100

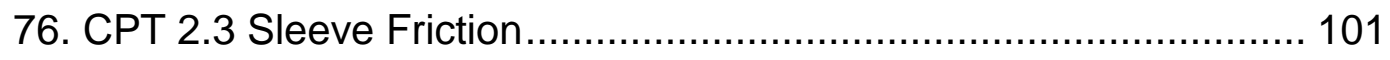

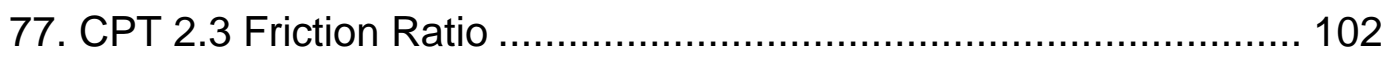

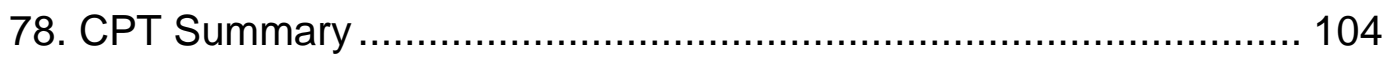

79. T-bar Pullout Pressure Summary ……………............................ 106

80. T-bar Pullout Pressure Cyclic Tests 1.1 and 2.1......................... 107

81. Cyclic Test 2.1 Excess Pore Pressures ......................................... 108

82. Cyclic Test 2.1 Accelerations ...................................................... 109

83. Comparison of Excess Pore Pressures and Accelerations (Cyclic

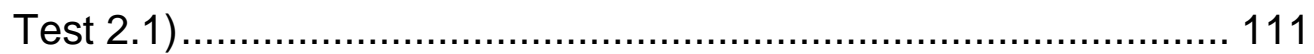

84. Su Calculated from T-bar Pullout Test Summary ............................ 113

85. Comparison of Su Calculated from T-bar Pullout Test Cyclic Tests

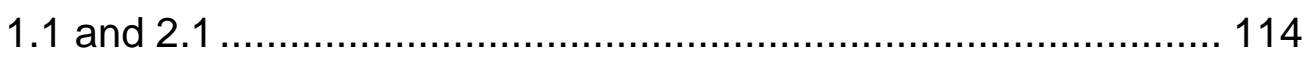

86. Cyclic Test 1.1 Liquefied Strength Ratio vs. Normalized CPT Tip Resistance 115

87. Comparison of Cyclic Test 1.1 Results to Olson and Stark (2003) .. 116 88. Cyclic Test 2.1 Liquefied Strength Ratio vs. Normalized CPT Tip

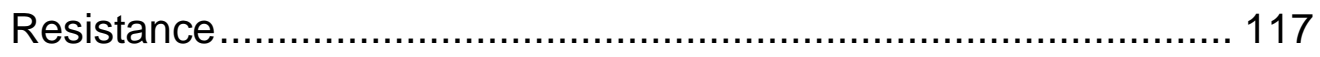

89. Comparison of Cyclic Test 2.1 Results to Olson and Stark (2003) .. 118 


\section{CHAPTER 1 LITERATURE REVIEW}

\subsection{Overview}

In areas underlain by loose saturated granular materials, soil liquefaction can be a major cause of damage in earthquake events. Soil liquefaction has been an area of extensive research in geotechnical engineering for over 50 years. The phenomenon was thrust into the geotechnical engineering world following two earthquakes in 1964: the Niigata, Japan and Great Alaskan earthquakes. Both events resulted in damage caused by seismically induced liquefaction (Seed et al., 2003). Seed et al. (2003) established a flow chart of key elements of liquefaction engineering (Figure 1). The research contained herein attempts to provide additional laboratory data for

step 2: assessment of post-liquefaction strength and overall post liquefaction stability. 


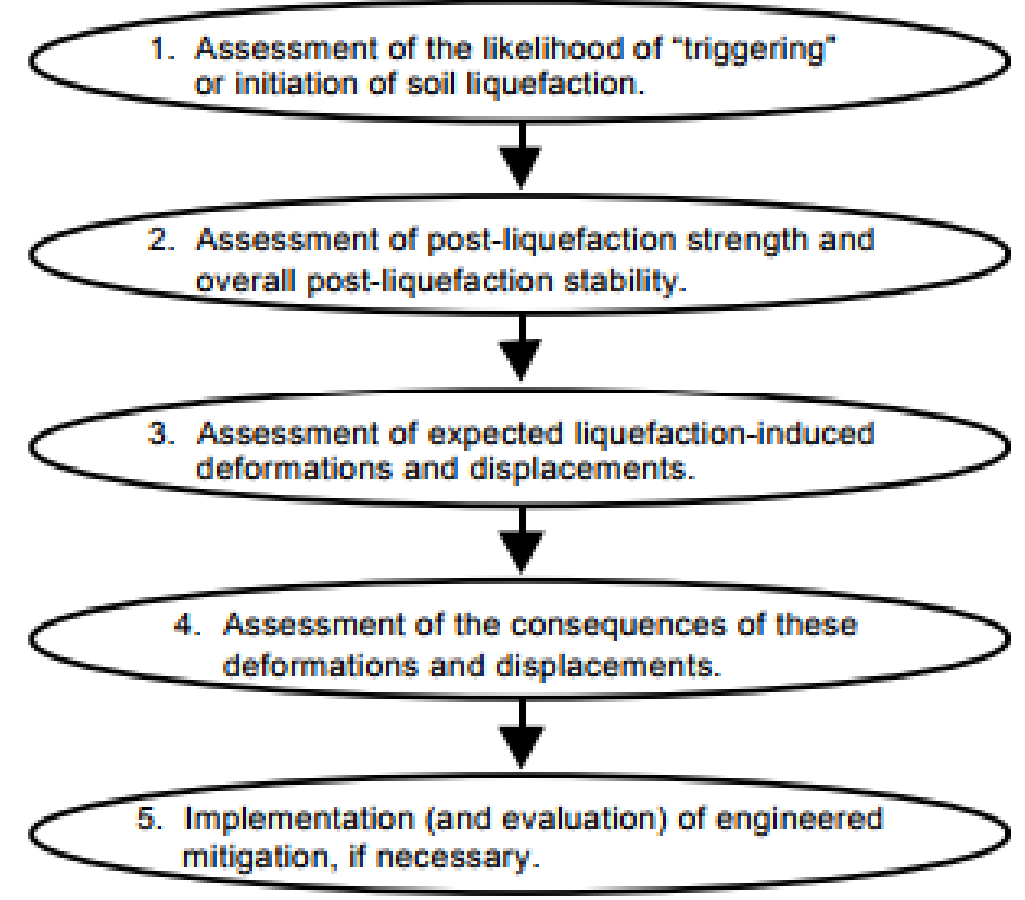

Figure 1: Key Elements of Soil Liquefaction Engineering (Seed et al., 2003)

\subsection{Seismically-induced liquefaction mechanics}

Saturated contractive sands can experience a loss of shear strength when subjected to rapid shearing strain. Rapid shearing causes the soil to develop excess pore water pressures that can cause the soil to temporarily behave as a viscous fluid, gradually regaining strength as the excess pore water pressure dissipates. Typical effects of seismically-induced liquefaction include: loss of bearing strength, lateral spreading, sand boils, flow failures, ground oscillation, flotation of underground structures, and settlement (NAE 2016). 
In past research, many terms have been used to describe the minimum strength of a soil in the liquefied state: undrained steady-state strength (Poulos et al., 1985), undrained residual shear strength (Seed, 1987), undrained critical shear strength (Stark and Mesri, 1992), shear strength of liquefied soils (Stark et al., 1998), liquefied shear strength (Olson and Stark, 2003), and residual strength (Dewoolkar et al., 2016).

This research will use the term residual strength $\left(\mathrm{S}_{\mathrm{r}}\right)$ to represent the minimum shear strength mobilized in the liquefied state.

\subsection{Liquefaction Triggering}

Engineers working with potentially liquefiable soils need to assess if liquefaction will be triggered by the earthquake motions considered in their design. The most widely used approach to assess potential for triggering liquefaction is a stress-based approach that compares the earthquakeinduced cyclic stresses with the cyclic resistance of the soil (Youd et al., 2001).

Seed and Idriss (1970) first compared the occurrence/non-occurrence of liquefaction with in-situ properties of sands in order to predict liquefaction based on in-situ tests (Figure 2). 


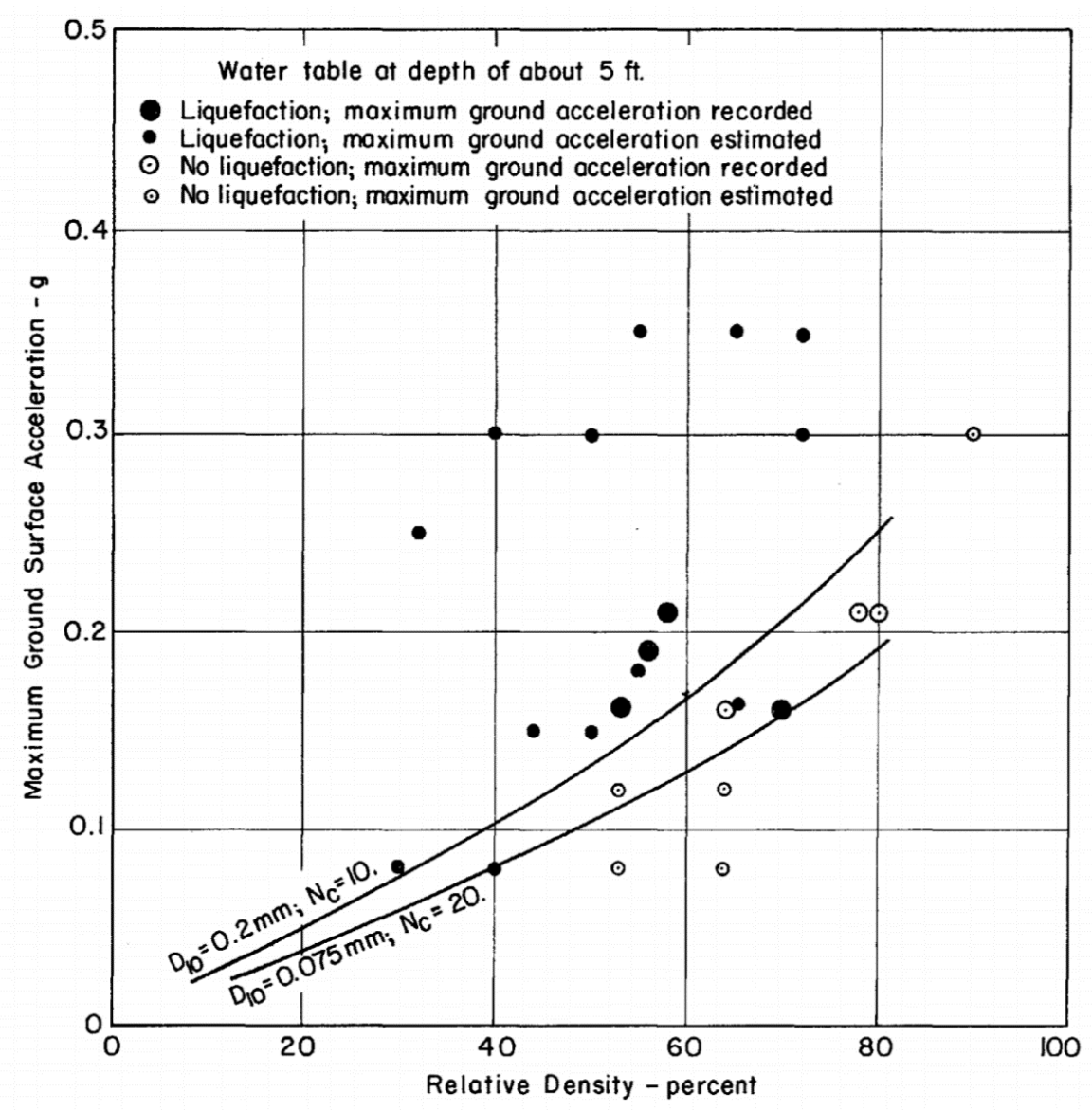

Figure 2: Evaluation of Liquefaction Potential for Fine Sands (Seed and Idriss, 1970)

Seed and Idriss (1971) further expanded on their previous research to create liquefaction triggering curves based on Standard Penetration Test (SPT) blow counts and cyclic stress ratio (CSR). CSR is the ratio of shear stress to vertical effective stress. The SPT blow counts were recorded postliquefaction. CSRs were estimated using the peak ground acceleration (PGA), duration of shaking, stress conditions of the liquefied layer, and a non-linear shear stress participation factor $\left(r_{d}\right)$. The simplified equation proposed by Seed and Idriss (1971) is:

$$
\operatorname{CSR}=\frac{\tau_{A V}}{\sigma_{0}{ }^{\prime}}=0.65 * \frac{a_{\max }}{g} * \frac{\sigma_{0}}{\sigma_{0}{ }^{\prime}} * r_{d}
$$


Seed and Idriss (1971) plotted $\left(\mathrm{N}_{1}\right)_{60}$ (SPT $\mathrm{N}$ values corrected for overburden and hammer efficiency) vs CSR for a selection set of earthquakes and marked whether or not the effects of liquefaction were observed post-shaking (Figure 3).

Over the years, researchers have added to the suite of liquefaction triggering data available in the triggering curves first presented by Seed and Idriss (1970).

Researchers created new liquefaction triggering curves based on different in-situ index tests, including CPT (Shibata and Teparaska, 1988; Seed and De Alba, 1986; Mitchell and Tseng, 1990; Stark and Olson, 1995; Suzuki et al., 1995; Robertson and Campanella, 1985; Robertson and Wride, 1998; Toprak et al., 1999; Juang et al. 2002; Moss, 2003; Moss et al., 2006; Idriss and Boulanger 2008).

An additional liquefaction triggering curve was developed using overburden-corrected shear wave velocity $\left(V_{s}\right)$ by Andrus and Stokoe (2000) (Figure 4).

Researchers have also created probabilistic correlations for the potential of triggering liquefaction to allow engineers to assess liquefaction triggering in performance-based engineering analyses (Moss et al., 2006) (Cetin et al., 2002) (Figure 5). 


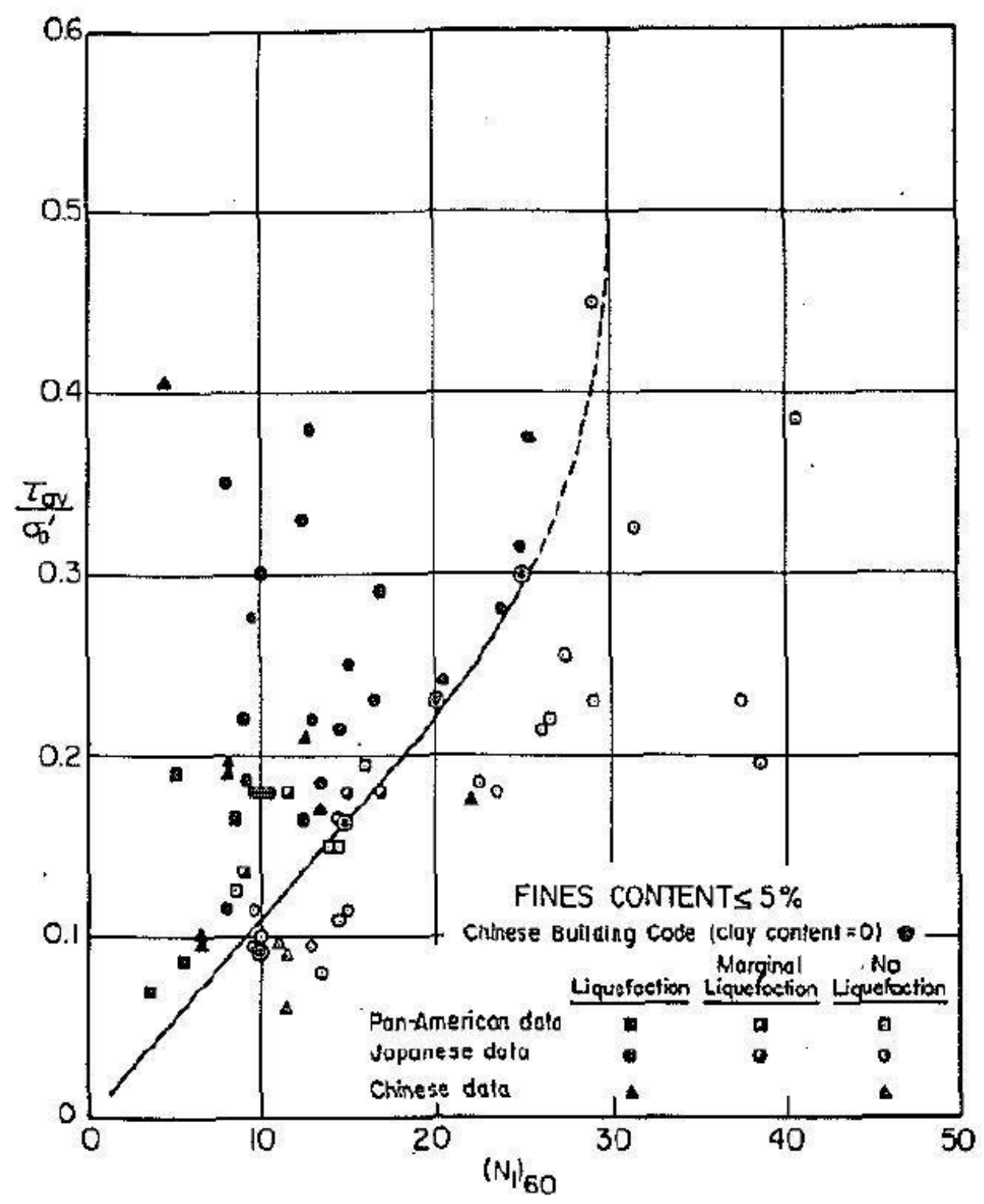

Figure 3: Relationship Between Stress Ratios Causing Liquefaction and N1-values for Clean Sands for M=7.5 Earthquakes (Seed and Idriss, 1971) 


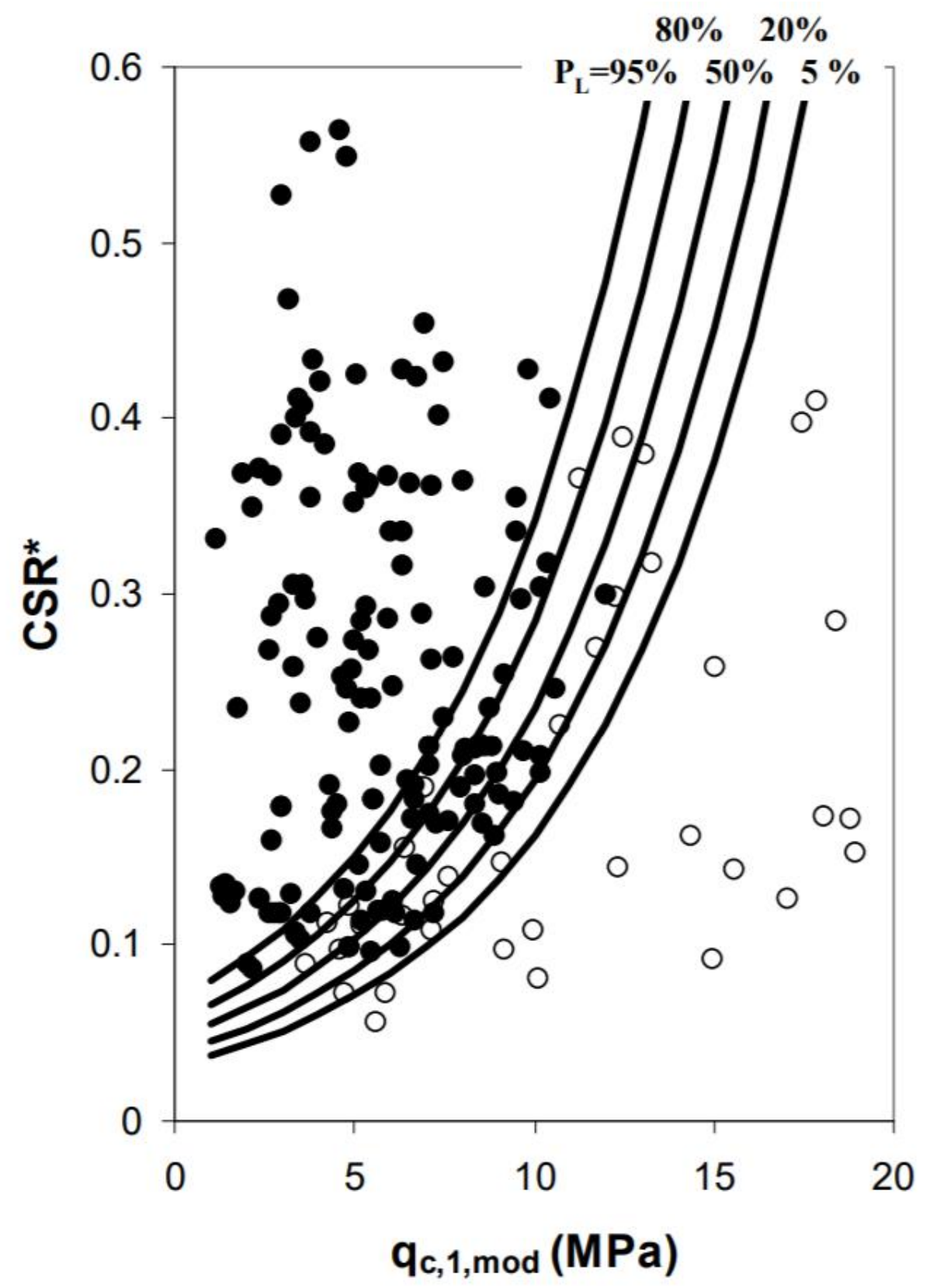

Figure 4: Vs Curves Recommended at Various Fines (Andrus and Stokoe, 2000) 


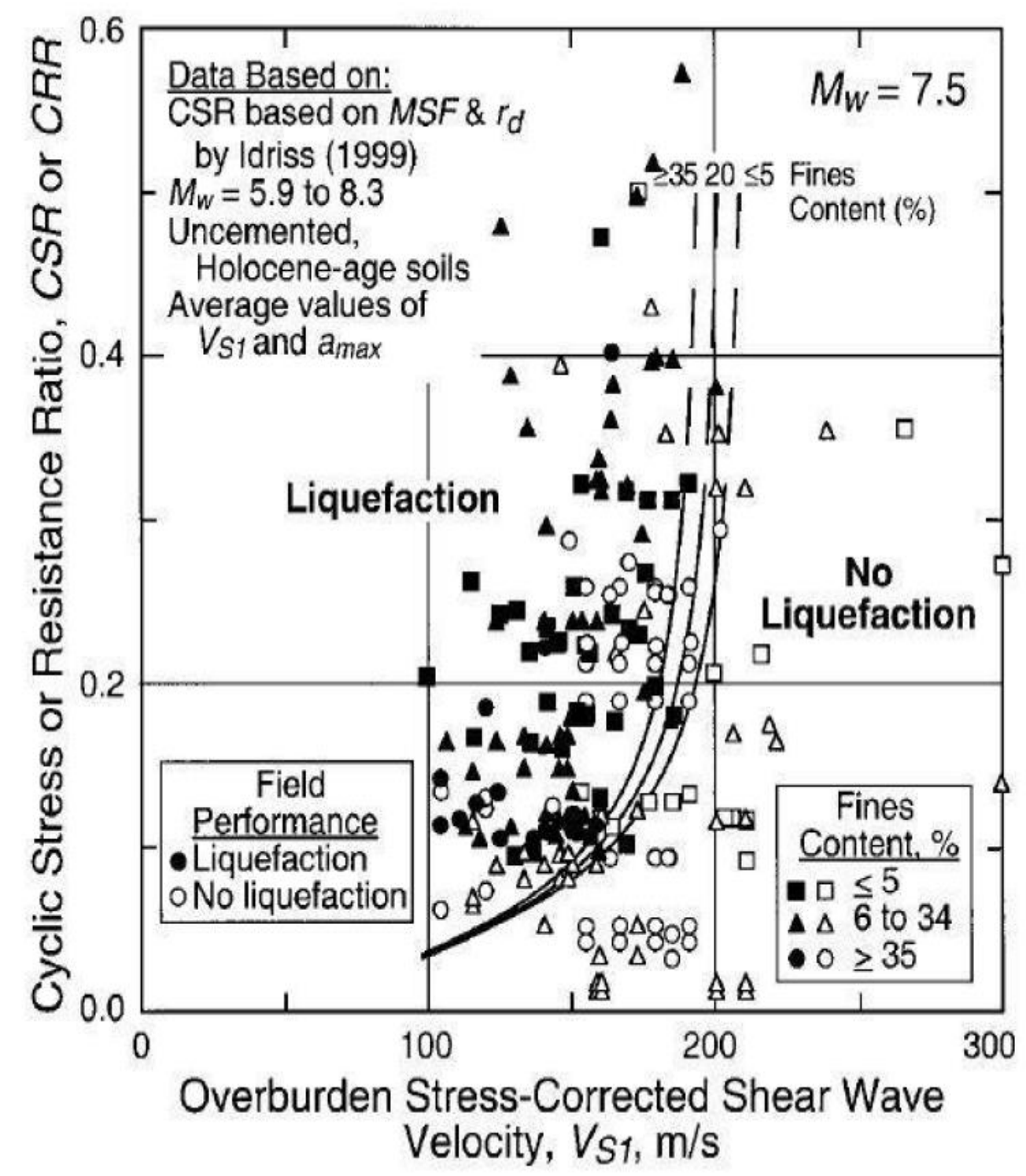

Figure 5: Contours of Probability of Liquefaction (Moss et al., 2006) 


\subsection{Residual Strength Estimation}

Static or dynamic loading of liquefiable soils can result in large permanent deformations of soil. These large deformations occur when shear stresses, dynamic or static, become larger than the available shear strength of the soil. Evaluation of this critical shear strength, residual strength, that can be mobilized by liquefiable soils is an important part of geotechnical engineering practice. Two methods are utilized to estimate residual strength of liquefiable soils: case history back-calculations and laboratory testing.

\subsubsection{Case History}

One method to estimate the residual strength of liquefied materials, is to back-calculate strengths from case history events. Seed (1986) first developed estimates for in-situ $S_{r}$ of liquefied sand using this method. Earth structures where liquefaction has occurred are modeled and analyzed to estimate $S_{r}$ of the suspected liquefied layers. Two main estimates of $S_{r}$ are evaluated using this method giving an upper and lower bound for residual strength. The upper bound is the value of $S_{r}$ that results in a sliding factor of safety of 1.0 for the undeformed (pre-failure) geometry of the earth structure. The other estimate of $S_{r}$ is performed similarly, but for the postdeformation geometry of the earth structure (Seed, 1986). This procedure has been modified and the suite of failures analyzed has been expanded by many researchers (Davis et al., 1988; Seed and Harder, 1990; Stark and 
Mesri, 1992; Ishiharara, 1993; Wride et al., 1999; Yoshimine et al., 1999; Olson and Stark, 2003; Kramer and Wang, 2015; Weber et al., 2015).

Researchers have interpreted this suite of back-calculated residual strength estimates for comparison to in-situ tests in an attempt to allow engineers to estimate $S_{r}$ for projects with liquefiable layers. Initially, $S_{r}$ was correlated with equivalent clean sand SPT corrected blow count ( $\left.\mathrm{N}_{1,60 \mathrm{cs}}\right)$ (Seed, 1987; Seed and Harder, 1990). Recent researchers have expressed $S_{r}$ as a normalized liquefied shear strength ratio $\left(\mathrm{S}_{\mathrm{r}} / \sigma^{\prime} \mathrm{vc}\right)$ (Vasquez-Herrera et al., 1990; Stark and Mesri, 1992; Yoshimine et al., 1999; Olson and Stark, 2002; Idriss and Boulanger, 2007).

Olson and Stark (2002) estimated shear strength of liquefied soil by backcalculating 33 cases of static liquefaction flow failure (Figure 6). They proposed a linear relationship between yield shear strength and pre-failure vertical effective stress. Olson and Stark (2003) correlated the yield strength ratios to corrected SPT and CPT penetration resistance (Figure 7). These correlations allow for an analysis of liquefaction susceptibility and an estimation of yield strength ratio with the proposed relationships using penetration resistance. 


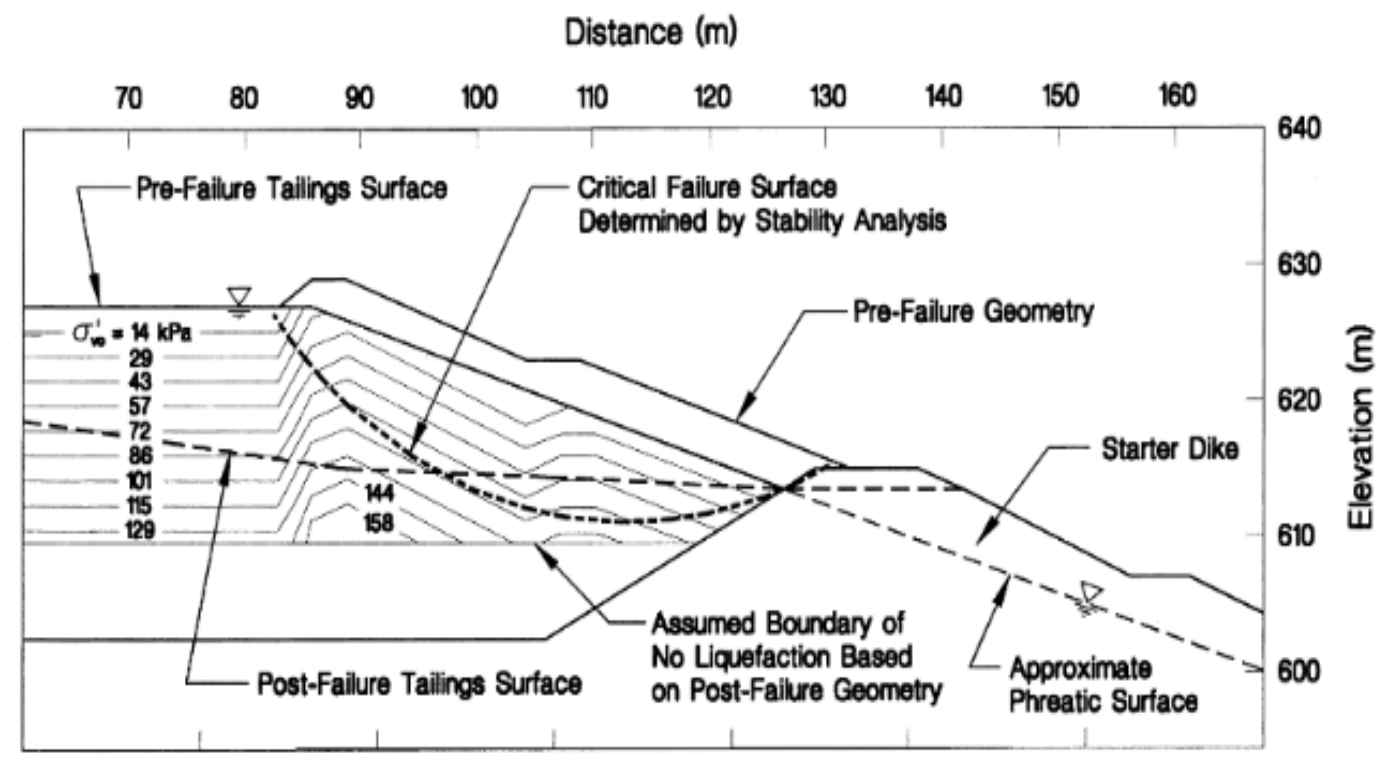

Figure 6: Prefailure Vertical Effective Stress Contours and Critical Failure Surface used for Yield Strength Analysis of Mochi-Koshi Tailings Dam No. 1 (Olson and Stark, 2002)

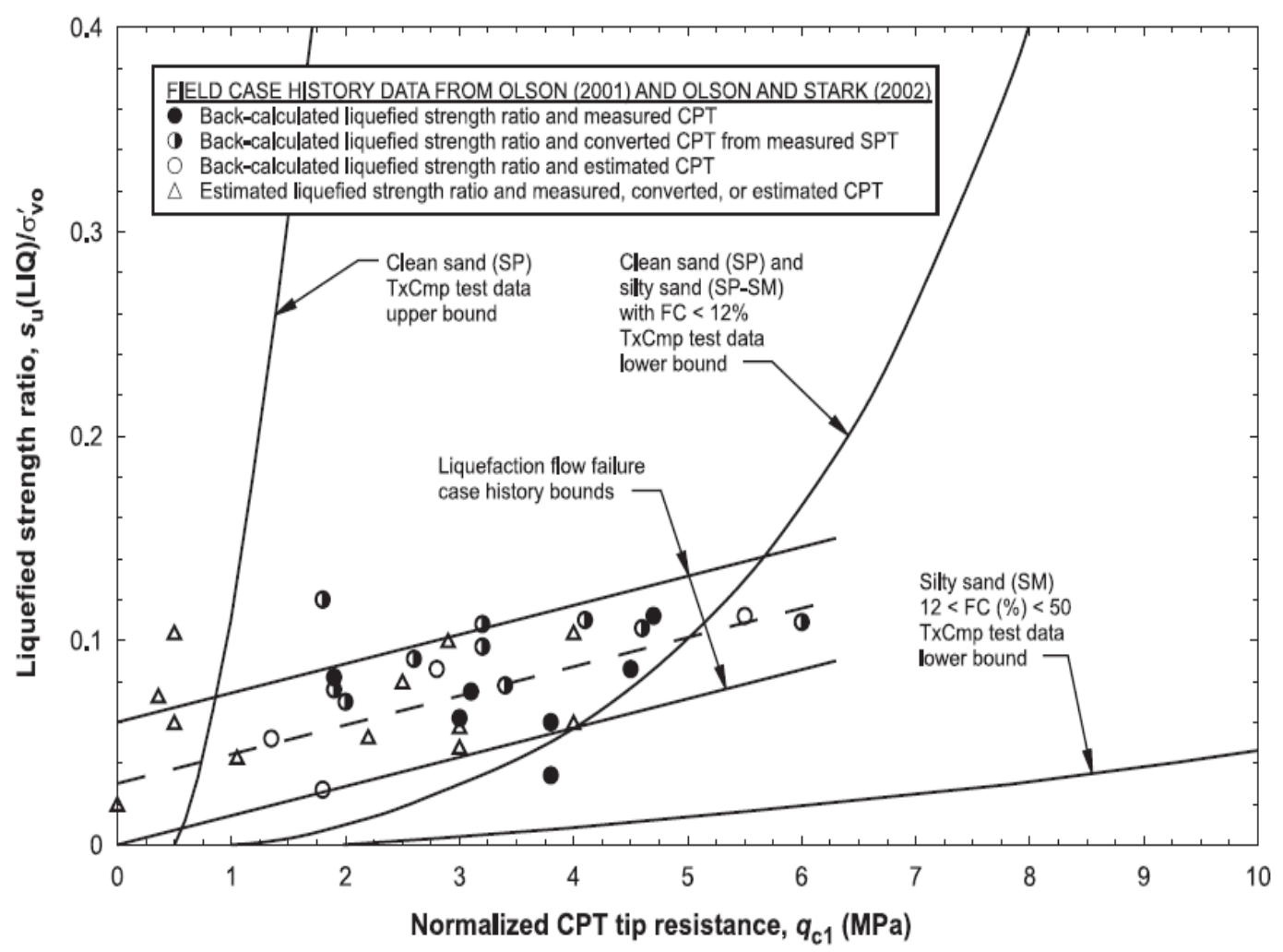

Figure 7: Comparison of Liquefied Strength Ratios and Normalized CPT Tip Resistance for Liquefaction Flow Failures (Olson and Stark, 2003) 
Kramer and Wang (2015) developed an alternative approach to the backanalysis of flow slide case histories. The alternate procedure attempts to characterize and account for uncertainties in the case histories, correct for inertial effects, and evaluate the quality of each case. Using the results of this alternate procedure, Kramer and Wang created a new model for estimating the residual strength of liquefied soil. Included in this new model are multiple forms of equations, direct and normalized, that relate residual strength to SPT resistance while accounting for effective stress (Figure 8, Figure 9).

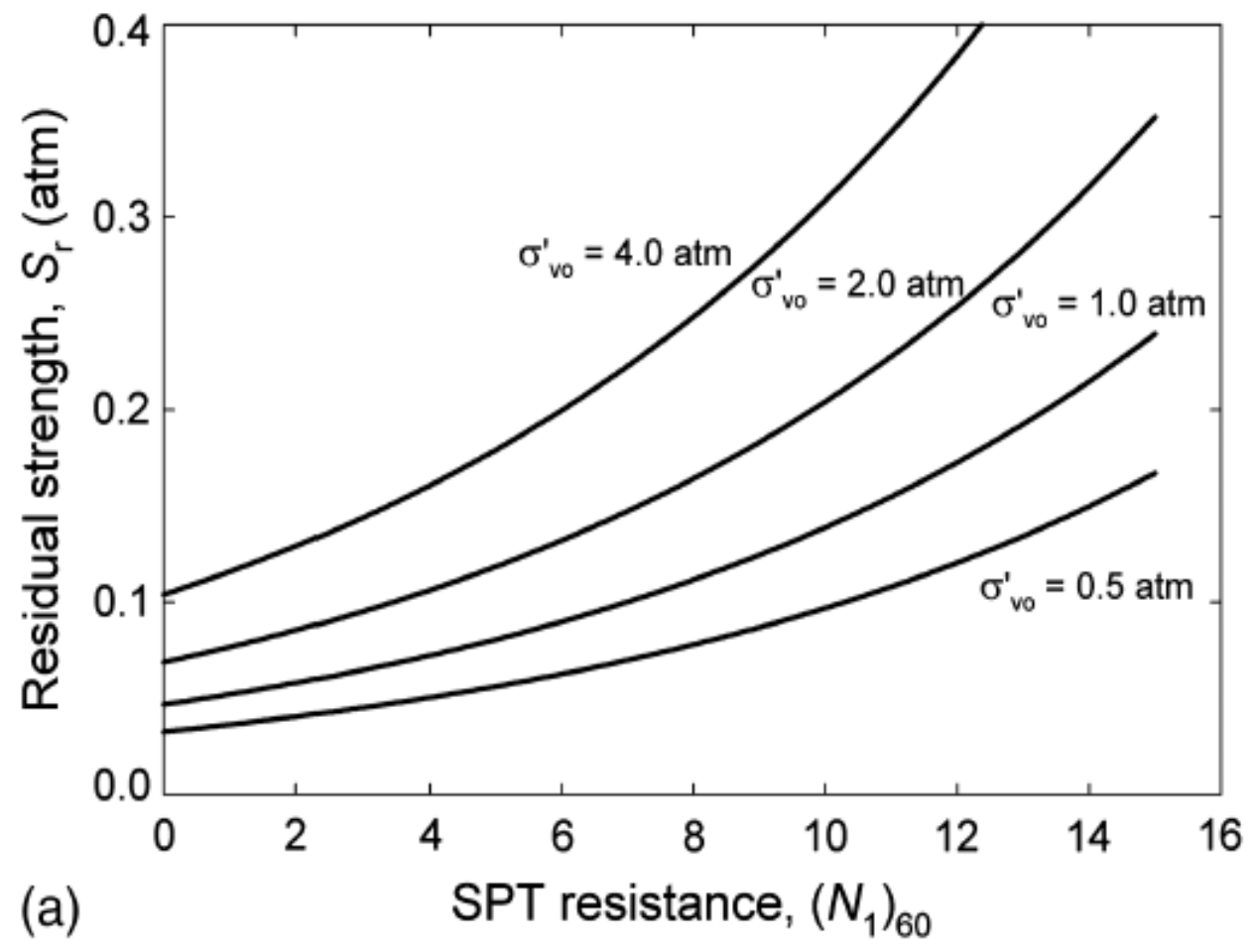

Figure 8: Median Residual Strengths Predicted by Model (Kramer and Wang, 2015) 


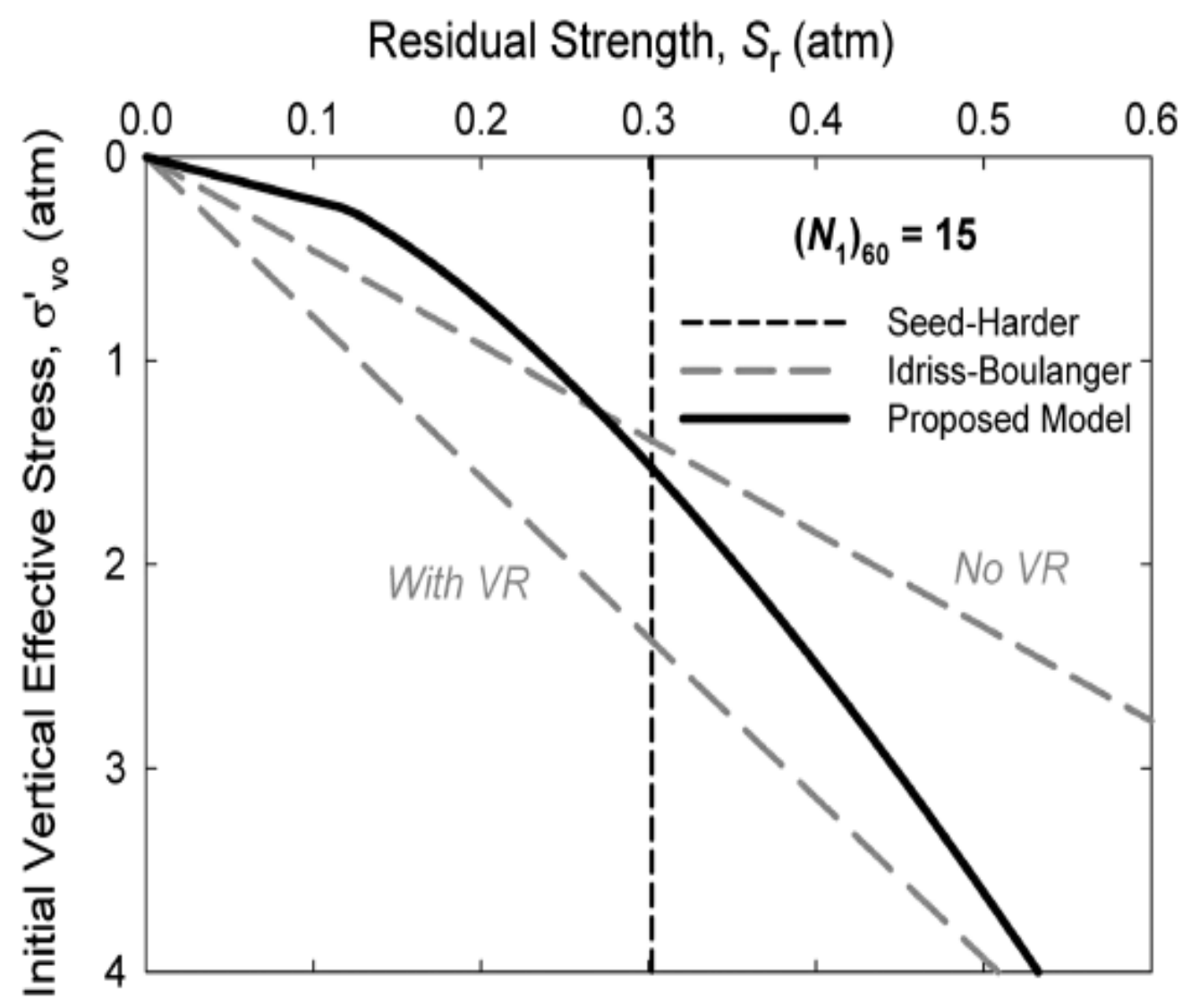

Figure 9: Predicted Variation of Residual Strength with Initial Vertical Effective Strength (Kramer and Wang, 2015)

Weber et al. (2015) also developed new methods for the evaluation of in situ liquefied strengths using full-scale liquefaction failure case histories. Like Kramer and Wang (2015), Weber et al. (2015) used a suite of 30 backanalyzed full-scale field liquefaction failures including inertial effects. This research created new predictive strength relationships that reasonably agree with previous recommendations over the lower ranges of effective stress and penetration resistance for higher ranges. These relationships were presented in a fully probabilistic form which could be used for risk studies, but were also simplified to deterministic recommendations that 
could be applied to simpler analyses. Figure 10 shows a comparison between the proposed relationships of Olson and Stark (2002) and Weber et al. (2015).

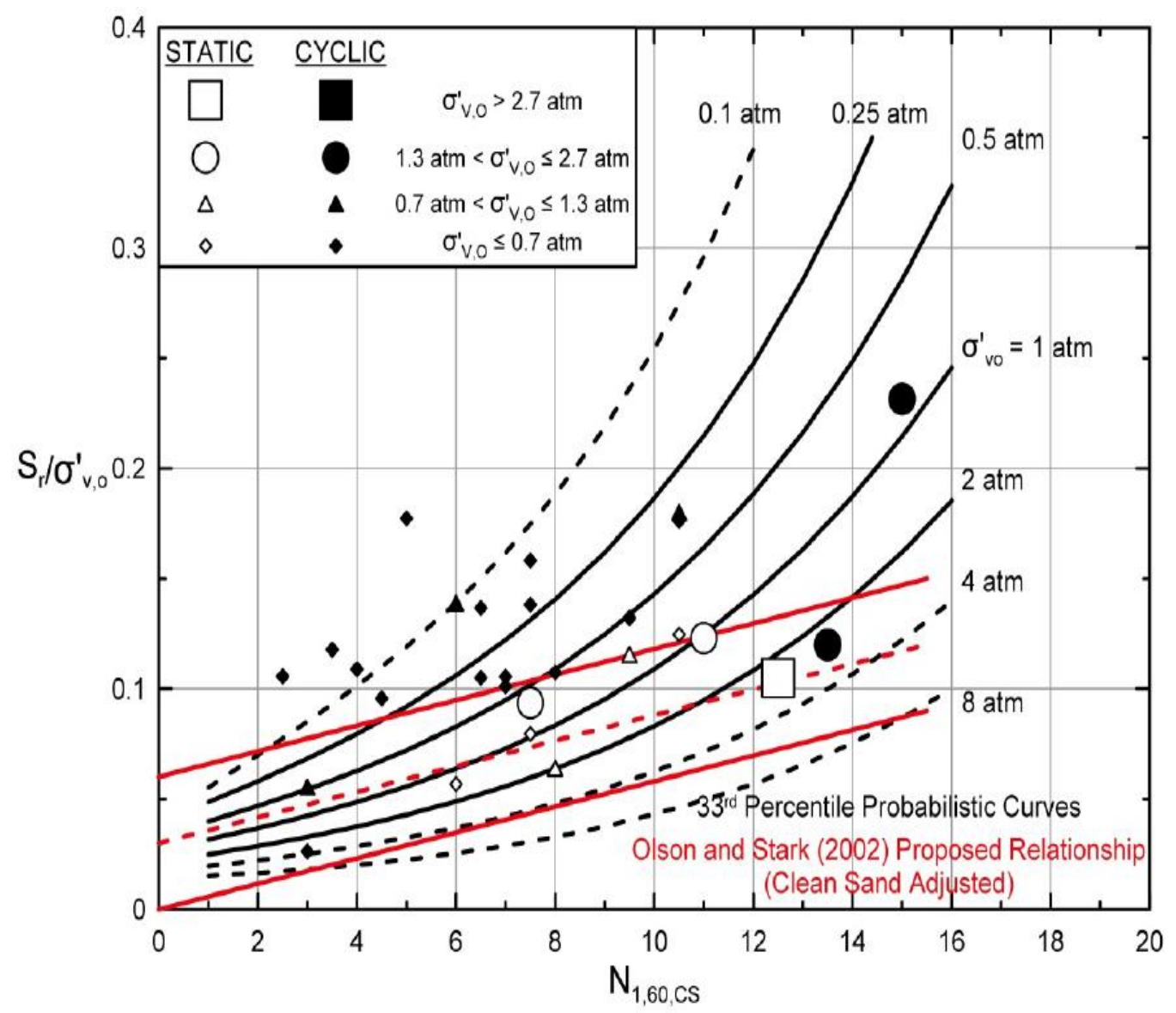

Figure 10: Comparison Between Olson and Stark (2002) and Weber et al. (2015)

\subsubsection{Laboratory Testing}

Laboratory tests used to estimate liquefied residual strength should be performed under similar loading conditions to field conditions because the measured shear resistance of the sample depends on consolidation stresses and the loading direction (Idriss and Boulanger, 2008). Traditional lab testing results in estimates of Scs (critical-state shear resistance) or 
Soss (quasi steady state shear resistance) that correspond to the void ratio of the sample when tested. Traditional laboratory testing is unable to replicate void redistribution, particle intermixing, and other field mechanisms that occur during earthquake motions. These mechanisms are difficult for engineers to estimate and quantify their effect on strengths measured in lab, making the results of these tests difficult to rely on in design (Idriss and Boulanger, 2008).

De Alba and Ballestero (2006) measured residual shear strength of liquefied sands using a sphere pulled through long triaxial specimens (Figure 11). Their research studied the effect of loading rate and drainage conditions on residual strength. De Alba and Ballestero found that liquefied sand behaves like a Bingham plastic with a residual strength that depends on strain rate up to a strain rate of about $100 \%$ strain per second. The shear resistance of the liquefied material above the transition shear strain rate (about $100 \%$ strain per second) tended to flatten out and not depend on strain rate. Their research showed that below the transition strain rate, residual strength remained proportional to initial effective stress. The dependency on strain rate helps explain the large variability in residual strength values estimated and back-calculated in previous studies. 


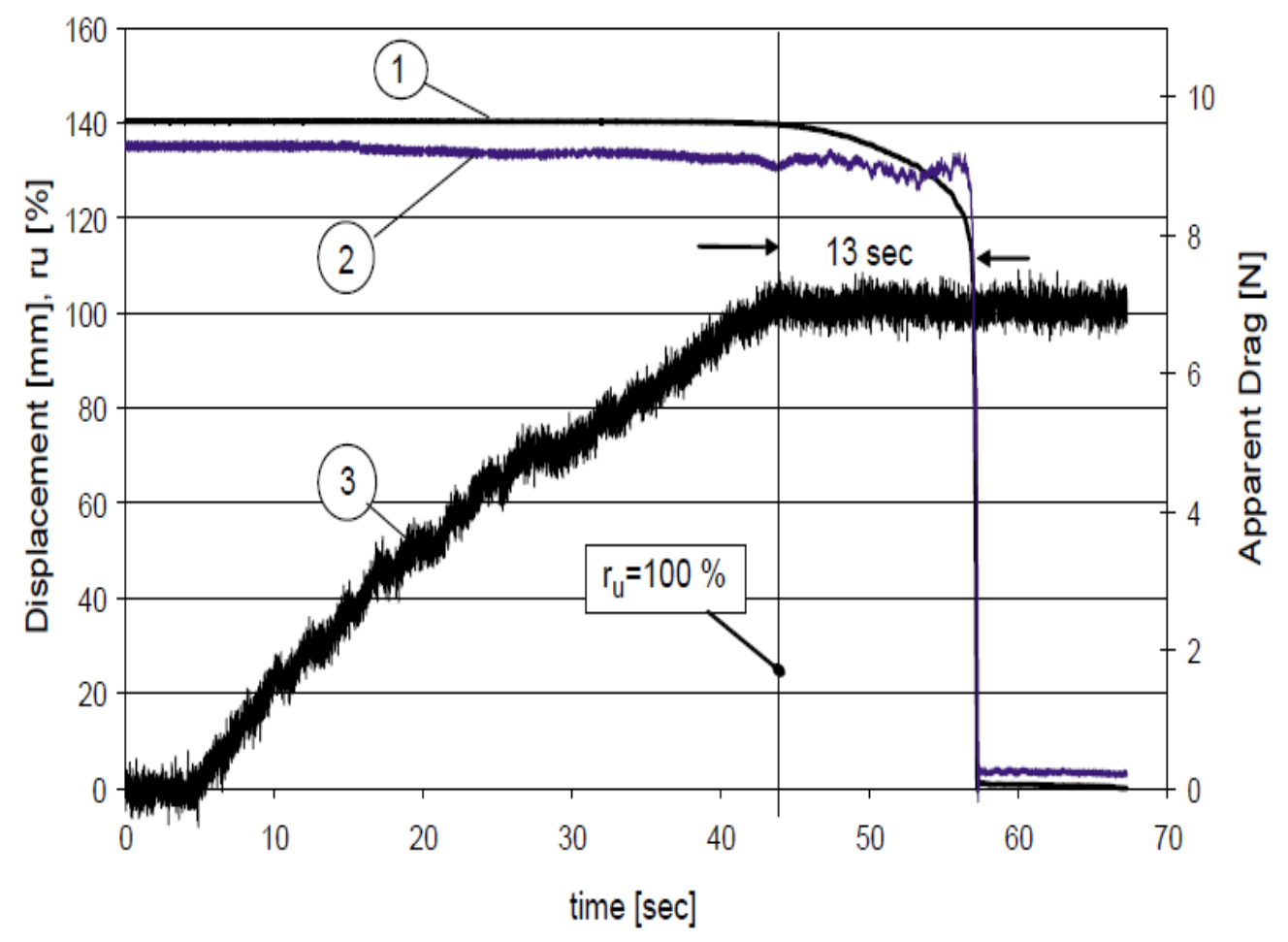

Figure 11: Static Liquefaction Test, 1. Sphere Displacement, 2. Apparent Drag, 3. Pore Pressure Ratio (de Alba and Ballestero, 2006)

DeWoolkar et al. (2016) measured the residual shear strength of liquefied sands using a seismic geotechnical centrifuge model, where thin coupons were pulled horizontally through sand models during shaking to estimate residual strength. A plan and sectional view of the apparatus used can be seen in Figure 12. 

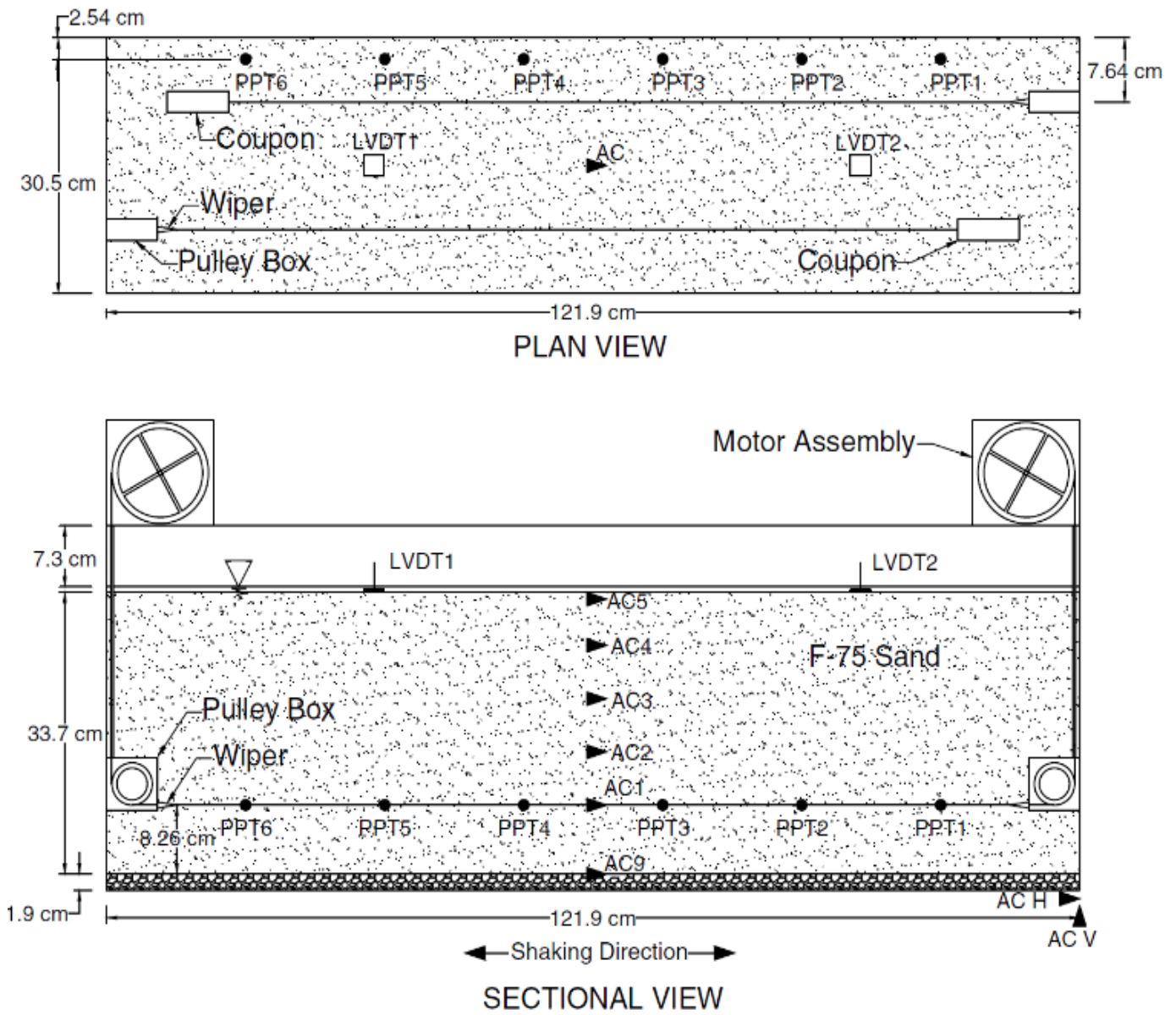

Figure 12: Plan and Sectional View of Typical Centrifuge Test Model Configuration (Dewoolkar et al., 2016)

Dewoolkar et al. (2016) observed a rapid decrease in the coupon force when shaking was initiated and excess pore pressures developed, indicating liquefaction (Figure 13). The researchers also observed that postliquefaction recovery of shear strength appears linearly related to the recovered effective vertical stress as pore pressures dissipate.

When comparing results of the residual strength measured in the centrifuge tests to the design curve established by Idriss and Boulanger (2008), Dewoolkar et al. (2016) observed that the measured $S_{r}$ values fell generally 
below the established design curve (Figure 14). The design curves' overestimation of residual strengths shows the need for additional testing and revisions to create design curves that can be trusted in practice.
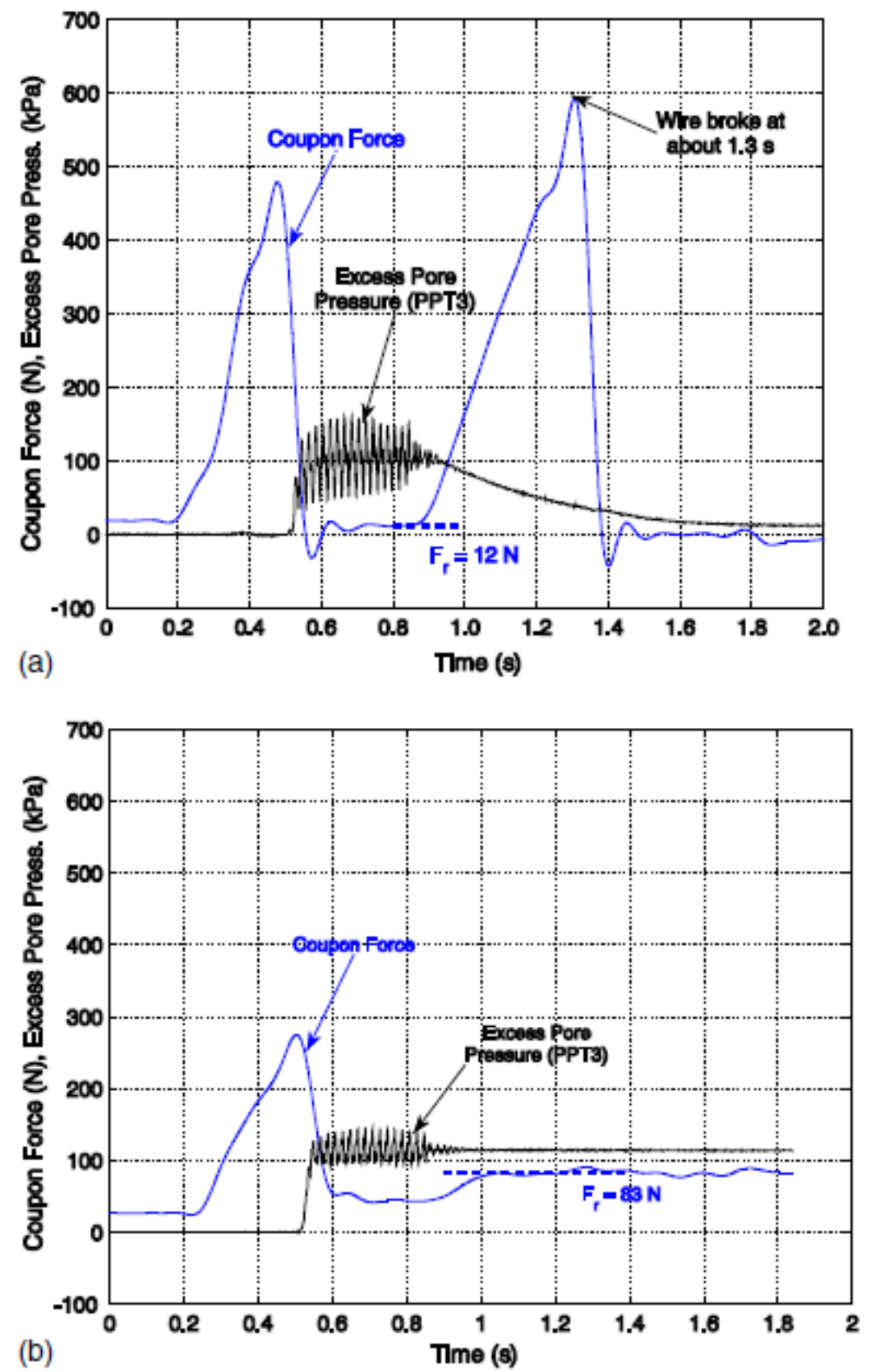

Figure 13: Typical Coupon Force and Excess Pore Pressure Measurements from Centrifuge Tests (Dewoolkar et al., 2016) 

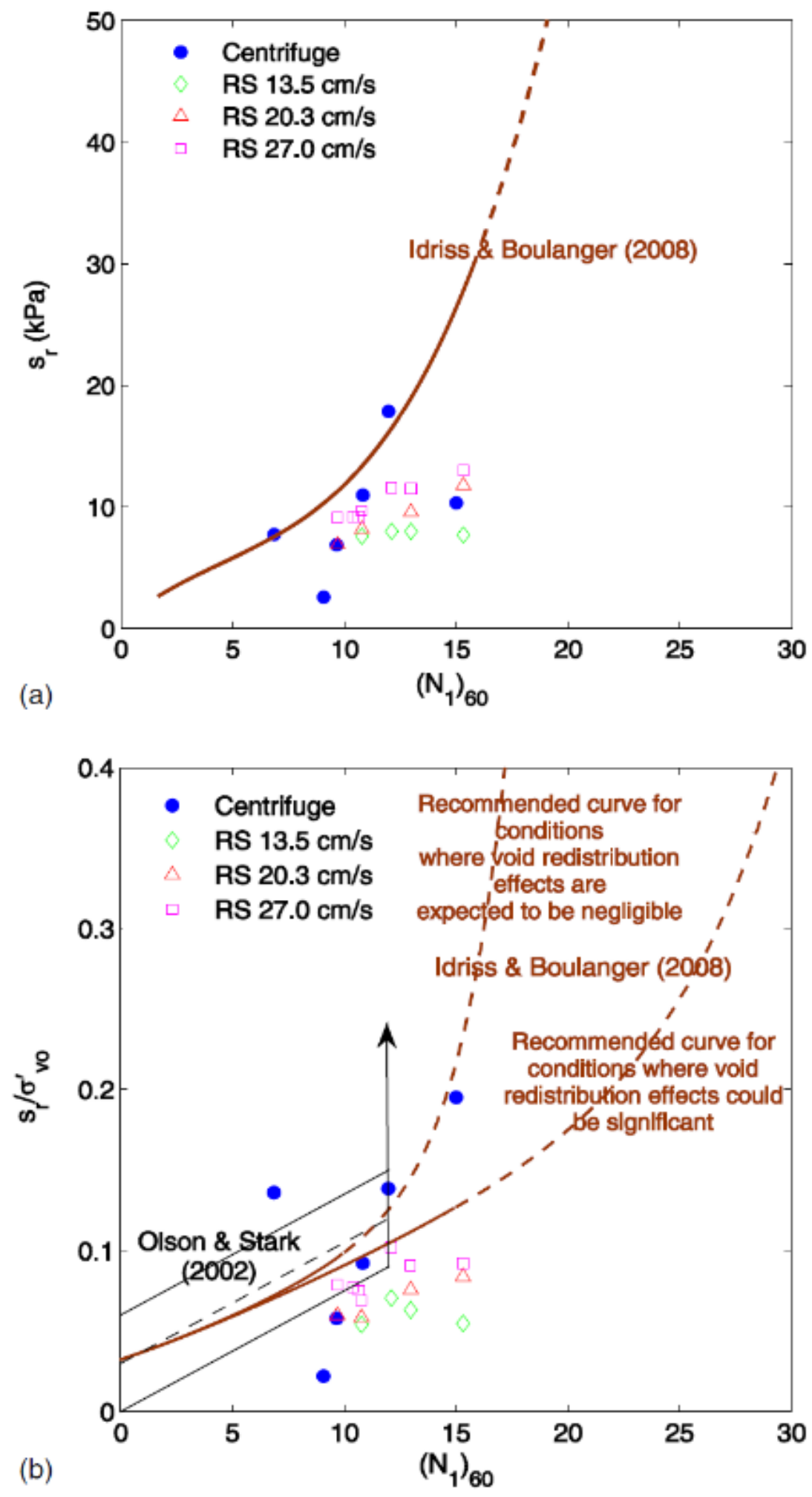

Figure 14: Comparison of Measured Residual Strength and Residual Strength Ratios with SPT-based Correlations (Dewoolkar et al., 2016) 
Dewoolkar et al. (2016) also measured residual strength using ring shear tests. The ring shear specimens were prepared using a similar method to the method used in the centrifuge models. A cyclic load with $+/-5 \%$ strain of rotation was applied with the top ring to liquefy the sample. The samples typically liquefied within two cycles. The ring shear tests measured residual strength values within the same range as those observed in the centrifuge tests. However, the residual strengths measured from the ring shear tests did not follow the same pattern with changes in relative density as the centrifuge tests and back-calculated estimates. Dewoolkar et al. (2016) attributes the different trend observed in the ring shear testing to two factors: ring shear does not capture the dilative soil response seen at higher relative densities; and particle damage that occurs in the shear zone in the ring shear tests.

\section{$1.5 \quad$ T-Bar Penetrometers}

Full-flow penetrometers have been used to measure undrained shear strength characteristics of soft soils. The T-bar penetrometer was developed as a new tool for measuring shear strength of soft clays in centrifuge experiments (Stewart and Randolph, 1991). The T-bar penetrometer was then applied to in-situ soil exploration with CPT test

equipment (Figure 15) (Stewart and Randolph, 1994). Stewart and Randolph (1994) showed that T-bar penetrometers can yield shear strength estimates that are consistent with vane shear testing. 

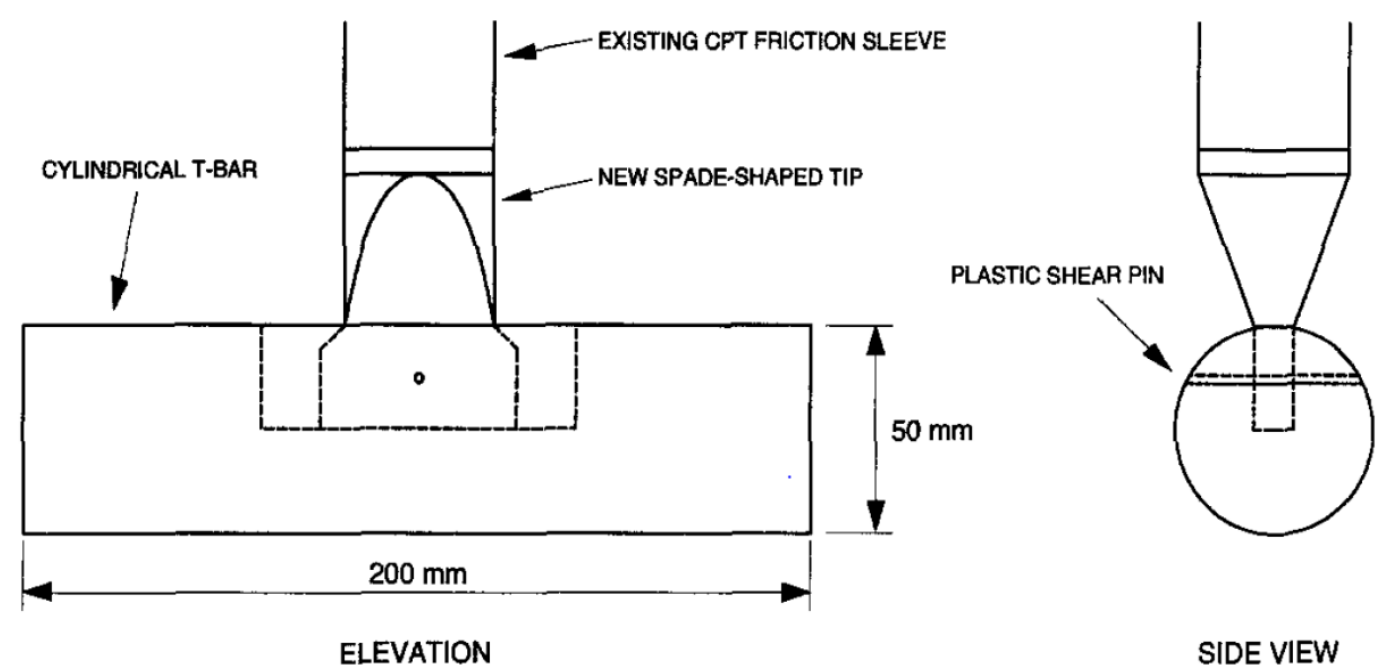

Figure 15: Field T-Bar Penetrometer (Stewart and Randolph, 1994)

Further testing using T-bar penetrometers has confirmed that the T-bar can reliably estimate undrained shear strengths (DeJong et al., 2011). Their ability to perform cyclic strength degradation testing and their increased load cell sensitivity has seen an increase in their use with thick deposits of soft clays, particularly offshore. See attached writeup in Appendix A. 


\subsection{Full-Scale Shake Table Testing}

Towhata et al. (1999) performed a variety of $1-\mathrm{g}$ shaking tests where the drag force required to pull an embedded pipe laterally through the sample was measured, similar to the centrifuge coupon drag tests described earlier (Figure 16). Their research showed a much lower drag force was required to pull the pipe through loose saturated sand than the force required to pull the pipe through dry sand subjected to strong shaking. They also observed the drag force to be rate dependent with the velocity of pipe movement, suggesting a high value of apparent viscosity of liquefied sand.

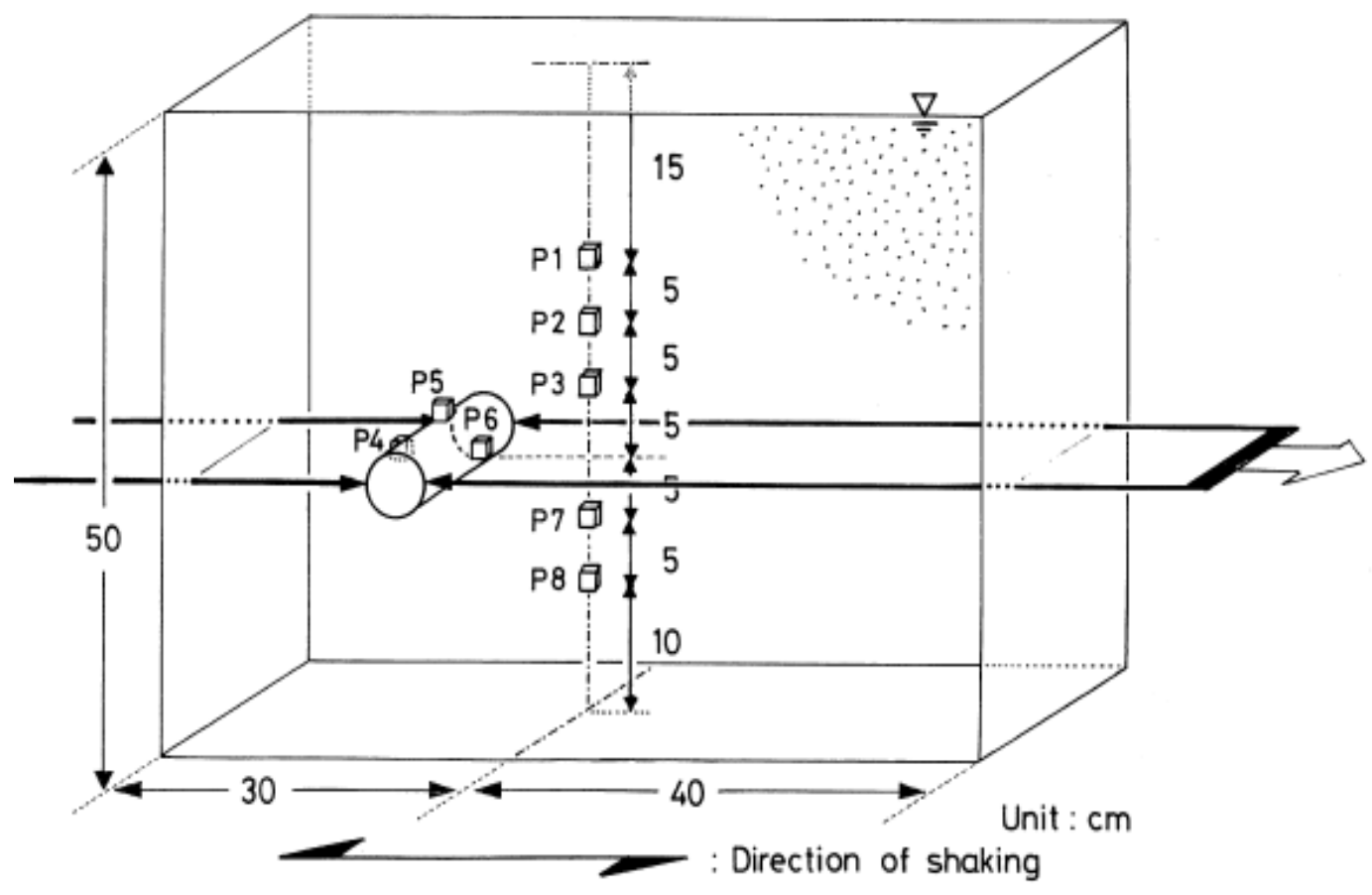

Figure 16: Model Sand Container and Embedded Pipe

(Towhata et al., 1999) 
Motamed and Towhata (2010) performed a series of 1-g shake table tests on a pile group and sheet-pile wall to observe the mechanisms of liquefaction induced ground deformations and the behavior of a pile group subjected to the large lateral displacements caused by liquefaction. They studied the effects of several parameters on liquefied lateral displacement including density, input motion amplitude and frequency, pile group head fixity, and superstructure. The density of the sample was found to have a significant effect on displacements because the development of excess pore pressures proved to be highly dependent on initial density. Their results showed that as the input motion's amplitude increases, the lateral deformations of the sample also increased; whereas, an increase in the input motion's frequency resulted in a decrease in lateral deformations (Figure 17). 


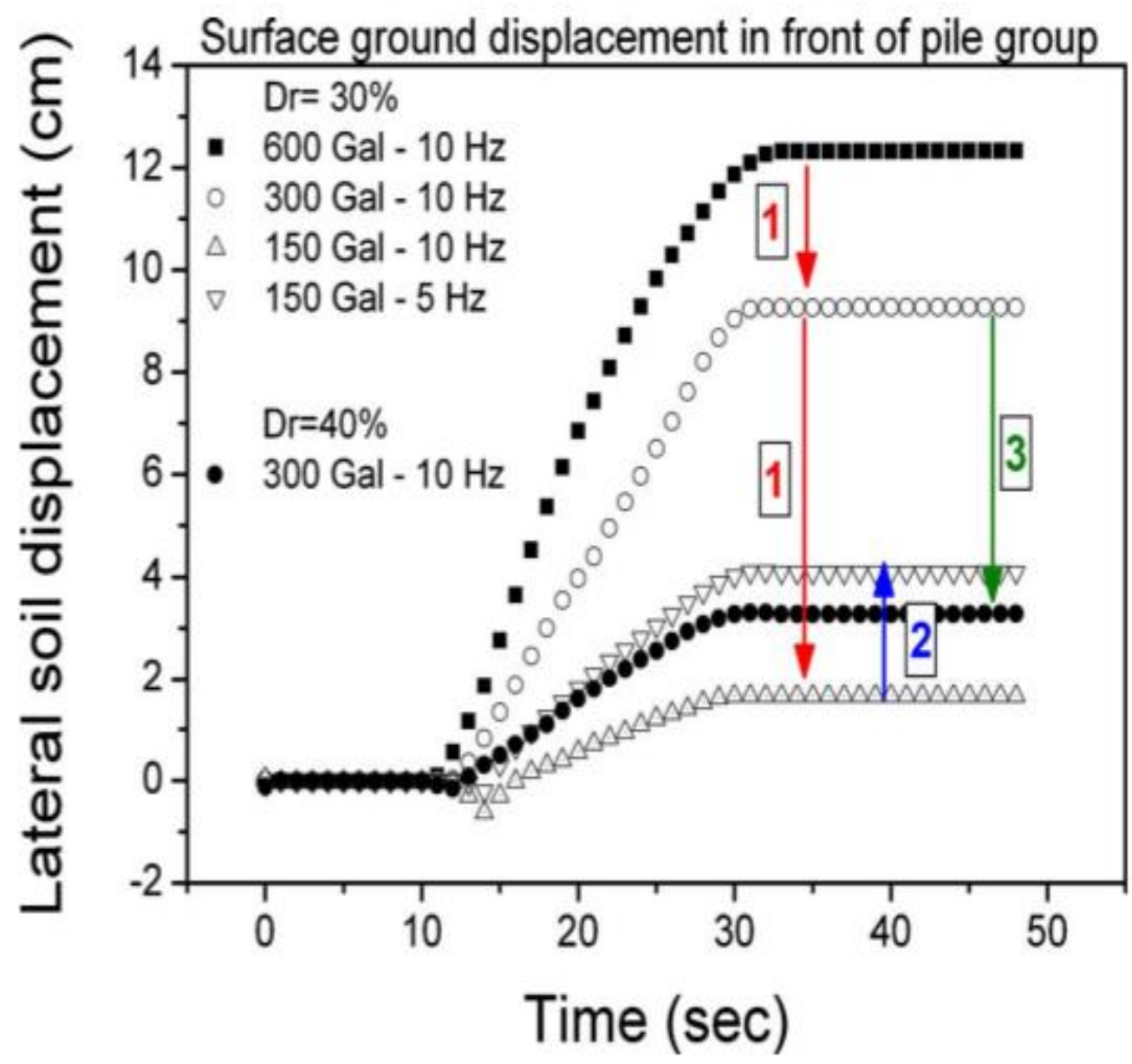

Figure 17: Time Histories of Surface Ground Displacement in Front of Pile Group (Motamad and Towhata, 2010) 


\section{CHAPTER 2 EQUIPMENT AND INSTRUMENTATION}

Small-scale laboratory testing has been shown to not reliably capture voidredistribution or the migration of excess pore pressure generation within a sample (Idriss and Boulanger, 2008). In addition, small-scale laboratory testing does not allow for full-scale CPT indexing to compare to in-situ field exploration data. For these reasons, a large-scale testing procedure was utilized herein in an attempt to capture these phenomena during testing.

\subsection{Load Cell}

A model SSC-500-0000 load cell manufactured by Tovey Engineering was used to measure the load required to pull out the T-bar penetrometers (Figure 18). The manufacturer's original calibration was input to LabVIEW and then a more precise calibration was performed on October 18, 2016 to correct for any variances from the manufacturer's original calibration. This calibration was performed by loading the cell with known weights in $22.7 \mathrm{~kg}$ increments ramped up to $229 \mathrm{~kg}$ and then ramped back down to zero in $22.7 \mathrm{~kg}$ increments. This revised calibration is saved to the LabVIEW module in the Parsons Geotechnical and Earthquake Engineering Laboratory. 


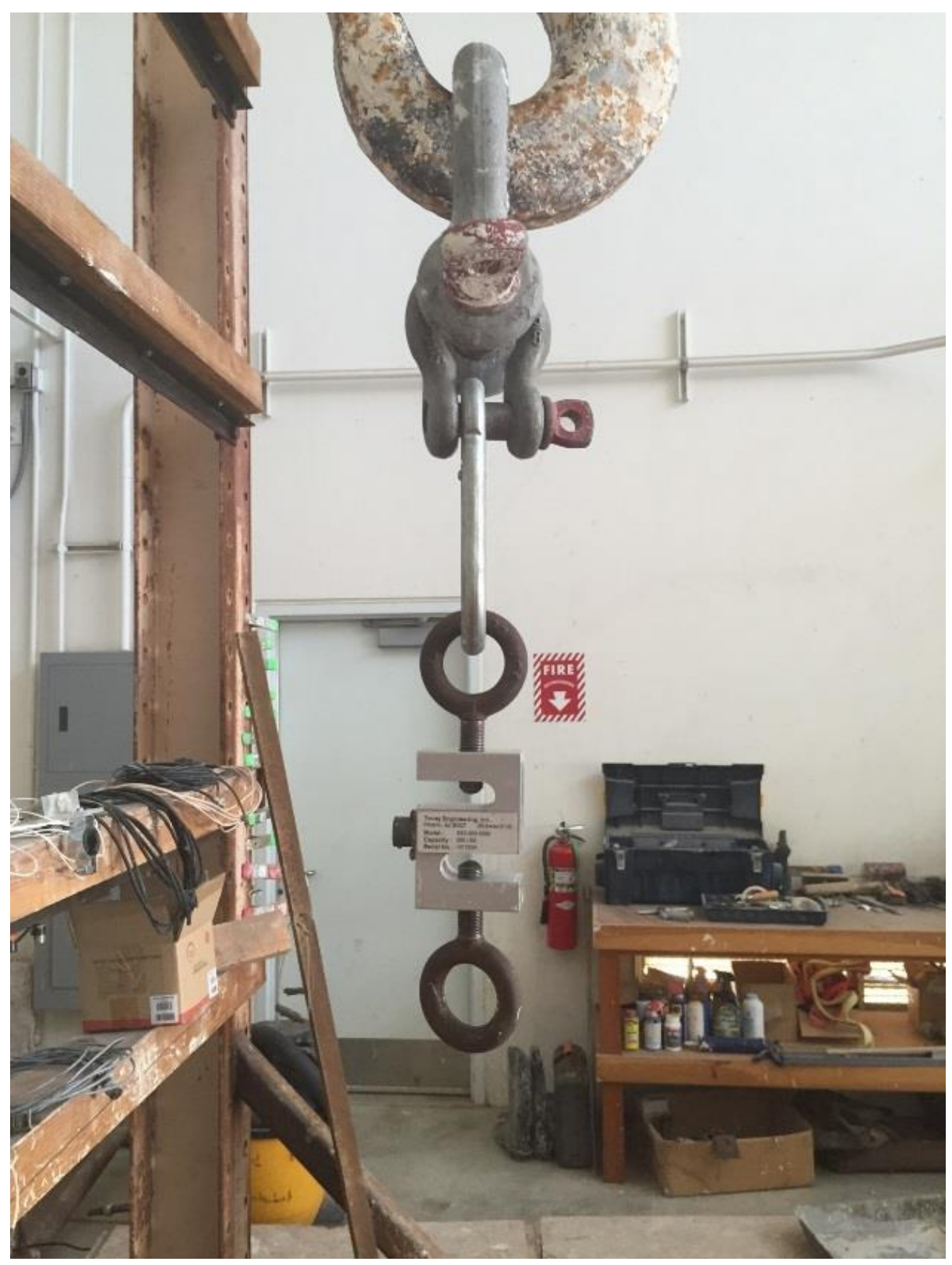

Figure 18: Tovey Engineering SSC-500 Load Cell 


\subsection{Cone Penetrometer}

Cone Penetration testing was utilized to monitor changes in soil stiffness before and after shaking, and to allow for correlations between the lab measurements and in-situ field data.

A $2.54 \mathrm{~cm}$ diameter instrumented piezometric cone penetrometer was provided for testing by the Naval Facilities Engineering Command (NAVFAC) (Figure 19). The cone penetrometer was mounted to a cross-bar that held the $231 \mathrm{~kg}$ reaction mass required to drive the cone. The crossbar was mounted to the gantry crane in the Parsons Geotechnical and Earthquake Engineering Laboratory which was used to raise and lower the cone. The crane lowered the cone at a rate of $1.4 \mathrm{~cm} / \mathrm{s}$. ASTM D5778 suggests a descent rate of $2 \mathrm{~cm} / \mathrm{s}$ for cone penetrometers; the gantry crane in the has the capabilities for two speeds, $1.4 \mathrm{~cm} / \mathrm{s}$ and $8.2 \mathrm{~cm} / \mathrm{sec}$. The discrepancy between the speeds was not expected to cause appreciable differences in the results of the cone penetrations.

The cone penetrometer used in this testing is capable of measuring tip load, sleeve load, pore pressure, and displacement. The cone penetrometer uses a DAQ system that is interfaced with a laptop to record four channels of data (Figure 20). 


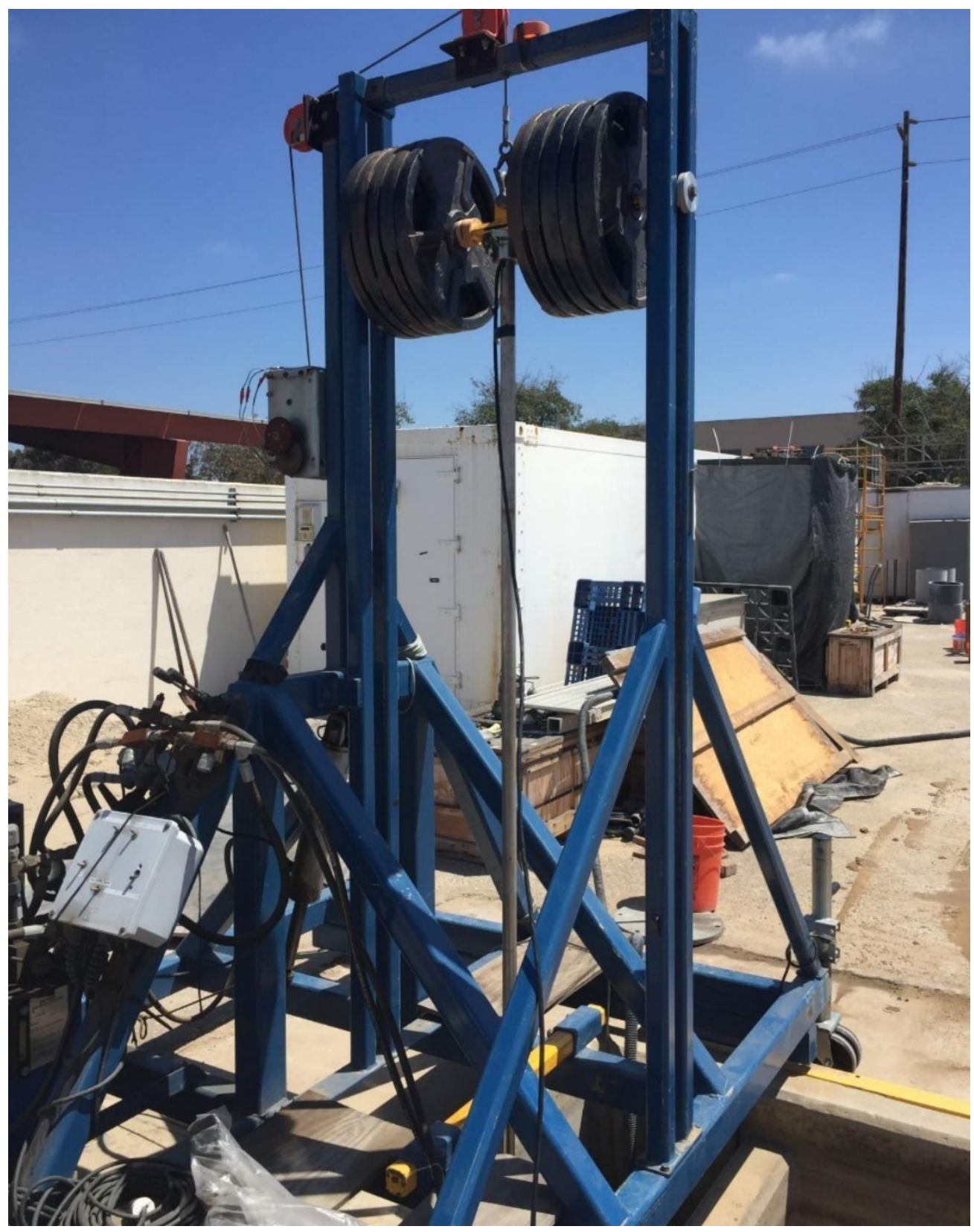

Figure 19: NAVFAC Cone Penetrometer 


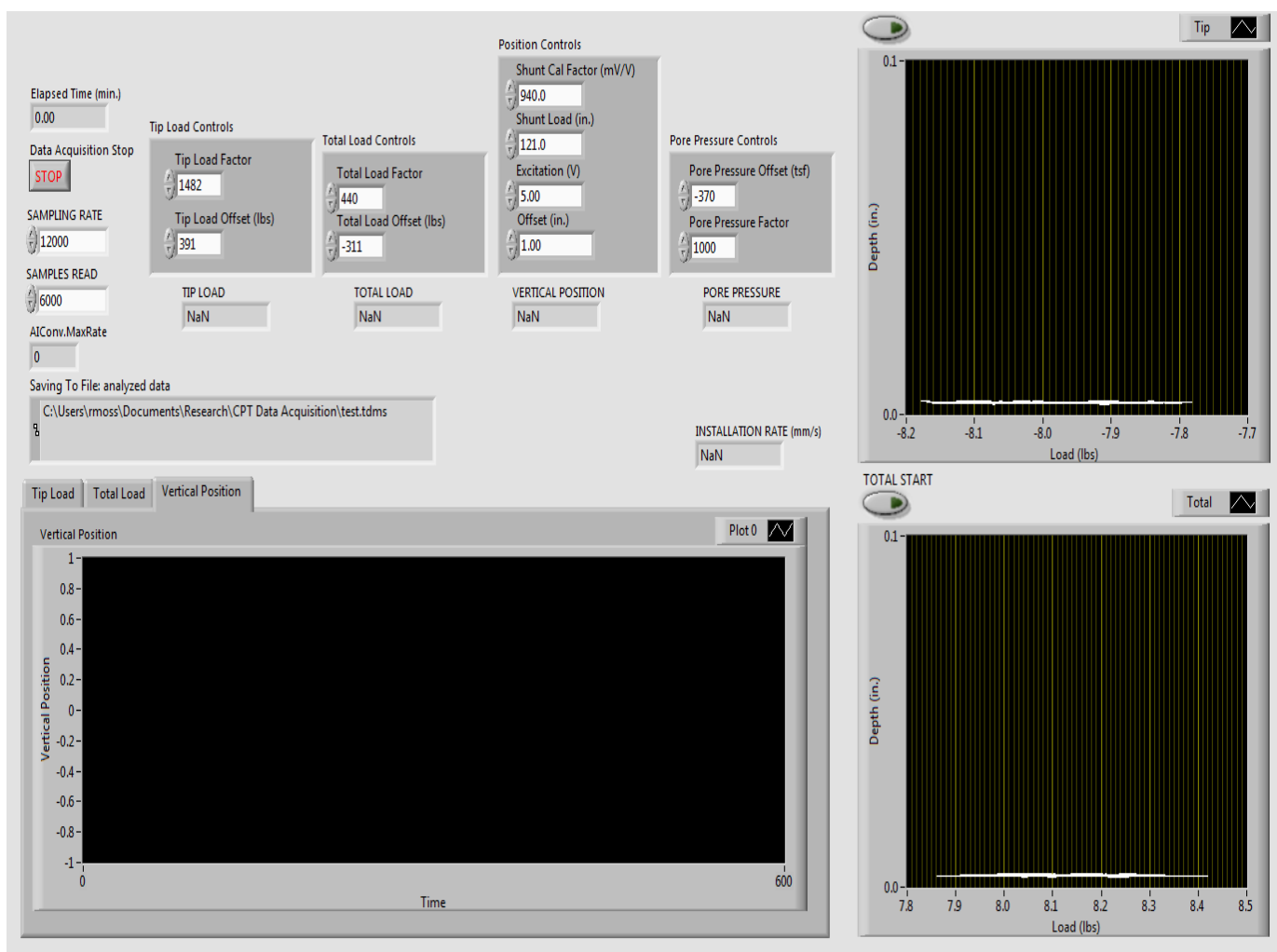

Figure 20: CPT Data Acquisition Interface

\section{$2.3 \quad$ T-bar Penetrometer}

The T-bar penetrometers used herein have previously been used in research by Crosariol (2010) and Kuo (2012). Both researchers used the Tbar penetrometers in a soft clay exposed to cyclic motion. A bar factor of 10.5 was used to analyze the T-bar results in their studies (Moss and Crosariol, 2013). 
The T-bar penetrometers consist of a $95 \mathrm{~mm}$ long, $19 \mathrm{~mm}$ diameter steel cylindrical cross bar welded to a $2.1 \mathrm{~m}$ long, $6.3 \mathrm{~mm}$ diameter steel rod (Figure 21). An eyelet adapter was fabricated to thread onto the steel pulling rod to allow for the load cell to be attached (Figure 22). Three identical T-bar penetrometers were used throughout this research.

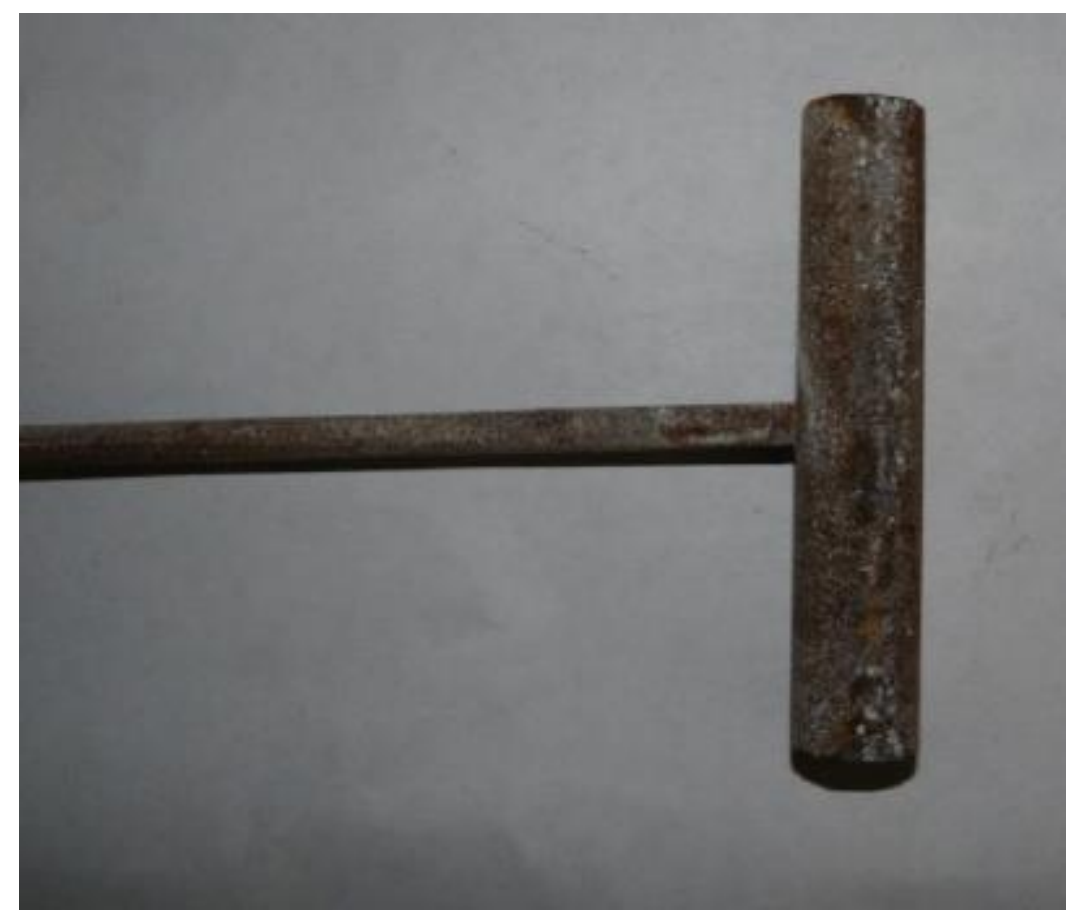

Figure 21: T-Bar Penetrometer (from Crosariol, 2010) 


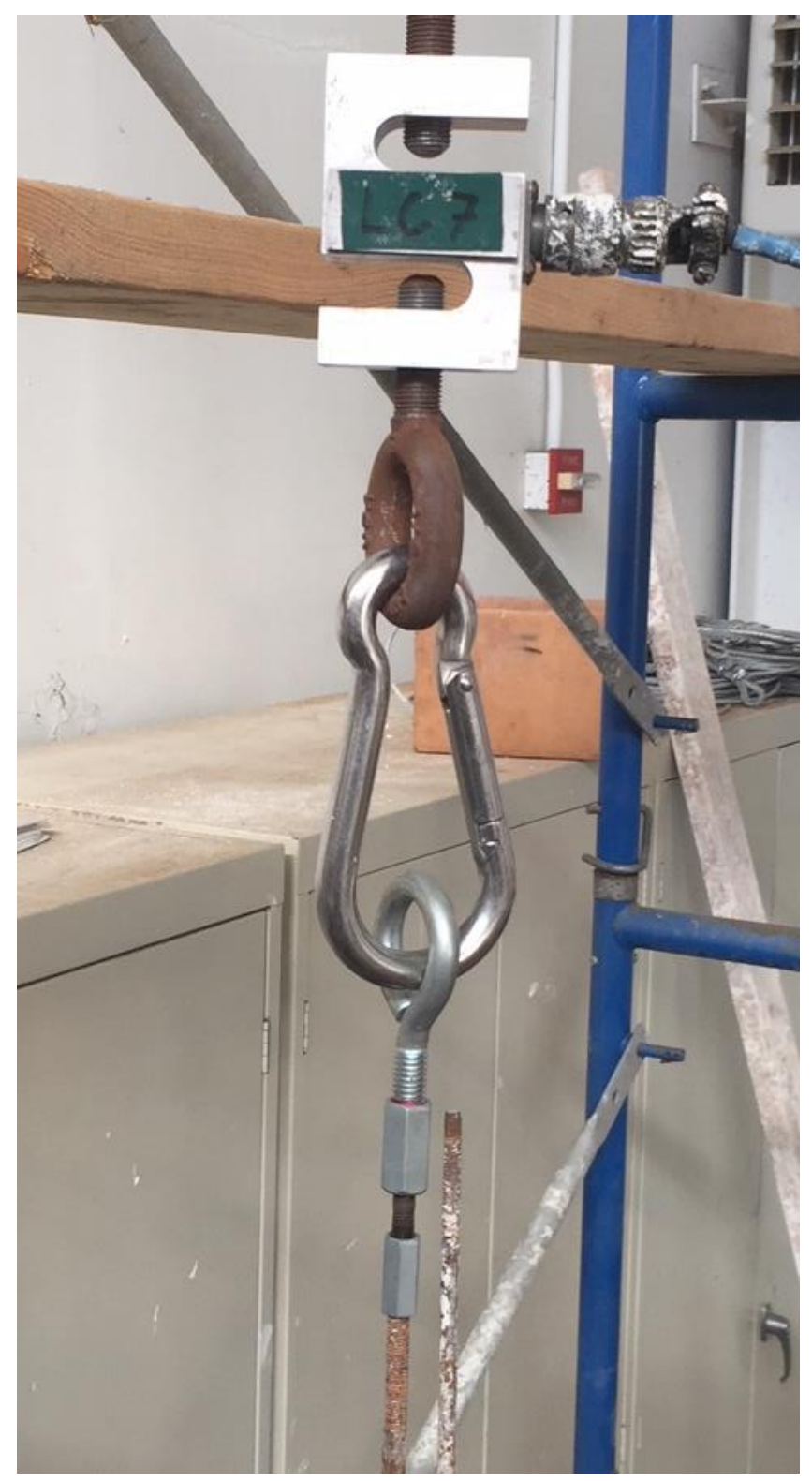

Figure 22: Eyelet Connector for T-Bar Penetrometer 


\subsection{Accelerometers}

Ten PCB 393B04 Integrated Circuit Piezometer (ICP) accelerometers were used to measure accelerations within the soil sample. These accelerometers can measure accelerations up to $+/-5$ g's. One PCB 353B52 ICP accelerometer was used to measure the accelerations of the shake table. The manufacturer calibrations of these accelerometers are saved to the DAQ system in the Parson's Earthquake and Geotechnical Laboratory. The accelerometers were connected to the DAQ system through a National Instruments SCXI 1531 accelerometer amplifier. All accelerometers were oriented to measure accelerations in the direction of shaking except for accv1 and accv4, which were oriented to measure vertical accelerations. The number attached to the accelerometer name refers to the instrument's location within the soil sample. The numbers increase as the sample is ascended. Calibration values for these accelerometers are in Table 1. The

shake table control system has an additional accelerometer embedded within the shake table to control the response. 
Table 1: Accelerometer Calibration Values

\begin{tabular}{|c|c|}
\hline Accelerometer & $\begin{array}{c}\text { Calibration } \\
\text { Value } \mathbf{~} \mathbf{V} / \mathbf{g}\end{array}$ \\
\hline acci1 & 1000 \\
\hline acci2 & 1000 \\
\hline acci3 & 988 \\
\hline acci4 & 1028 \\
\hline acct1 & 982 \\
\hline acct2 & 1020 \\
\hline acct3 & 1000 \\
\hline acct4 & 1028 \\
\hline accv1 & 1000 \\
\hline accv4 & 1000 \\
\hline acctable & 502 \\
\hline
\end{tabular}

\subsection{Pore Pressure Transducers}

Four Omega PX481A-015G5V stainless steel industrial pore pressure transducers (PPTs) were used to measure excess pore-water pressures generated during shaking. These gages require an excitation voltage of 10 volts and provide output voltages ranging from 0 volts to 5 volts that correspond to a pressure range of $0 \mathrm{kPa}$ to $103 \mathrm{kPa}$ gage. The pore pressure transducers follow a similar naming convention as the accelerometers, with the suffix number increasing with ascending vertical height in the sample. These pressure transducers were calibrated in 
previous testing (Jacobs 2016) using a hydrostatic water column and an air compressor. Calibration values for each pore pressure transducer are presented in Table 2. The PPTs were interfaced with the DAQ system with a National Instruments SCXI 1520 Universal Strain Gage input module.

Table 2: Pore Pressure Transducer Calibration Values

\begin{tabular}{|c|c|c|c|c|}
\hline $\mathrm{ppt}$ & 0 & 1 & 2 & 3 \\
\hline $\mathrm{kPag}$ & \multicolumn{4}{|c|}{ Volts D.C. } \\
\hline 0.7 & 0.82 & 0.79 & 0.81 & 0.81 \\
\hline 13.8 & 1.34 & 1.31 & 1.33 & 1.33 \\
\hline 34.5 & 2.15 & 2.13 & 2.15 & 2.14 \\
\hline 68.9 & 3.50 & 3.47 & 3.49 & 3.49 \\
\hline 103.4 & 4.85 & 4.82 & 4.84 & 4.84 \\
\hline
\end{tabular}

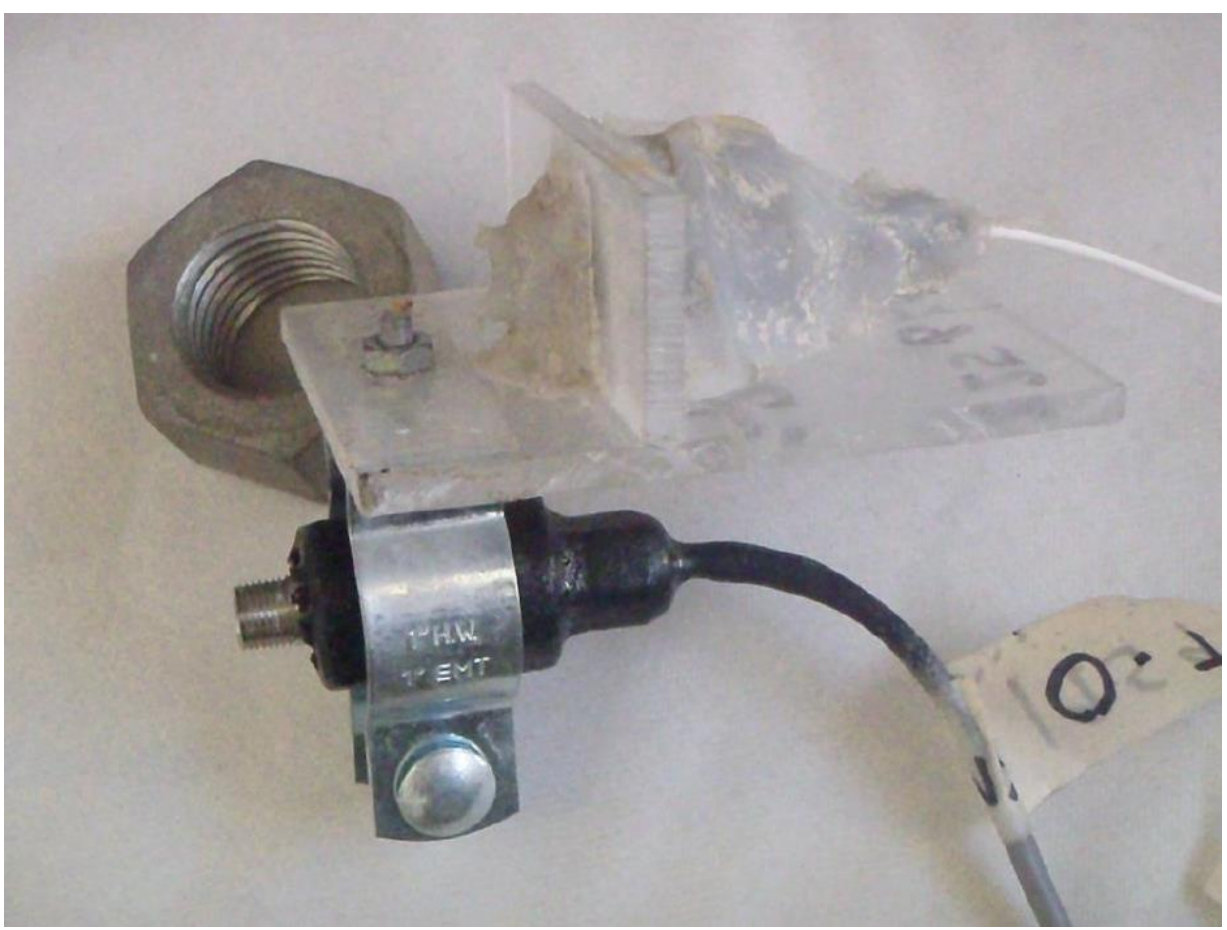

Figure 23: Pore Pressure Transducer and Accelerometer Instrument Package (From Jacobs, 2016) 


\subsection{Tactile Pressure Sensors}

Two PPS ConTacts C-500 Tactile Sensors were used to estimate the overburden pressure applied to the soil sample. The sensors are set up in waterproof jackets. Calibration values and plots were provided by the manufacturer for each sensor. The sensors were placed above the sand layer, between the landscape fabric the bottom plate of the overburden assembly.

\subsection{Backup overburden estimation}

As a backup to the tactile pressure sensors. A flat scale was placed between the inner tube and top plate of the overburden assembly. The force on the scale was recorded to estimate the overburden pressure acting on the bottom plate.

\subsection{Displacement Transducers}

Three ASM WS10SG Posiwire Cable Extension Position Sensors were used to measure displacement of the outside of the flexible bucket membrane. The sensors were mounted to the Kevlar bands at three different heights above the table. Previous testing showed that other wire potentiometers were incapable of accurately measuring displacements at 8 $\mathrm{Hz}$ (Jacobs, 2016). The sensors used in this research proved to be effective at accurately measuring displacements at $8 \mathrm{~Hz}$. 
The sensors were calibrated by mounting the sensor body to a work table and setting a grid of screws at $10 \mathrm{~cm}$ increments (Figure 24). The voltage value of each sensor at every distance increment was recorded in LabVIEW and calibration equations created that were input to the data acquisition system.

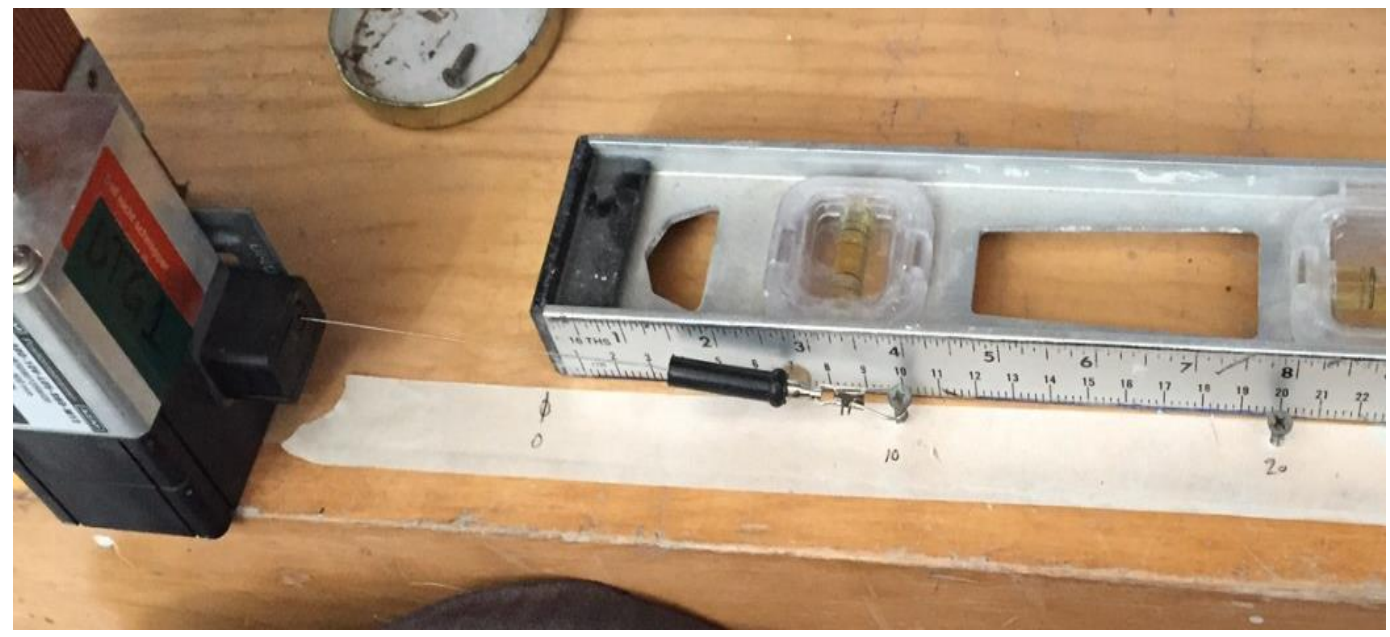

Figure 24: Calibration of Cable Extension Position Sensors

\subsection{Flexible Walled Testing Apparatus}

This research used a 2.3 meter diameter by 1.5 meter tall flexible walled testing apparatus (Figure 25). This apparatus consists of steel top and bottom plates, and a $10 \mathrm{~mm}$ thick rubber membrane wall. The outer diameter of the rubber was confined by 2.3 meter diameter Kevlar bands, which are designed to act similar to the wire reinforced membranes used in table top simple shear tests. The spacing of the bands varied with height along the outside of the membrane. The bands were placed closer together near the bottom of the membrane to better confine the higher pressures present near the base. 
Meymand (1998) investigated the effectiveness of the flexible walled bucket used in this research in allowing free-field response. Meymand compared soil accelerations recorded at various depths in a soft clay sample with numerically simulated accelerations simulated by SHAKE 91 . Figure 26 shows relative agreement between the tested (solid) and the computed (dashed) $5 \%$ damped response spectra.

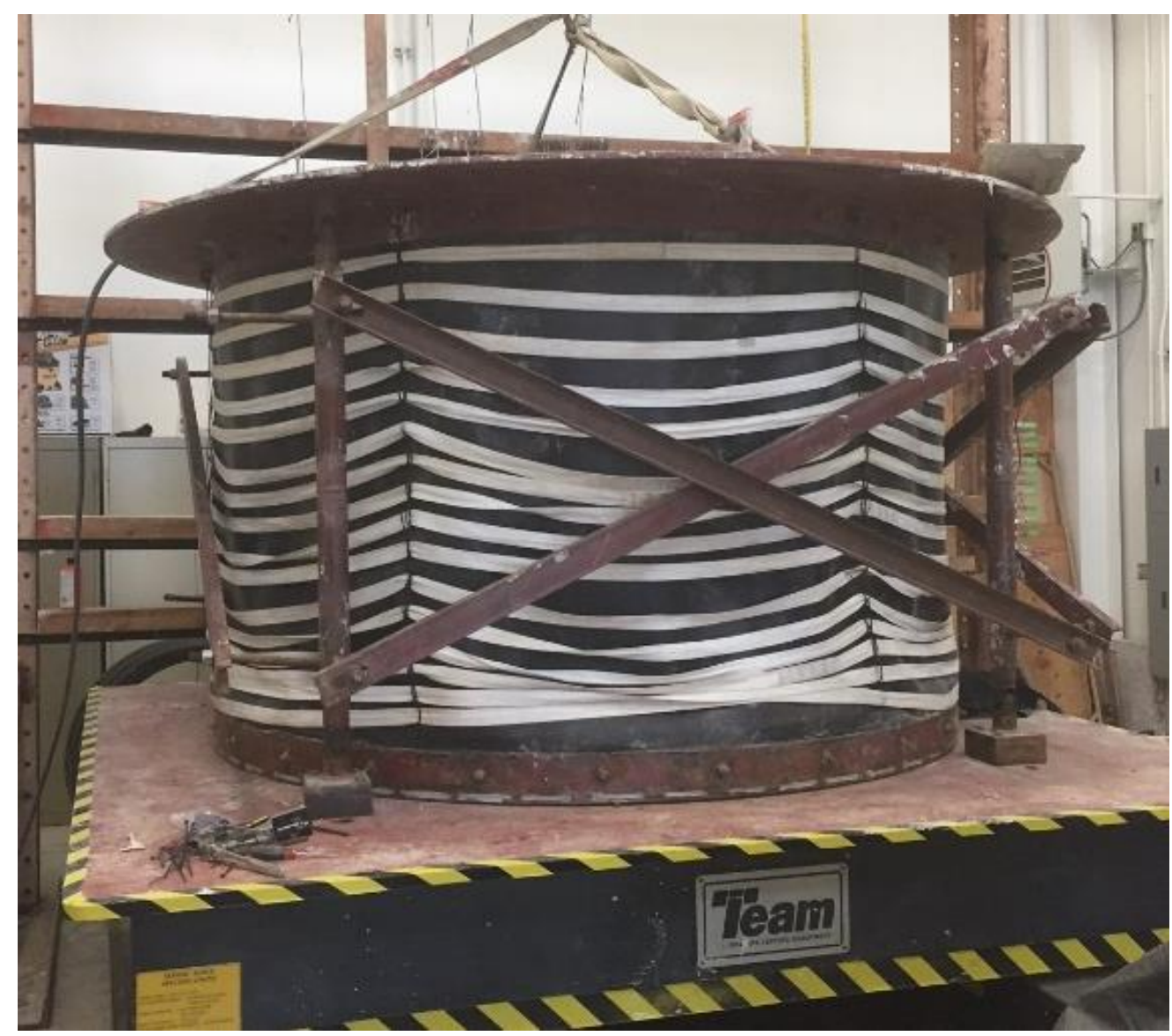

Figure 25: Flexible Walled Testing Apparatus 


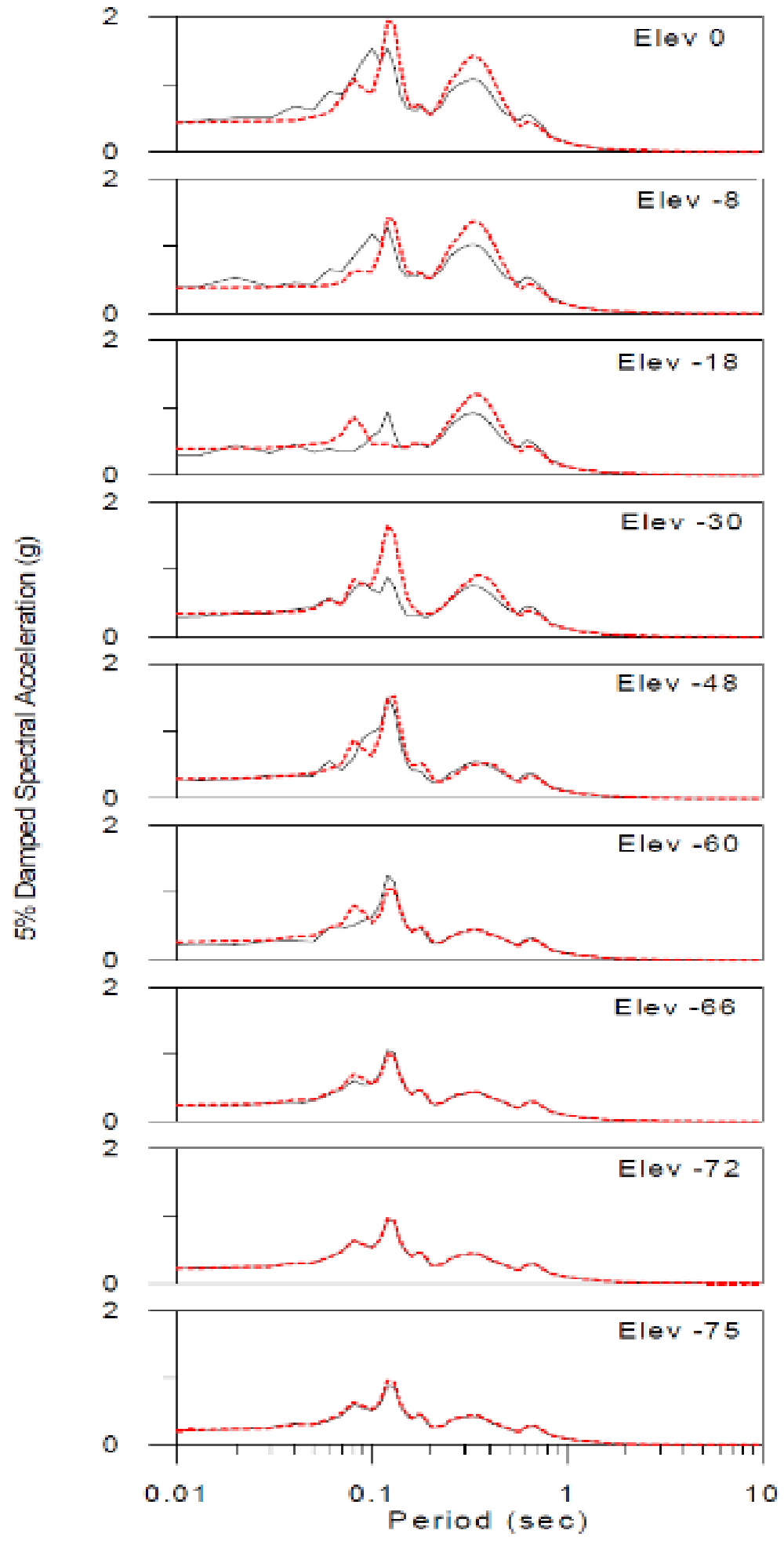

Figure 26: Site Response (solid) vs Predicted Response (dashed) Spectra (Meymand, 1998) 


\section{CHAPTER 3 PRE-TESTS}

To familiarize use of the load cell, gantry crane, pluviation method, and the data acquisition system, a series of pre-tests were completed using the same or similar equipment to the main testing.

\subsection{Dry Pluviated Trash Can Test}

Monterey sand was dry pluviated into a 44-gallon container using the large scale pluviation device described in Section 4.3. Three T-bar penetrometers were embedded at the base of the sample spaced equidistant radially around the center (Figure 27). The dry pluviation technique resulted in a sample $59 \mathrm{~cm}$ tall with a dry unit weight of $16.8 \mathrm{kN} / \mathrm{m}^{3}$ relative density of approximately $89 \%$.

The three T-bar penetrometers were pulled out individually at a rate of 8.2 $\mathrm{cm} / \mathrm{sec}$, the faster speed of the gantry crane used for pullout. Figure 28 shows the average profile of the pullout pressure experienced by the three T-bars. 


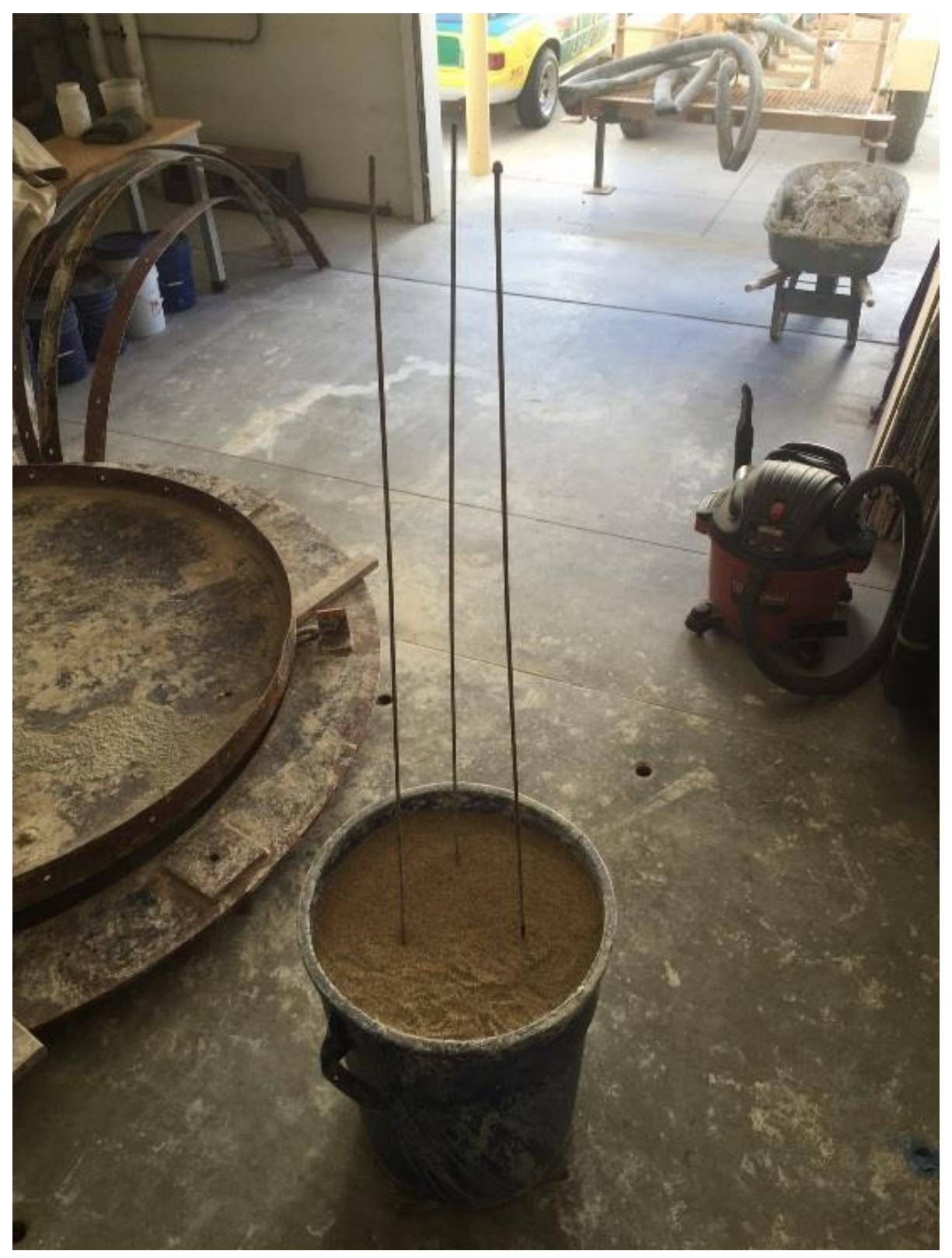

Figure 27: Dry Pluviated 44 Gallon Test Sample 


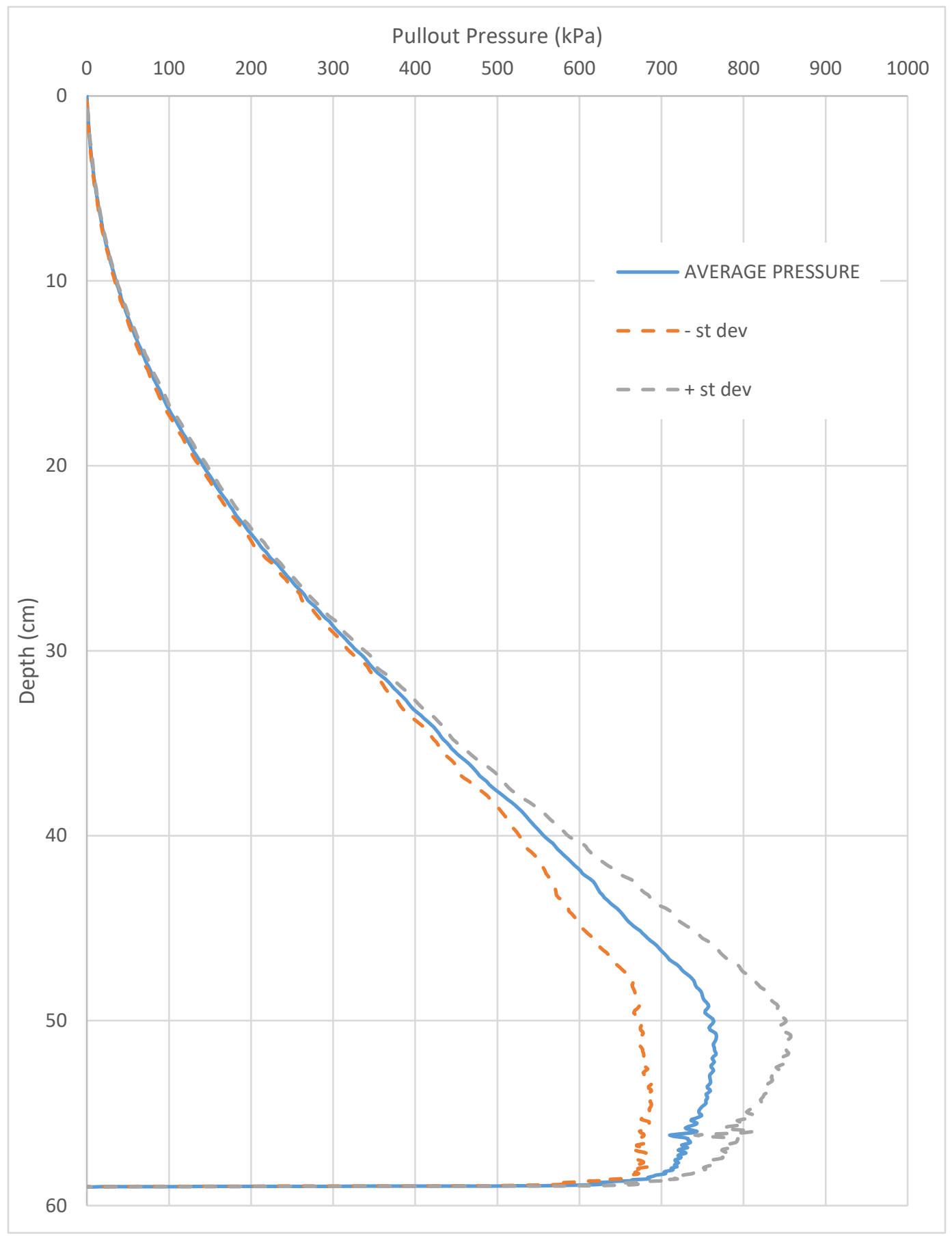

Figure 28: Average Dry Pluviated T-bar Pullout Pressure 
Multiple CPT tests were performed on this dry pluviated sample. The first CPT sounding was not perfectly vertical when the sounding began, causing the penetrometer to drift. The second sounding was successful; however, data were only obtained to a depth of $48 \mathrm{~cm}$ because the cone reached a refusal depth where the driving force was not enough to continue pushing the cone through the sample (Figures 29-31). 


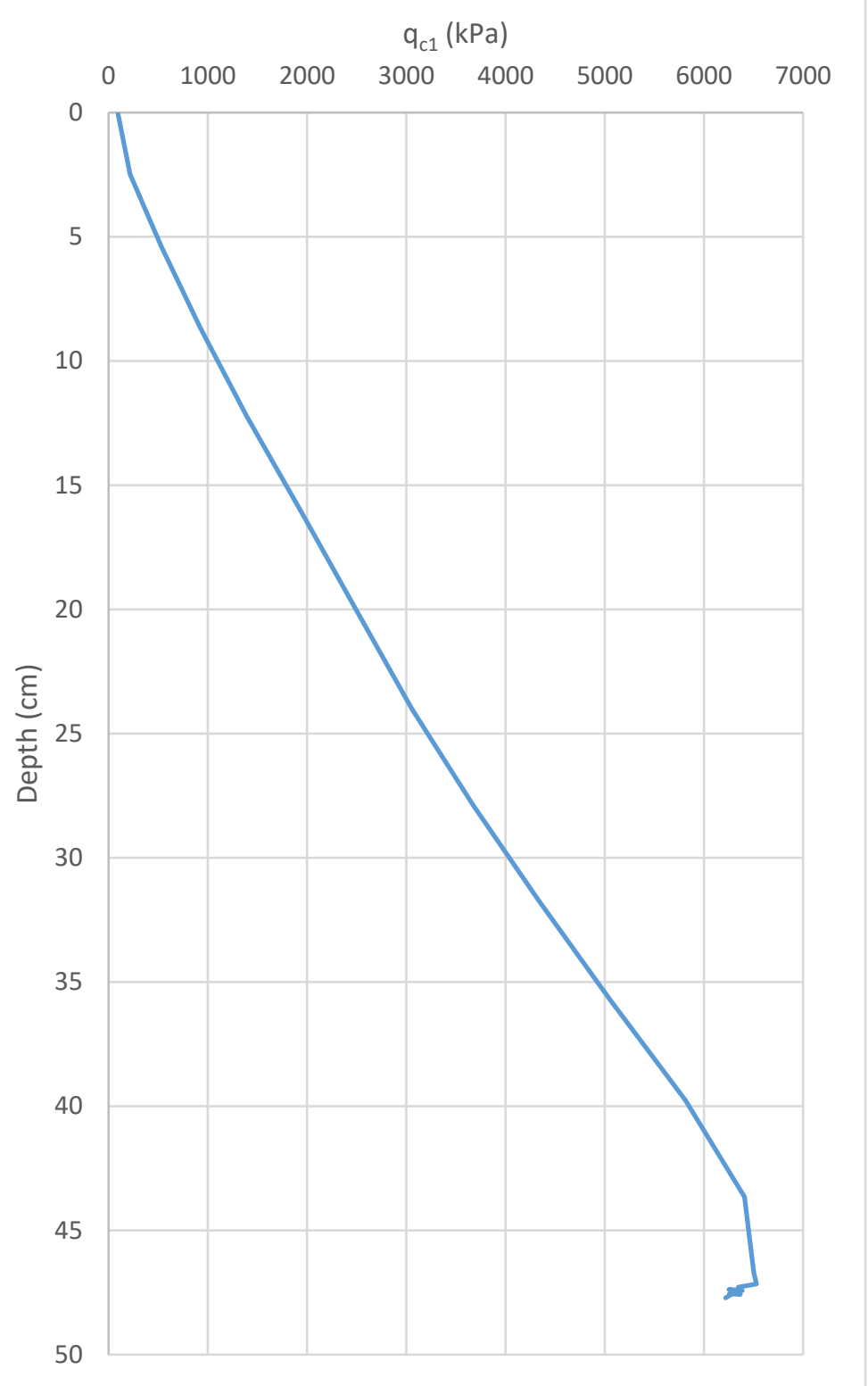

Figure 29: Dry Trash CPT 1.2 Corrected CPT Tip Resistance 


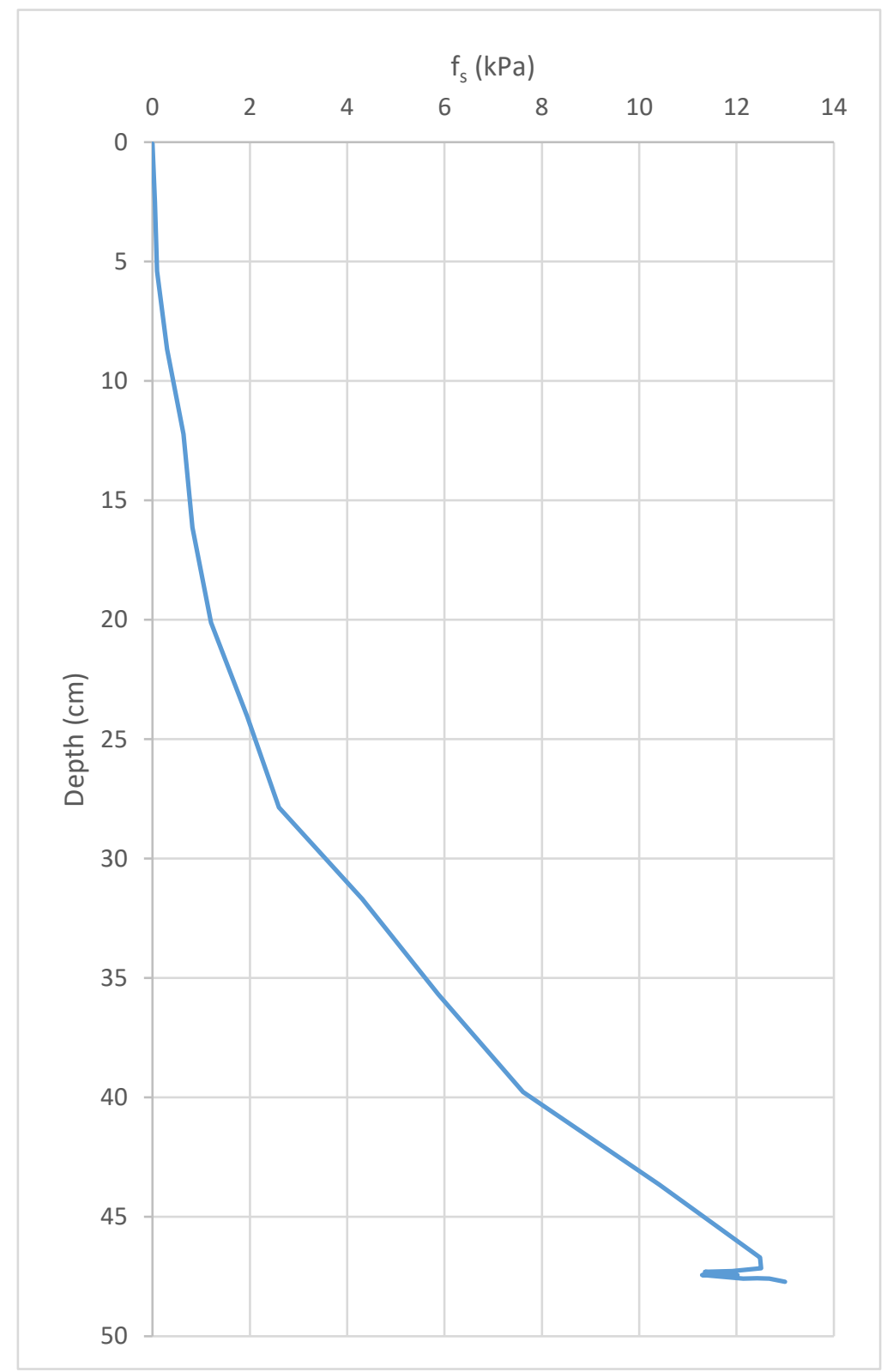

Figure 30: Dry Trash CPT 1.2 Sleeve Friction 


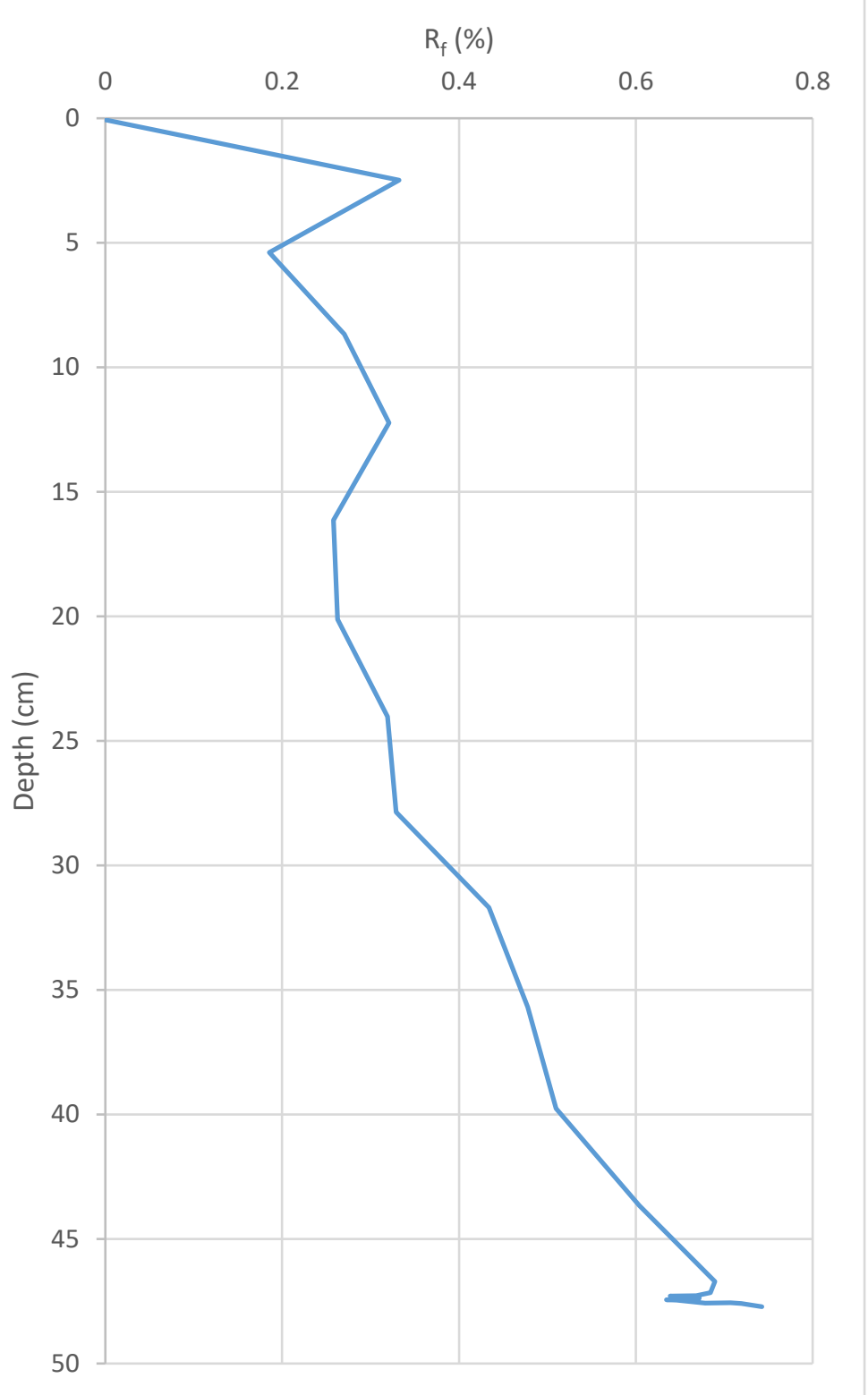

Figure 31: Dry Trash CPT 1.2 Friction Ratio 


\subsection{Wet Pluviated Trash Can Test 1}

Two additional test samples were created using a wet pluviation method. These samples provided estimates for the relative density created using wet pluviation, as well as provided a representative medium to test time-rate effects of T-bar pullout.

Monterey sand was pluviated into a standing head of 5 to $15 \mathrm{~cm}$ of water into a $44 \mathrm{gal}$ container with three $\mathrm{T}$-bars spaced equidistant at the bottom (Figure 32). This wet pluviation method resulted in a sample with a dry unit weight of $15.7 \mathrm{kN} / \mathrm{m3}$ and a relative density of $45 \%$. The T-bars were pulled

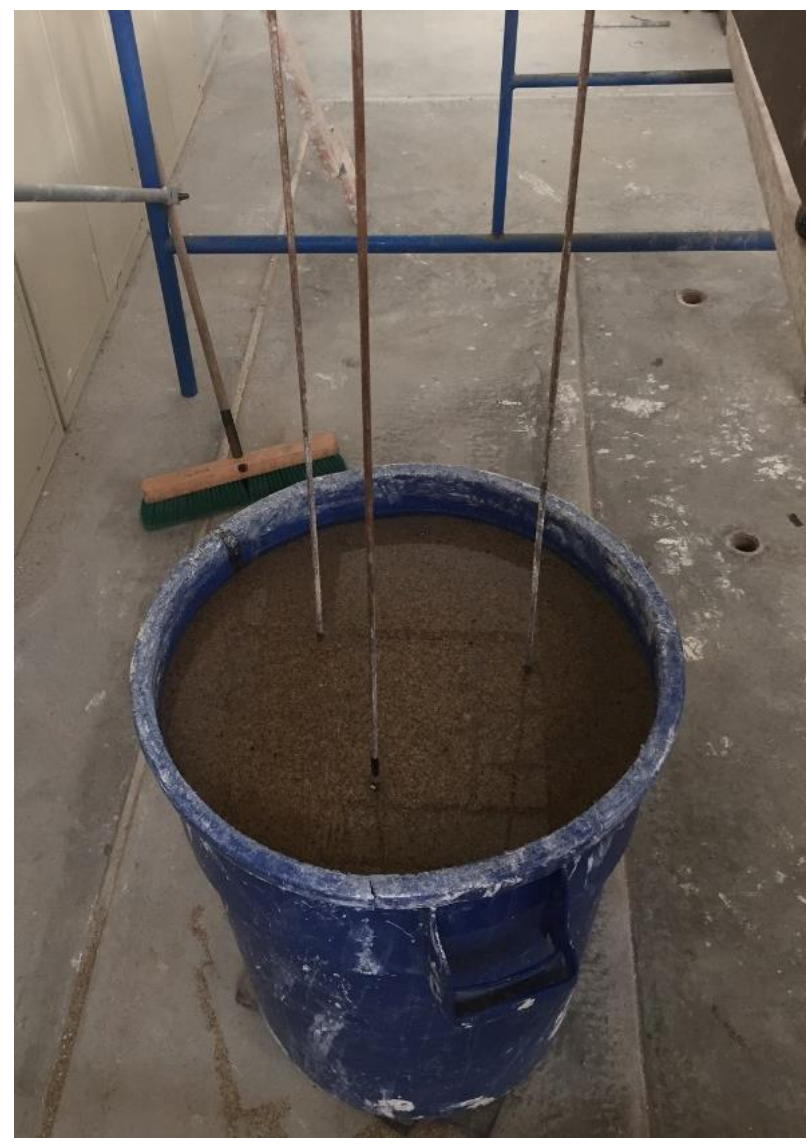

Figure 32: Wet Trash Can Specimen 
at a rate of $8.2 \mathrm{~cm} / \mathrm{sec}$. The average of the three T-bar pullouts can be seen in Figure 33.

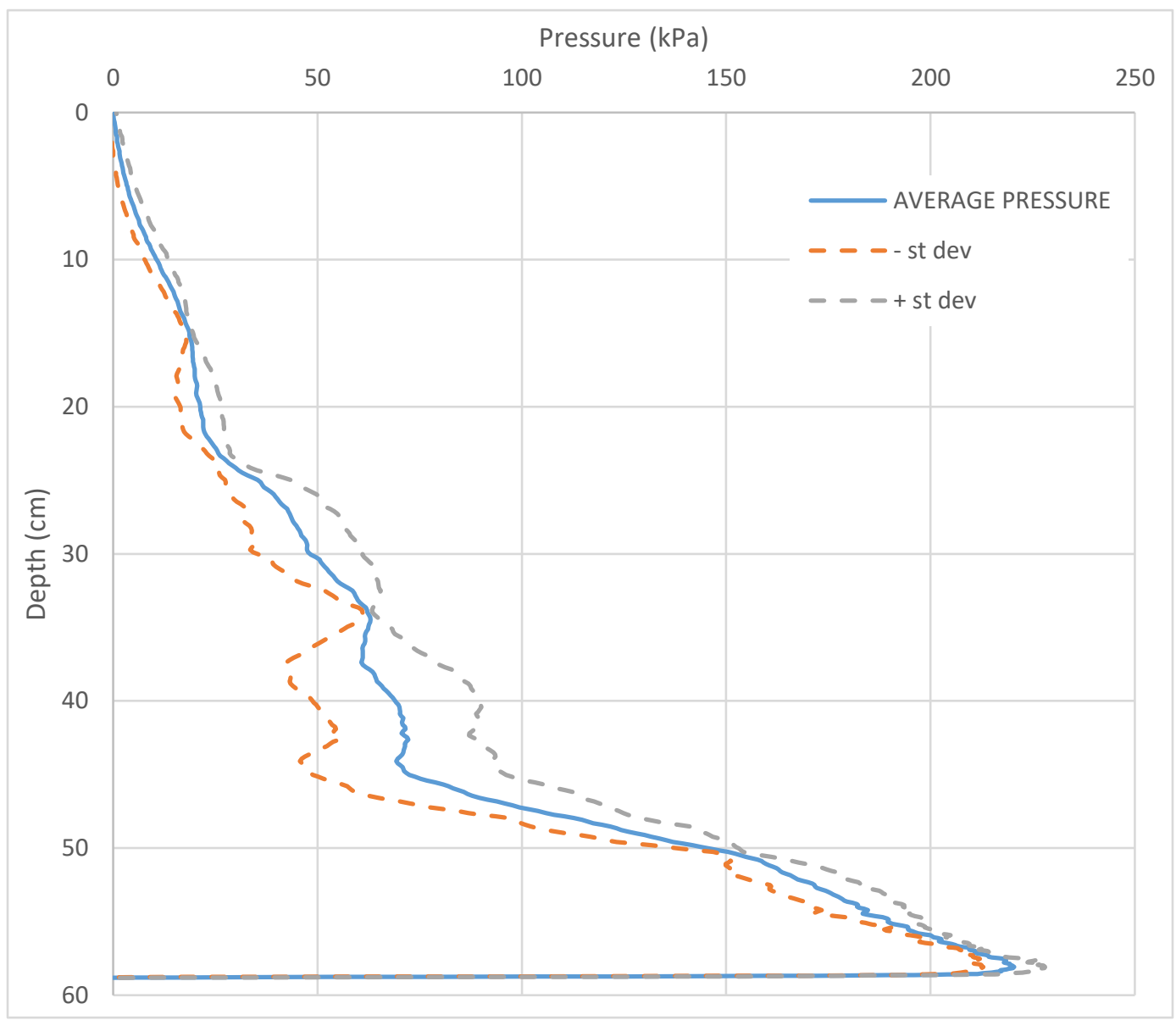

Figure 33: Average Wet Pluviated Trash 1 T-bar Pullout Pressure

A CPT sounding was performed in this sample. The cone was pushed at a rate of $1.4 \mathrm{~cm} / \mathrm{s}$, the slower speed of the gantry crane used to lower the cone penetrometer. The CPT cone was able to penetrate the full depth of the specimen in this drive. The results of this sounding are shown in Figures 34-36. 


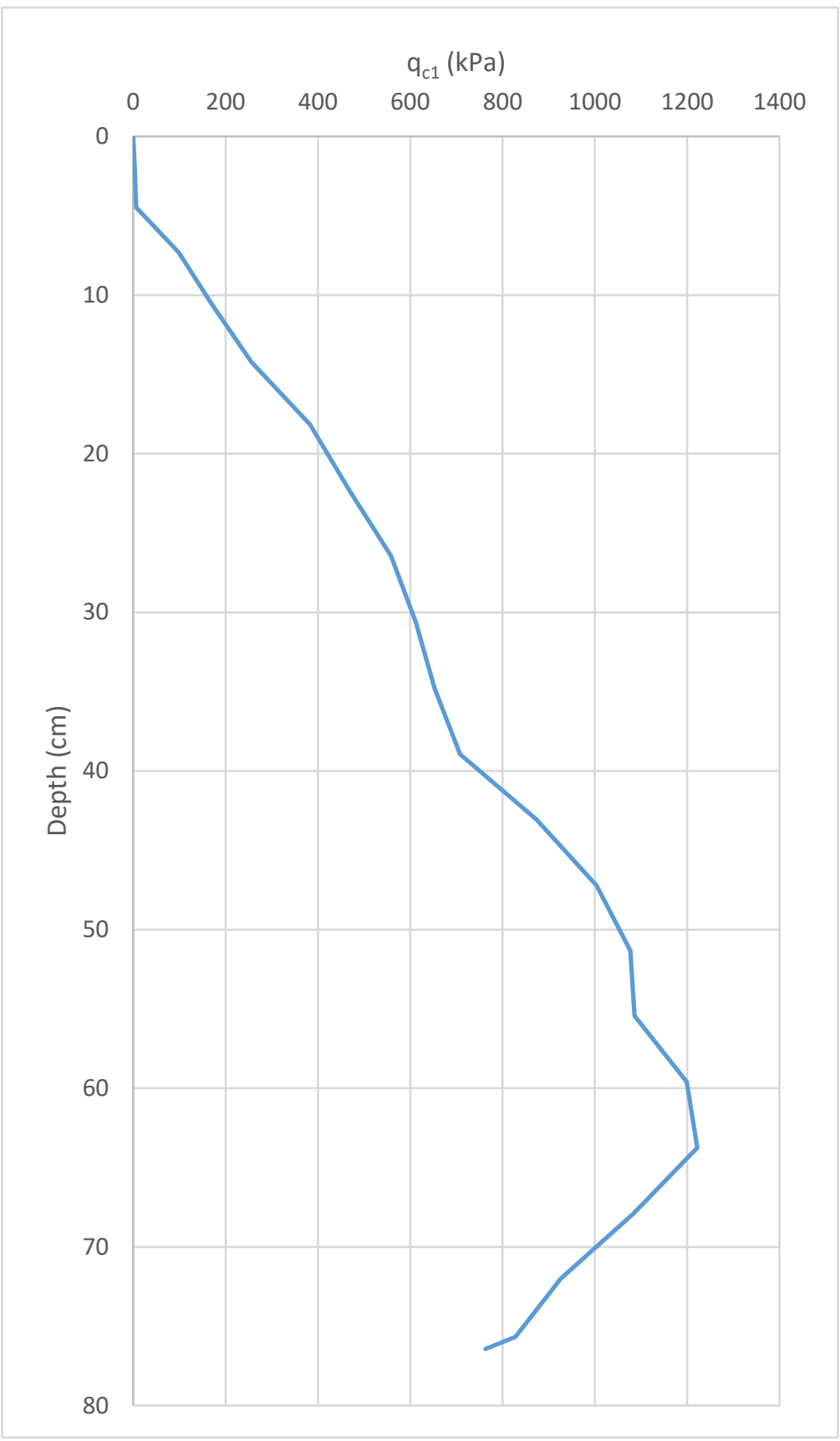

Figure 34: Wet Trash CPT 1.1 Corrected CPT Tip Resistance 


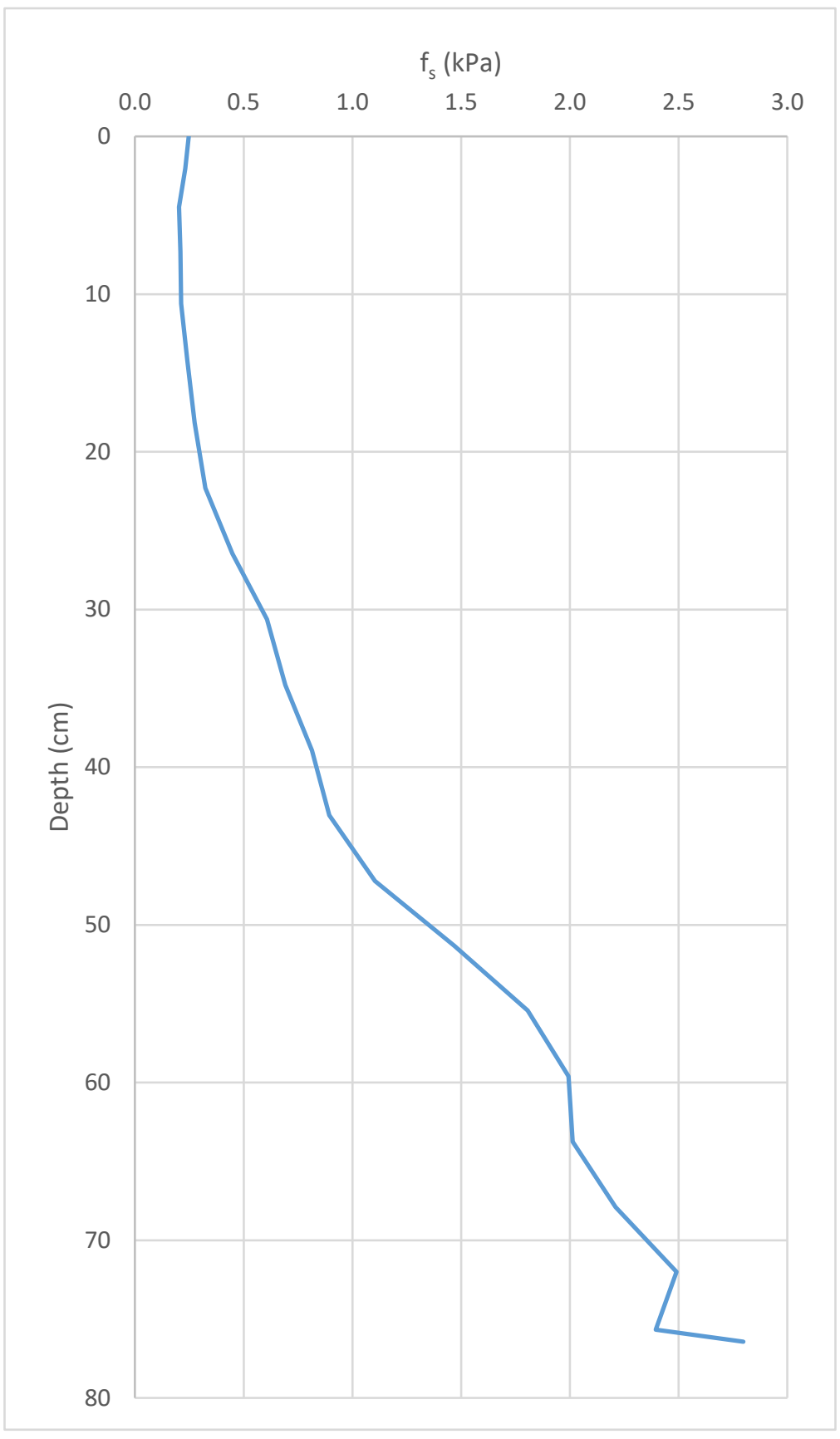

Figure 35: Wet Trash CPT 1.1 Sleeve Friction 


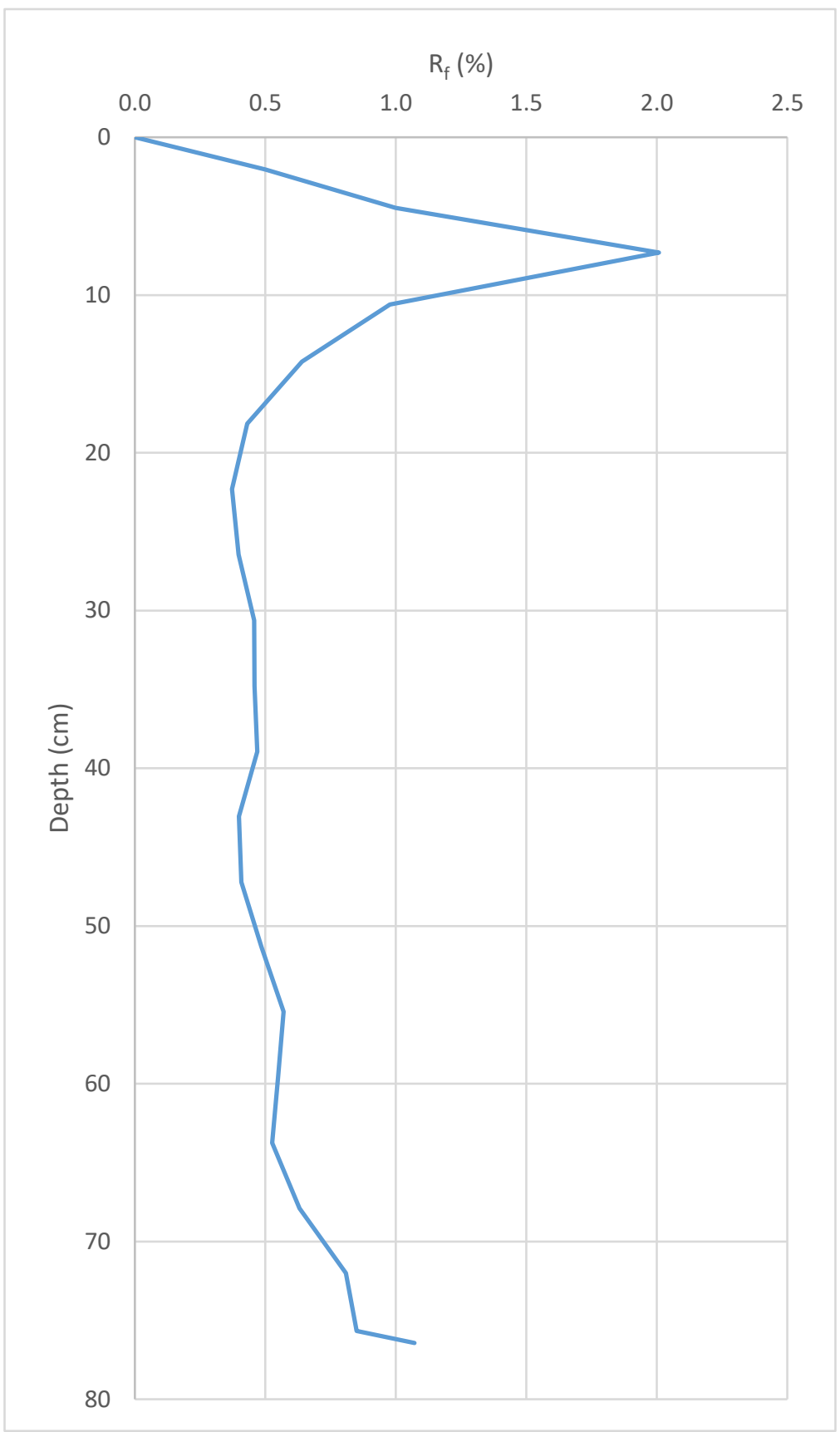

Figure 36: Wet Trash CPT 1.1 Friction Ratio 


\subsection{Wet Pluviated Trash Can Test 2}

Another sample was set up using the same method as Section 3.2 to test the time rate effects of using the higher pullout rate. This sample had a dry unit weight of $15.7 \mathrm{kN} / \mathrm{m3}$ and a relative density of $47 \%$. One T-bars was pulled at a rate of $8.2 \mathrm{~cm} / \mathrm{sec}$ while two were pulled at a rate of $1.4 \mathrm{~cm} / \mathrm{sec}$. The results at these rates are shown in Figure 37.

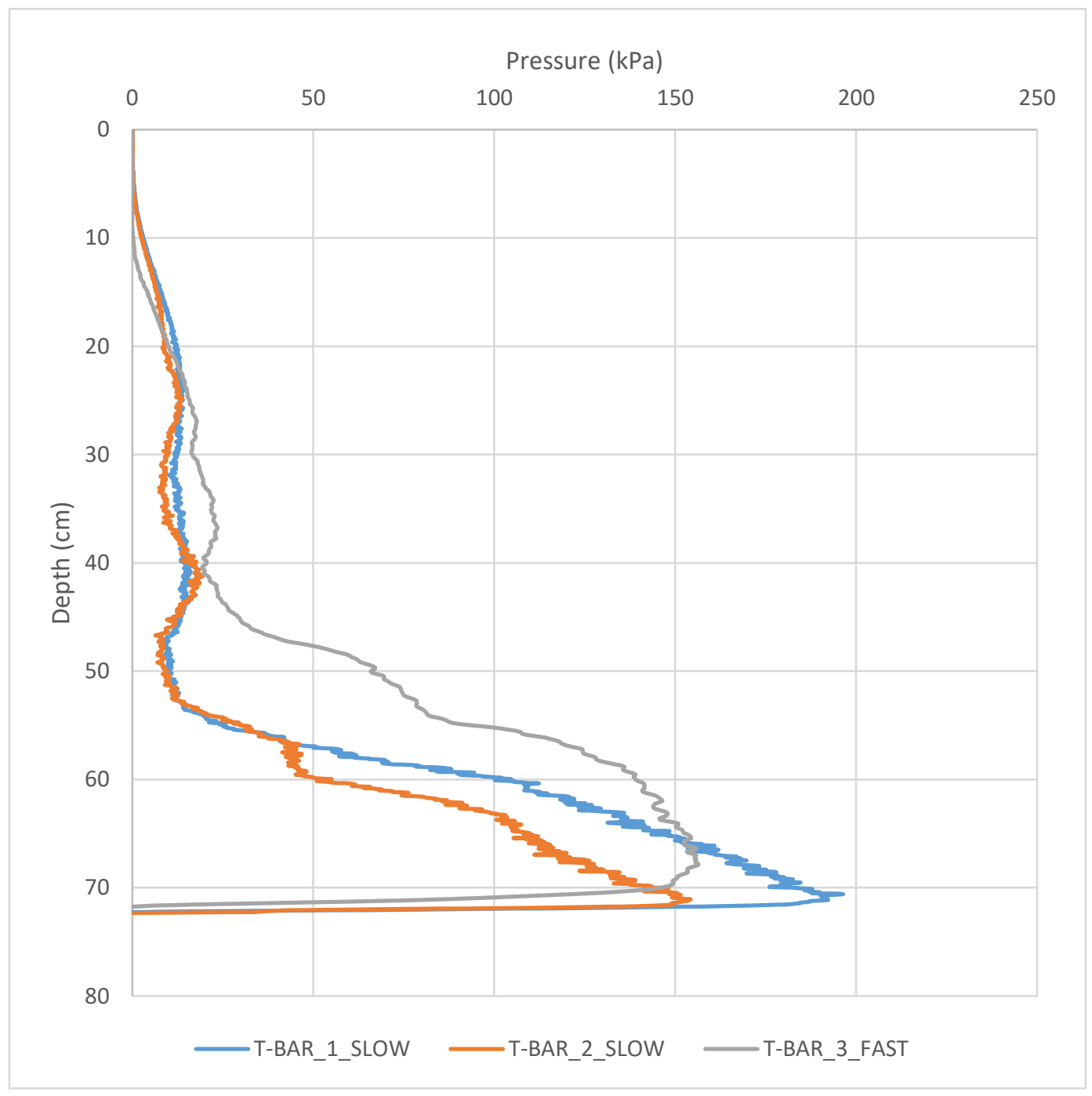

Figure 37: Wet Trash 2 T-bar Pullout Pressures 
As can be seen in Figure 37, time rate effects were observed for the T-bar pullouts. The T-bars pulled at the faster rate $(8.2 \mathrm{~cm} / \mathrm{sec})$ remained at a higher pressure for approximately $30 \mathrm{~cm}$ before settling, while the $\mathrm{T}$-bars pulled at the slower rate $(1.4 \mathrm{~cm} / \mathrm{sec})$ remained at a higher pressure for approximately $15 \mathrm{~cm}$ before settling. However, the results, although stretched, are comparable. Therefore, a pullout rate of $8.2 \mathrm{~cm} / \mathrm{sec}$ was determined to be appropriate to use for the full-scale shake table testing. This higher rate is much better suited to this testing because the T-bars can ascend the height of the sample in approximately 15 seconds, as opposed to approximately 60 seconds if the slower pullout rate was used.

\subsection{Shake Table Transfer Function}

Prior to the clay and sand placement, the bucket was filled approximately half-way with water to test the waterproofing and to estimate the transfer function $\left(\mathrm{H}_{\text {inv }}\right)$ for the shake table control. This transfer function dictates what the table control needs to send to the table in order to achieve a desired output motion. The table was shaken with an $8 \mathrm{~Hz}, 0.5 \mathrm{~g}$, sine wave with the water. The transfer function from this test was saved and used for the full-scale sand tests. Originally, the transfer function from this pre-test was designed to be used for the first test, with all subsequent tests using the transfer function obtained from the previous test. However, after the first cyclic test, the transfer function derived from the water-only was deemed to be acceptable for all future tests. 
Previously, a sine-sweep fast fourier transformation was performed on a similar test configuration to that used in this research (Jacobs 2016). The research found a first modal response of the soil column near $8 \mathrm{~Hz}$ (Figure 38). For this research, an $8 \mathrm{~Hz}$ sine wave was set to run for 122 cycles (15.3 seconds) to provide sufficient time to pull the T-bars through the liquefied sample.

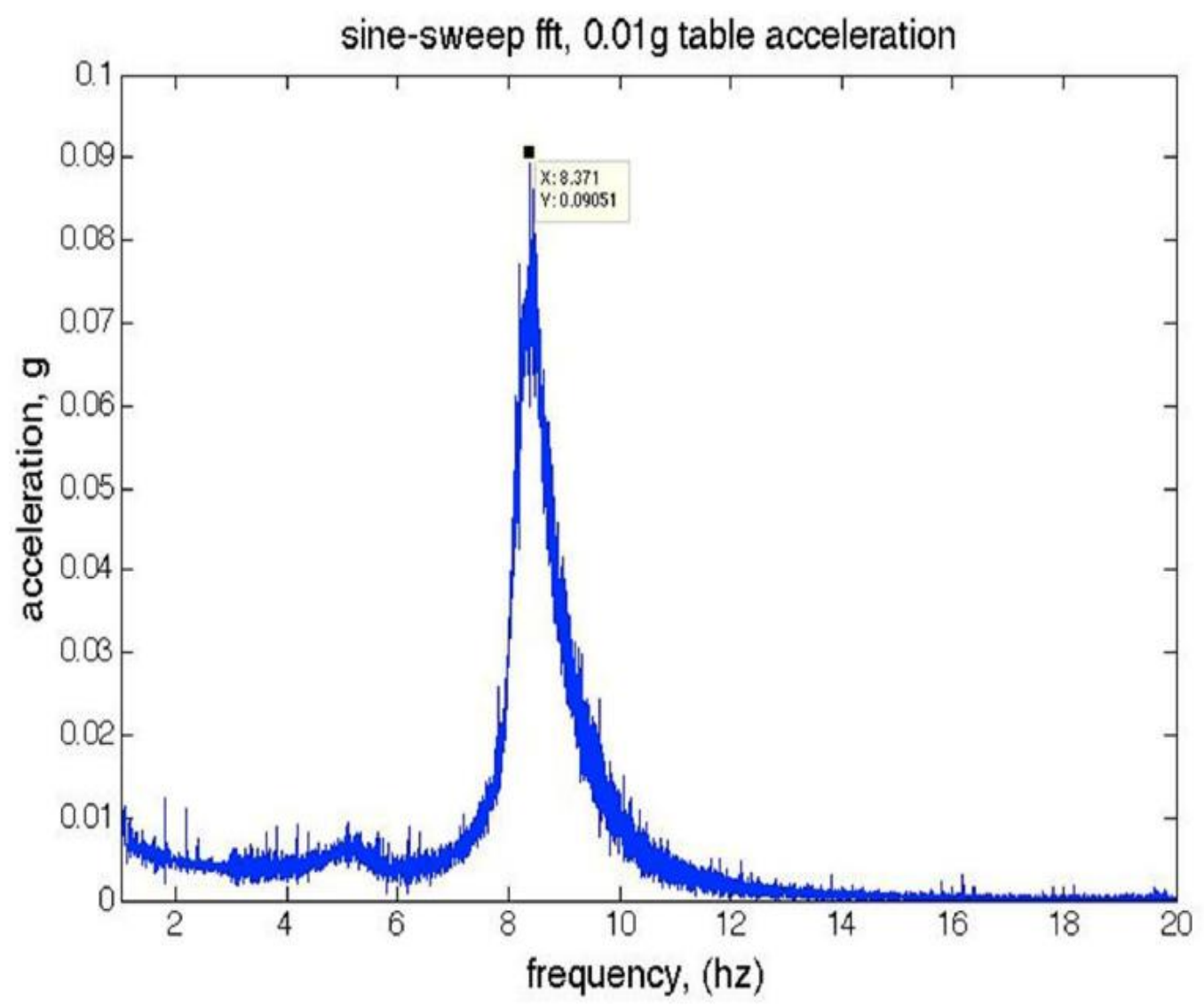

Figure 38: Sine Sweep Fast Fourier Transformation of the Uppermost Accelerometer (From Jacobs, 2016) 


\section{CHAPTER 4 MODEL PREPARATION}

\subsection{Bucket Waterproofing}

Previous tests performed using the same flexible walled testing apparatus were hindered due to imperfect waterproofing of the bucket. The steel base of the apparatus was waterproofed using a combination of Titebond ${ }^{\circledR}$ Weathermaster ${ }^{\mathrm{TM}}$ Metal Roof Sealant and an aerosol spray rubber coating. The interface of the rubber wall and the steel base was waterproofed by placing silicone between all interfaces at the bolt holes. This waterproofing technique proved to be effective during testing, with no visible signs of leakage.

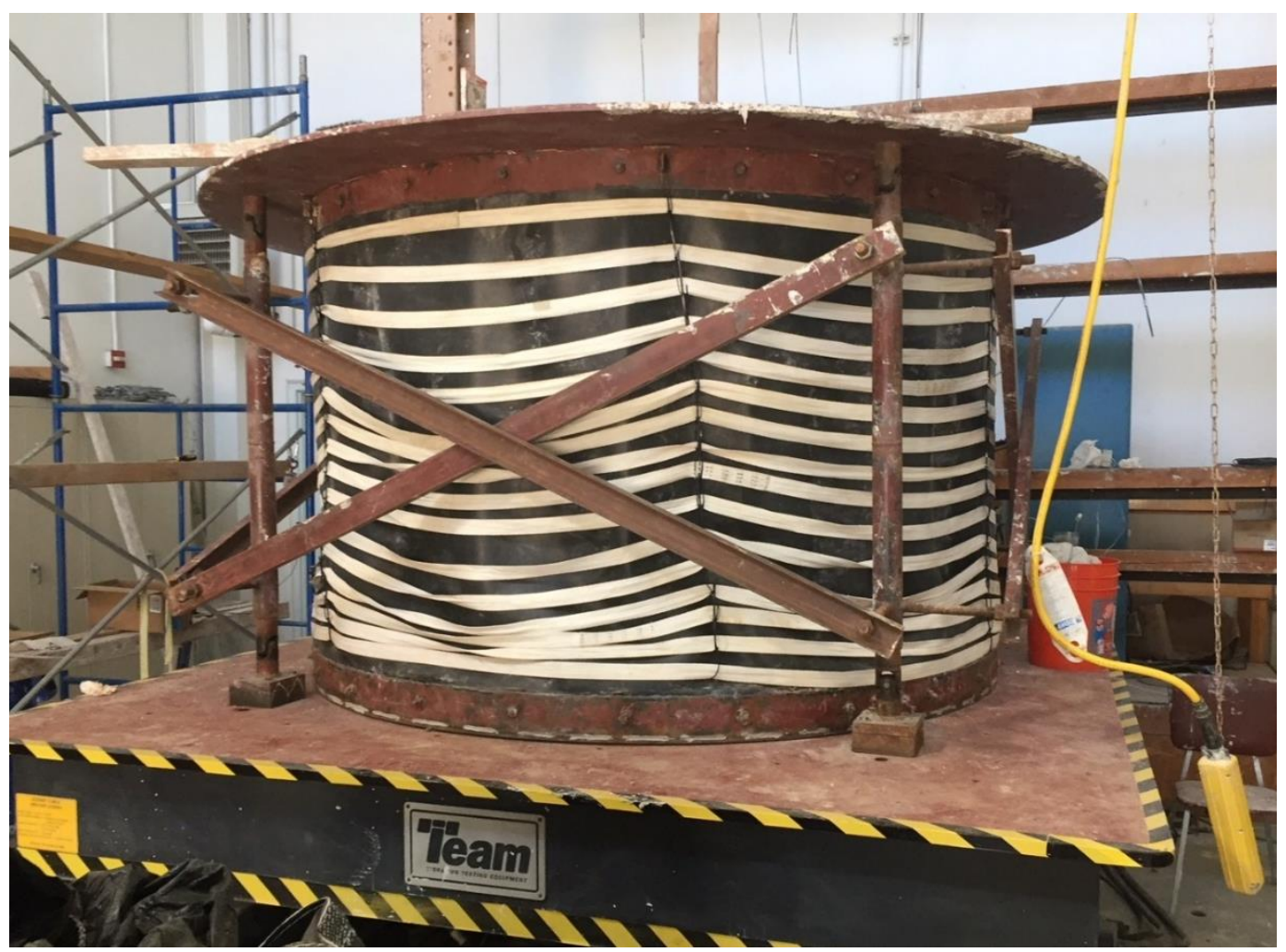

Figure 39: Flexible Walled Testing Apparatus 


\subsection{Clay Placement}

A $15 \mathrm{~cm}$ thick layer of soft clay was placed at the base of the flexible walled testing apparatus. This clay layer helped ensure the apparatus was water tight by providing an impermeable boundary between the saturated loose sand and the base. The clay also allowed the appropriate height of the sand layer to create a height to diameter ratio of 0.4 as specified in ASTM D6528 for simple shear testing.

The soft clay consisted of approximately $67.5 \%$ kaolonite, $22.5 \%$ betonite, and $10 \%$ class C fly ash by mass of solids mixed at a water content of $125 \%$. This soft clay mixture has previously been vetted in studies by Crosariol (2010), Kuo (2012), Noche (2013), Moss \& Crosariol (2013), and Stanton (2013). The clay mixture was mixed and pumped into the testing flexible wall testing apparatus using an industrial grade Chem-Grout soil mixer. The clay layer was separated from the saturated sand layer using semipermeable landscape fabric (Figure 40). The landscape fabric prevented the fines from the clay from migrating into the saturated sand layer. 


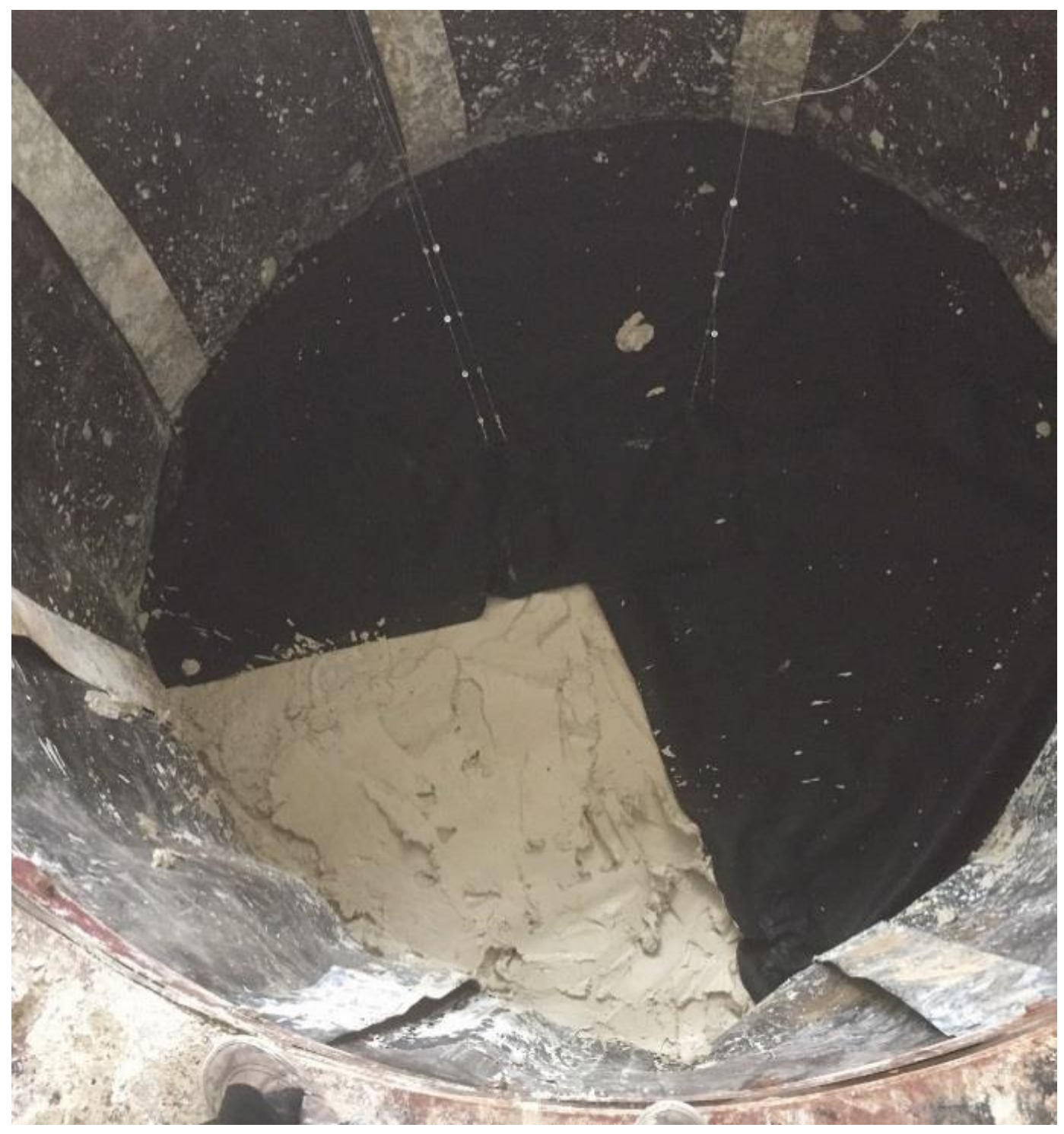

Figure 40: Clay Mixture and Filter Fabric at Base of Specimen

\subsection{Sand Placement}

The sand used in this testing is a \#2/16 Monterey sand sourced from the CEMEX Lapis Plant in Marina, California. Figure 41 shows an approximate gradation of the \#2/16 Monterey sand as reported by CEMEX quality control (from Stanton, 2013). The sand created a $92 \mathrm{~cm}$ thick layer of granular material above the soft clay. The sand layer was placed by dry pluviation 
into a standing head of water ranging from 5 to $15 \mathrm{~cm}$ in depth. A large scale pluviation device (Figure 42) was modeled after a No. 8 ASTM E-11 sieve with a $2.36 \mathrm{~mm}$ aperture. The full device consisted of a large reservoir hopper suspended above a metal screen constructed within a timber frame with a 24" square opening. The metal screen of the pluviation device was previously shown to produce samples with a $0.19 \%$ difference in total unit weight when compared to a No. 8 ASTM E-11 sieve (Jacobs, 2016). The large scale pluviation device was used to deposit the sand in the center of the flexible walled testing apparatus while a No.8 ASTM E-11 sieve was used to deposit the sand near the walls of the flexible walled testing apparatus.

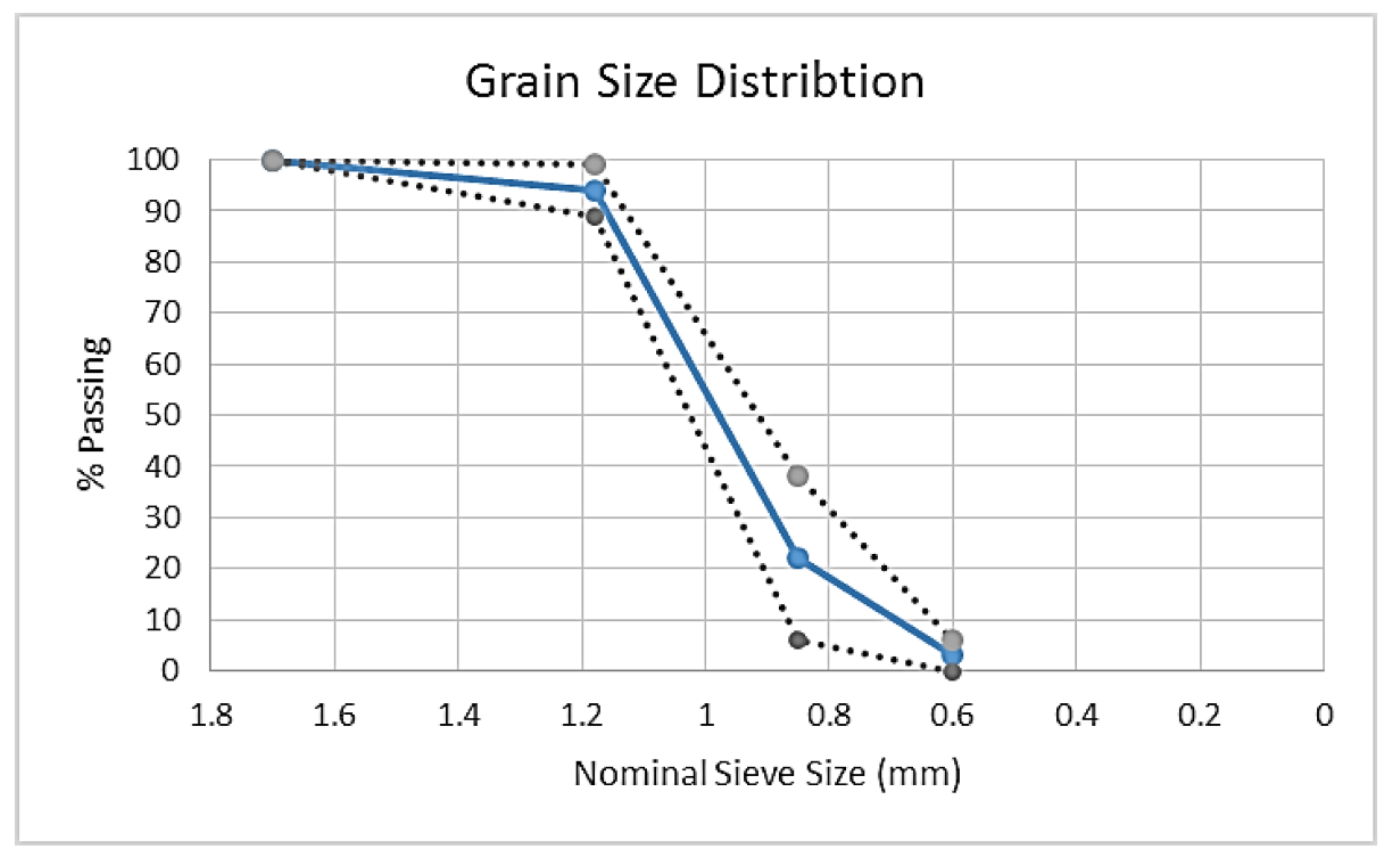

Figure 41: Approximate Grain Size Distribution of \#2/16 Monterey Sand (Stanton 2013) 


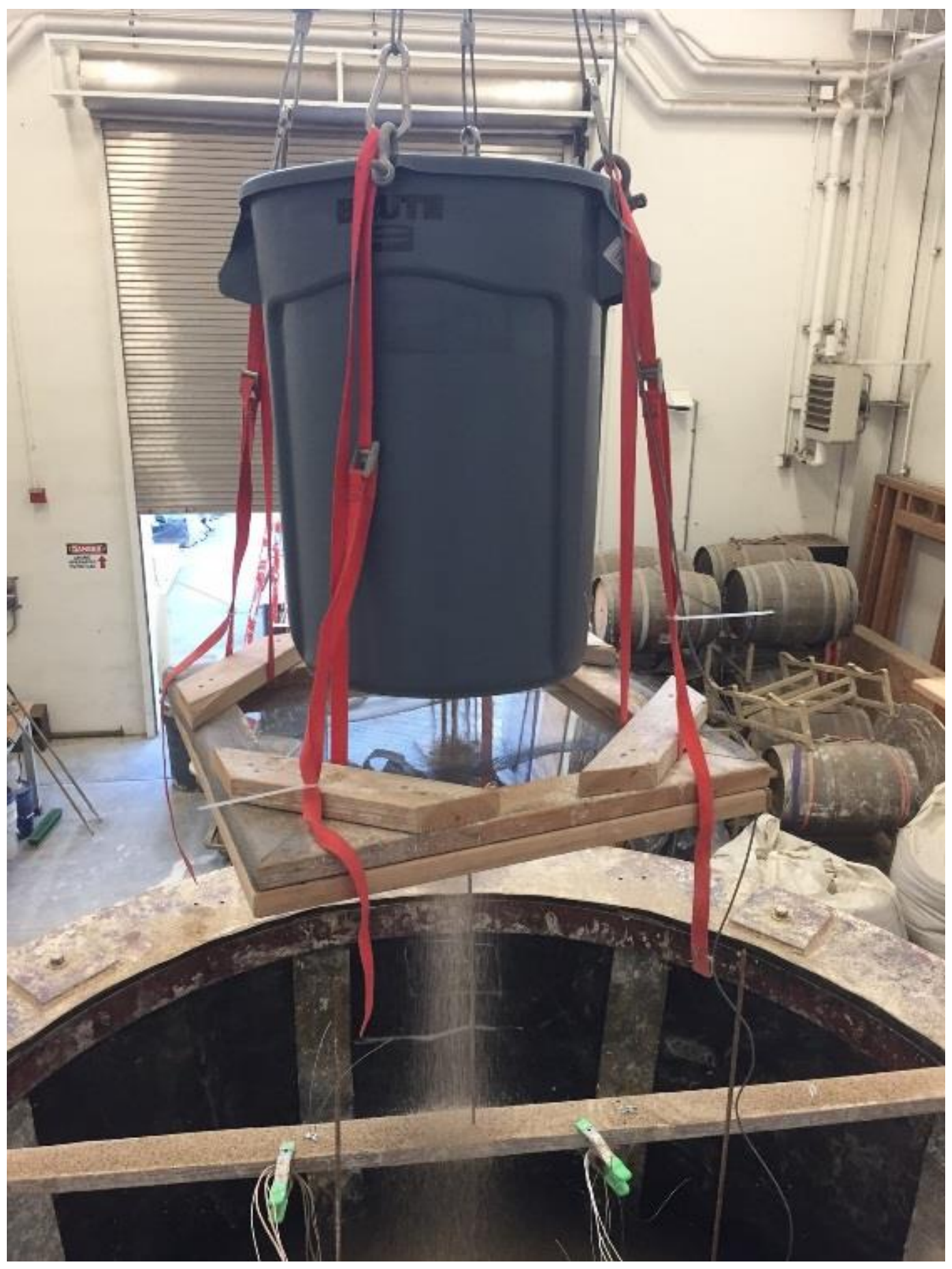

Figure 42: Large-Scale Pluviation Device 
The maximum and minimum dry unit weights of the \#2/16 Monterey Sand were previously measured using the ASTM D4254-14 and D4253-14 procedures, respectively (Jacobs, 2016). The maximum and minimum dry unit weights were calculated to be 17.1 and $14.7 \mathrm{kN} / \mathrm{m}^{3}$, respectively. These results are in close agreement to previous studies performed by Hazirbaba and Rathje (2009), Boulanger and Seed (1995), and Kammerer et al. (2005), where the maximum dry unit weights of Monterey Sand ranged from 16.0-17.1 kN/m ${ }^{3}$, and minimum dry unit weights ranged from 13.1-13.9 $\mathrm{kN} / \mathrm{m}^{3}$. During the sample placement, the mass of sand added was recorded to determine an estimated dry unit weight of the sample. Assuming the sand filled the volume of a rigid cylinder with a diameter of $230 \mathrm{~cm}$ and a height of $92 \mathrm{~cm}$, the dry unit weight of the sample is roughly $15.4 \mathrm{kN} / \mathrm{m}^{3}$, resulting in a relative density (Dr) of approximately $32 \%$.

Once the sand was deposited the full height of the sample $(92 \mathrm{~cm}$ ) (Figure 43), additional landscape fabric was placed down to protect the interface between the top of the sand layer and the bottom of the overburden assembly. 


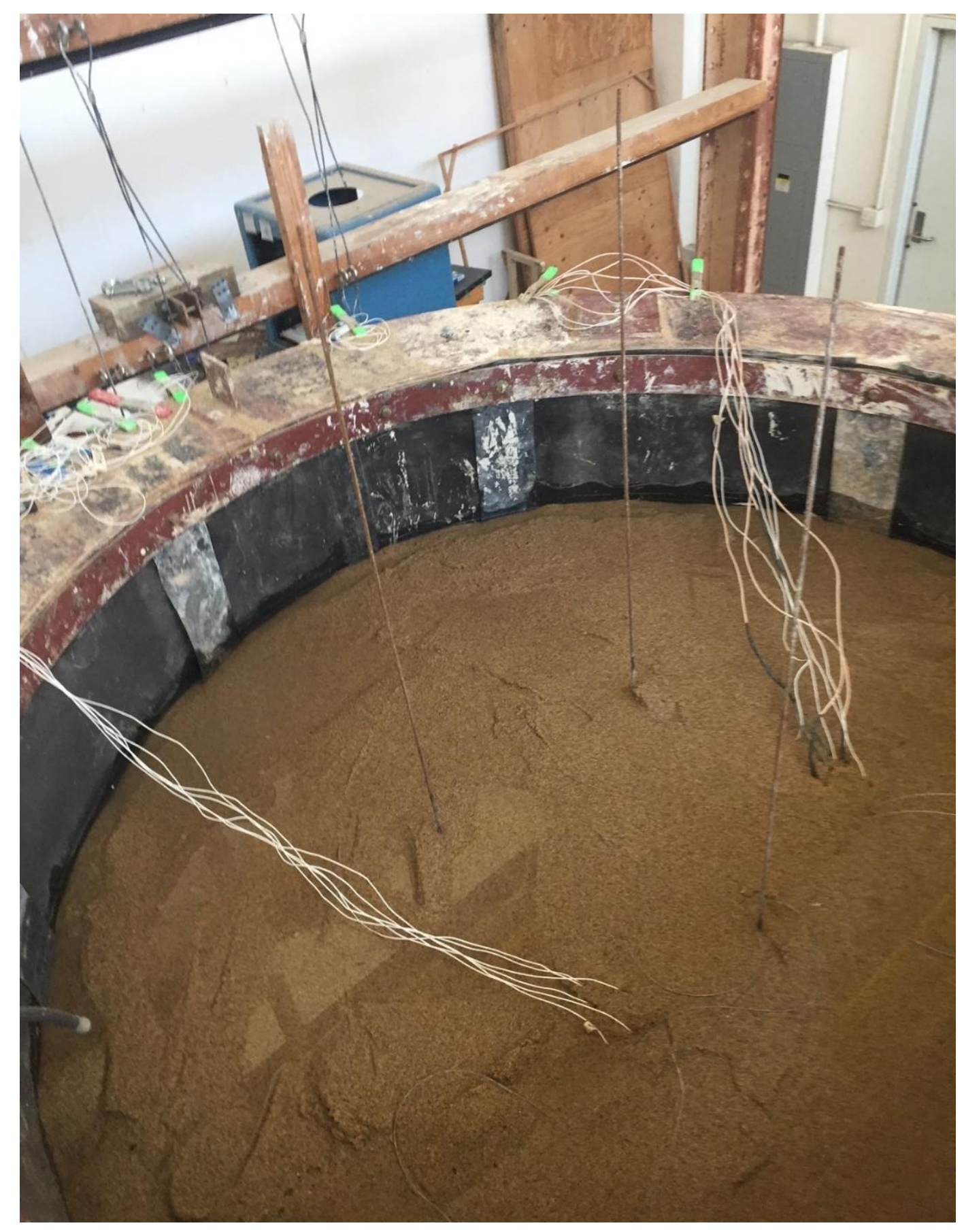

Figure 43: Top of Deposited Sand 


\subsection{Overburden Assembly}

Confinement of the soil sample was applied by inflating an 18.4/20.8R-42 inner tube within a confined area at the top of the flexible walled testing apparatus. The inner tube was confined by $5 / 8$ " plywood at the bottom and 1-1/8" T\&G plywood subfloor at the top protected by visqueen plastic. Two W8x13 grade A992 rolled steel beams were attached to the upper rim of the flexible walled testing container to provide the reaction force necessary on the top plate to provide confinement of the inner tube. In order to prevent the inner-tube from expanding into the space reserved for the T-bars and CPT soundings, a $91 \mathrm{~cm}$ diameter high density polyethylene corrugated drain pipe was placed in the annular space of the inner tube. The inner tube was then inflated to apply an overburden pressure to the soil. The overburden pressure was measured in two ways: PPS tactile pressure sensors placed below the bottom plate of the overburden assembly, and a flat scale placed between the inner tube and top-plate. 


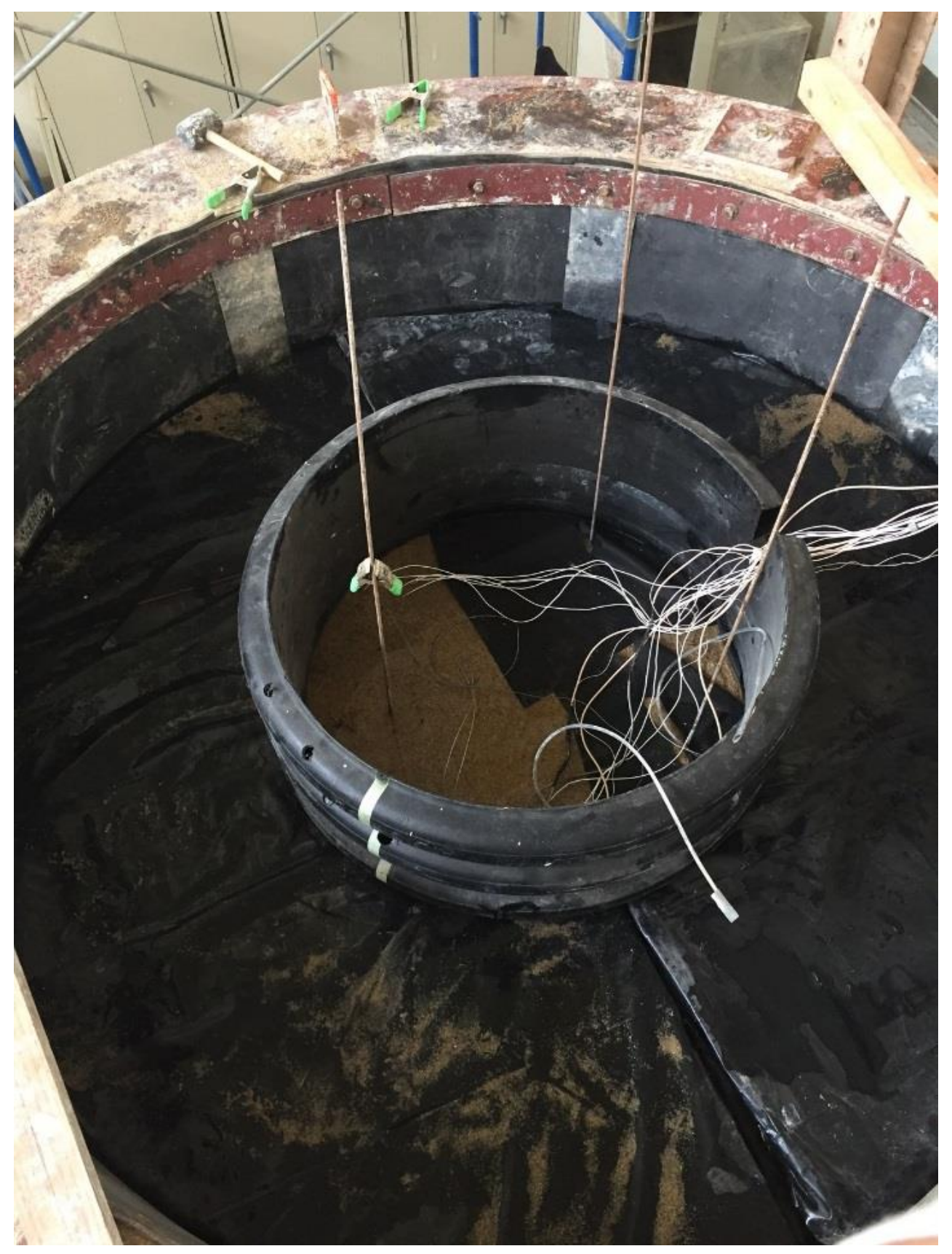

Figure 44: Bottom Plates of Overburden Assembly 


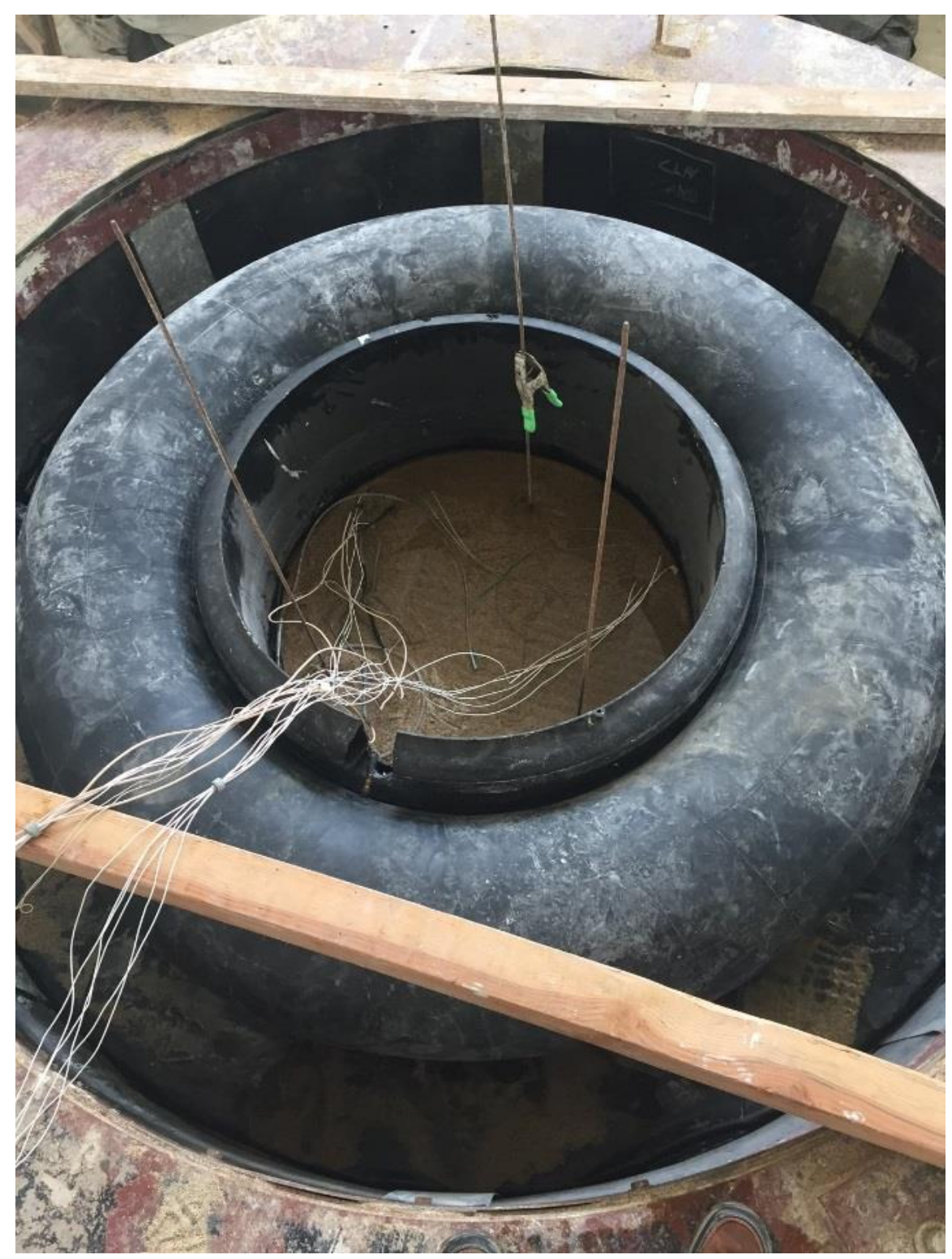

Figure 45: Semi-Inflated Inner-Tube 


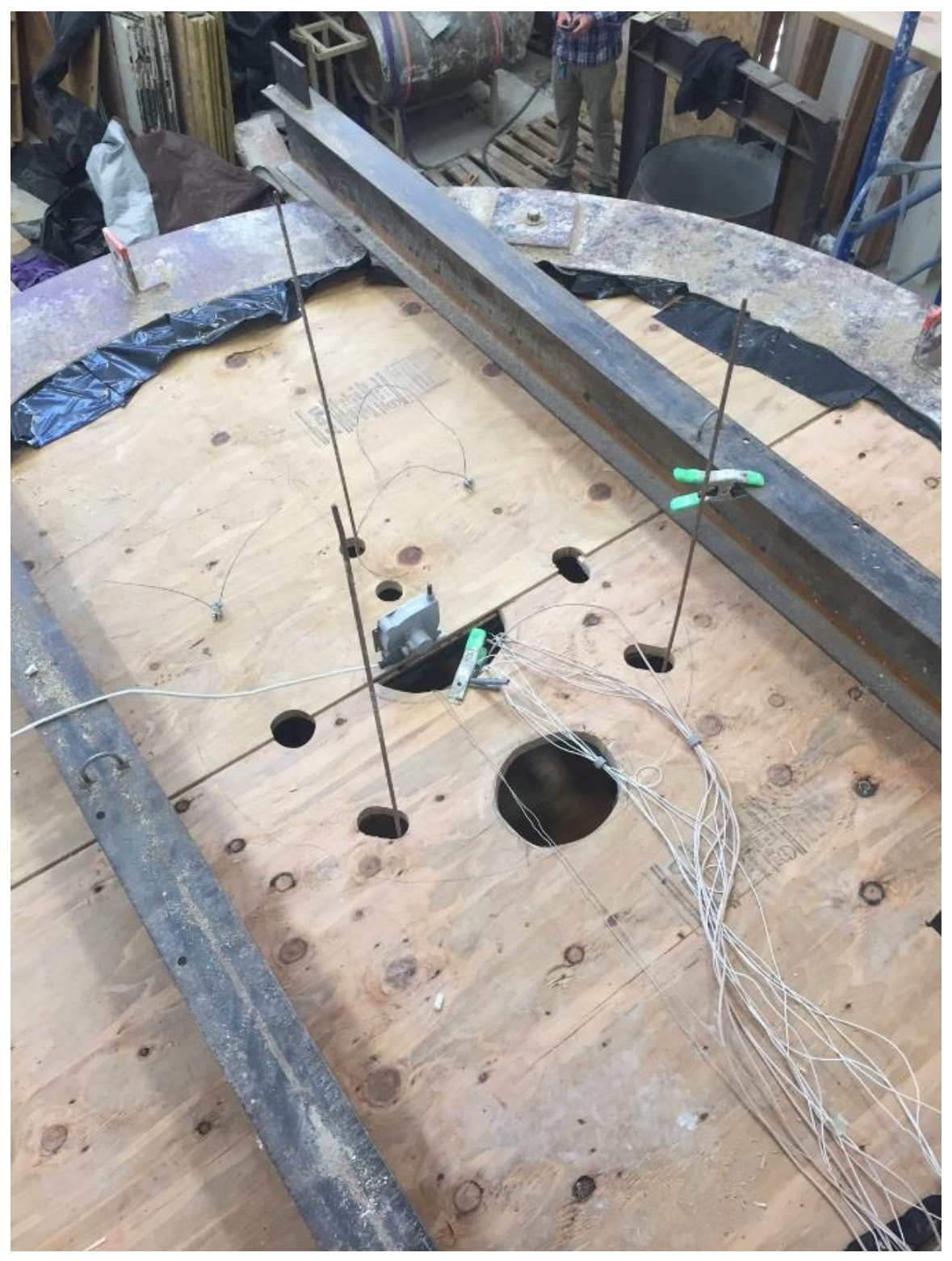

Figure 46: Completed Overburden Assembly 


\subsection{Instrument Embedment}

Two vertical arrays of instruments were embedded within the saturated sand layer (Figure 47). Each array consisted of 4 instrument packages. Each instrument package was mounted on an acrylic plate. The arrays used anchored cables with crimped stoppers to rest at the proper height during sand deposition and testing.

For each array, two $1.6 \mathrm{~mm}$ diameter cables were attached to the base of the flexible walled testing apparatus using eyelets epoxy-bonded to the base. The cable stoppers were spaced equidistant at a $20 \mathrm{~cm}$ spacing with the bottom cable stop located $10 \mathrm{~cm}$ above the bottom of the saturated sand layer. One array contained accelerometers oriented in the direction of shaking motion with a vertical oriented accelerometer paired on the bottom accelerometer. The second array contained accelerometers and pore pressure transducers oriented in the direction of shaking motion. Both arrays were spaced $30 \mathrm{~cm}$ forward (in the direction of shaking) of the center of the bucket, with one array $25 \mathrm{~cm}$ to the left and the other array $25 \mathrm{~cm}$ to the right. A schematic section and top view of the compelted bucket assembly and instrument embendment can be seen in Figure 48 and Figure 49. 


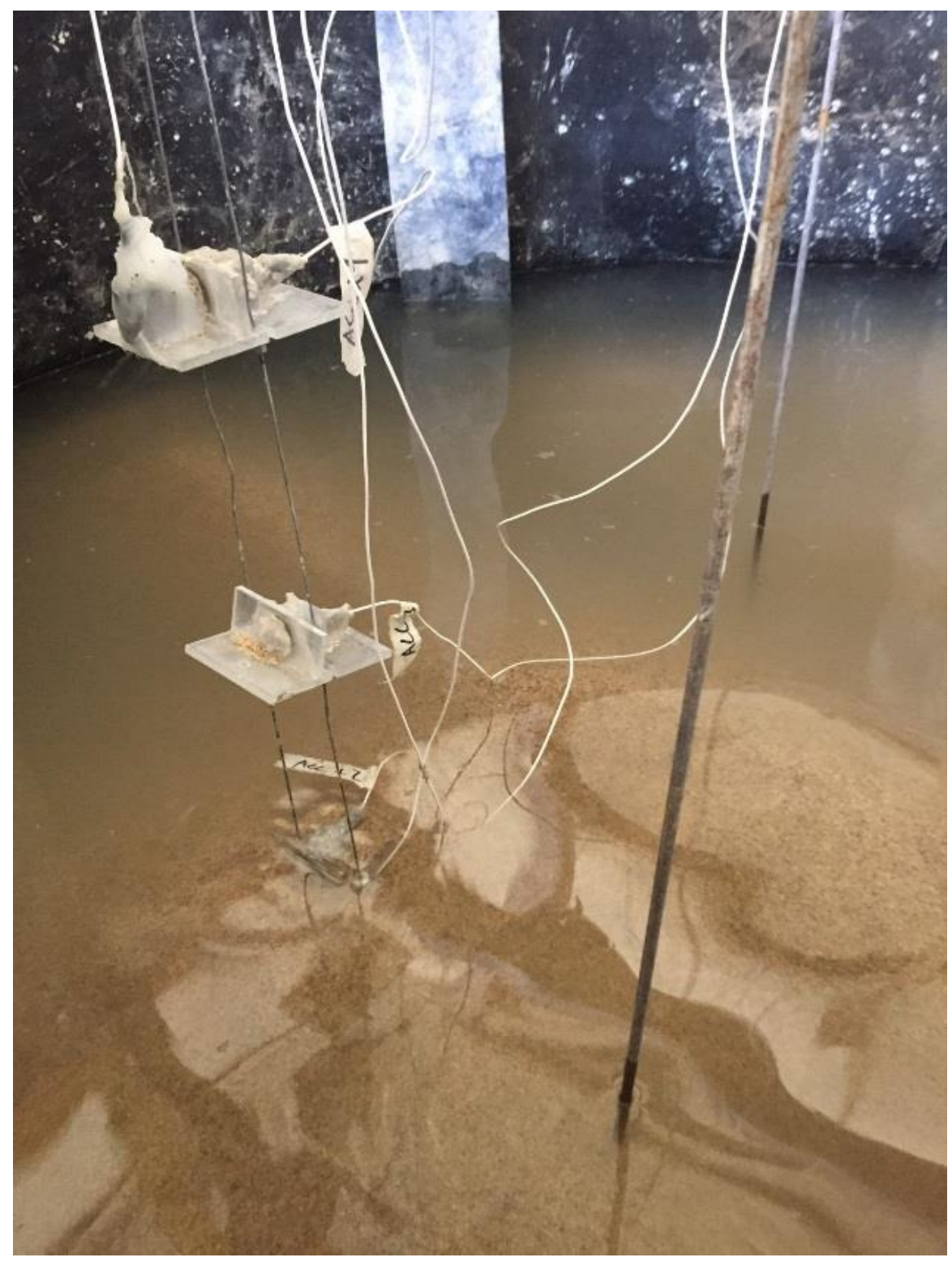

Figure 47: Accelerometer Embedment in Sand 


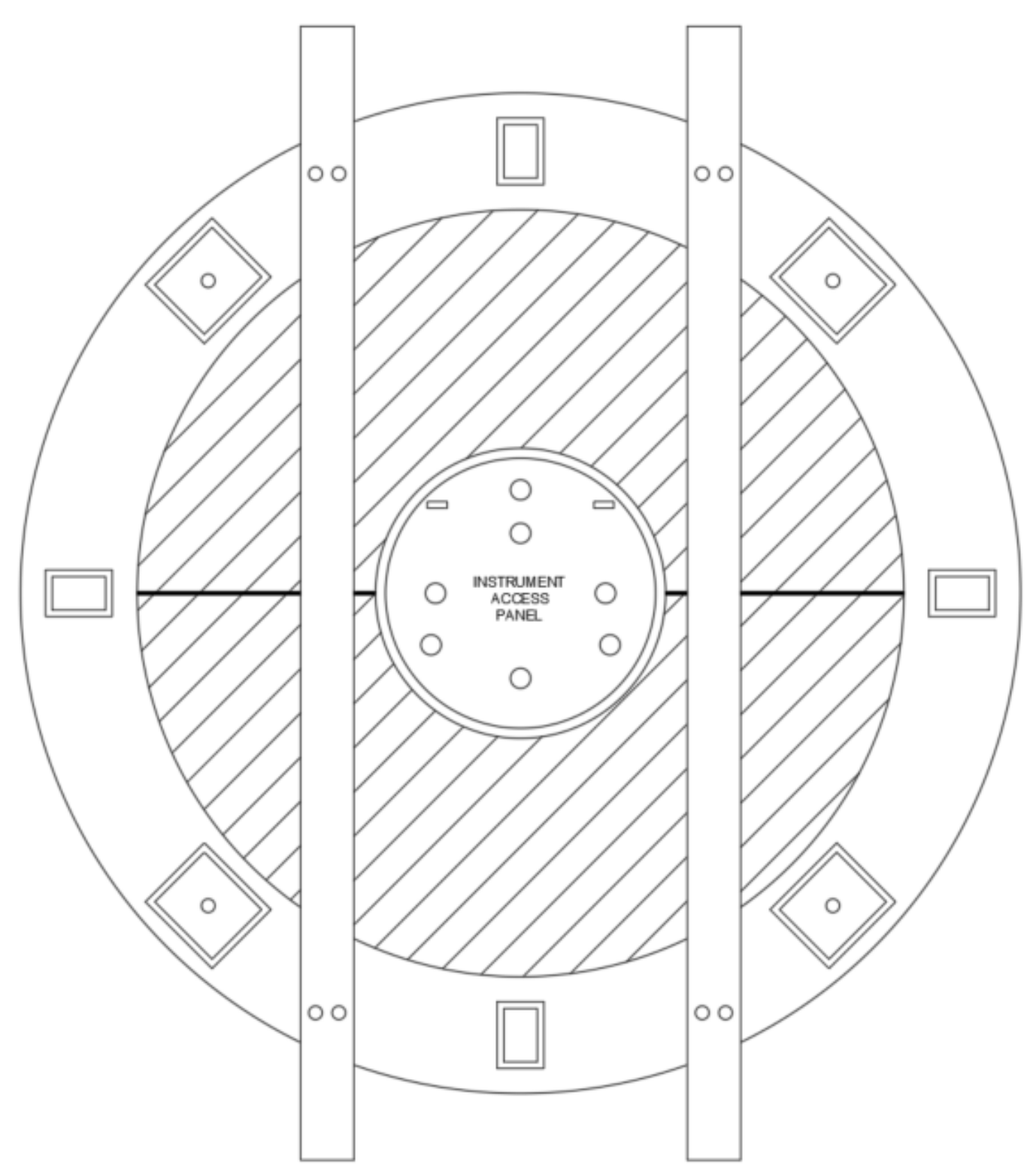

Figure 48: Top View of Completed Specimen 


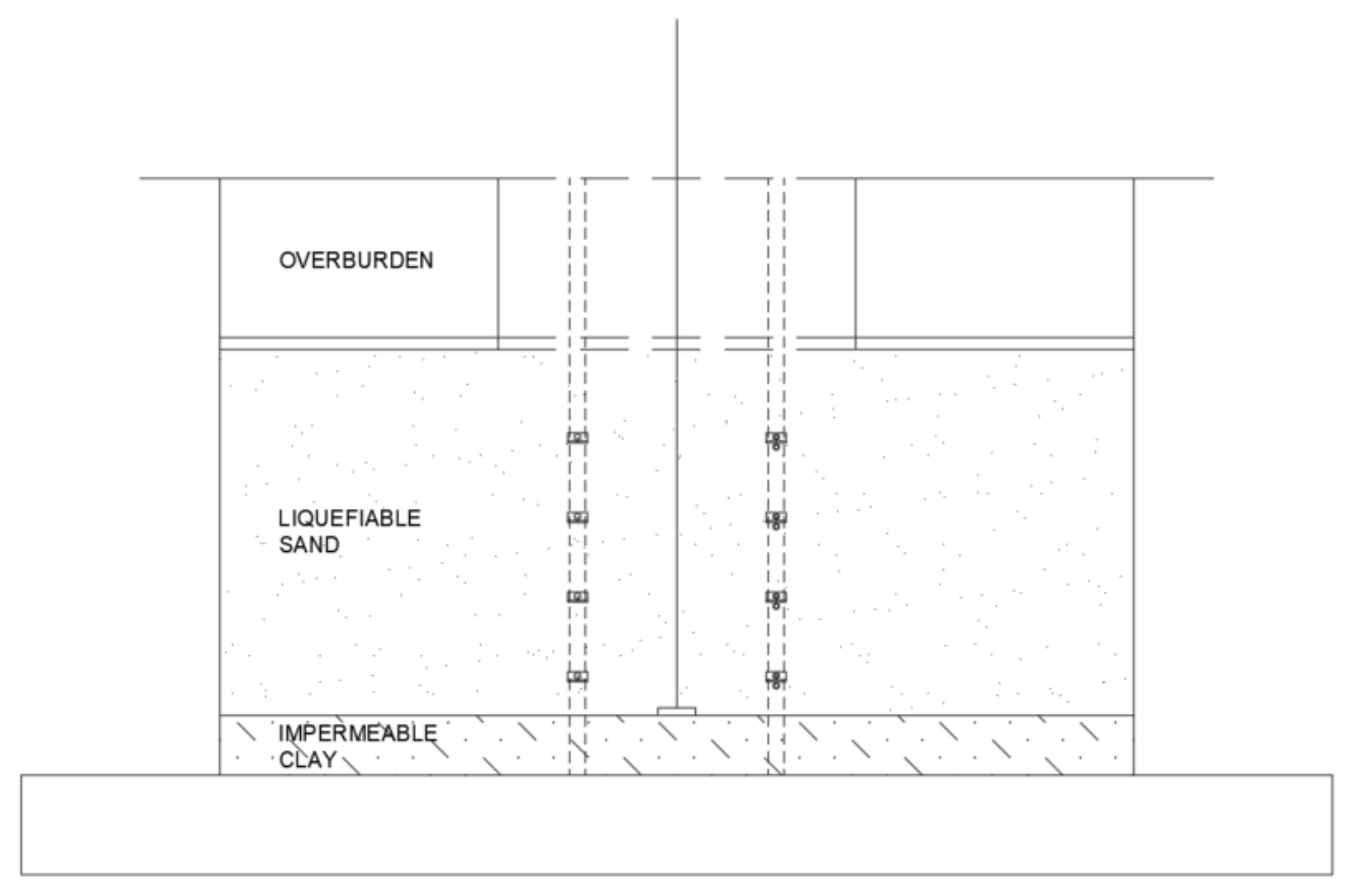

Figure 49: Schematic Section of Completed Specimen 


\section{CHAPTER 5 TESTING}

\subsubsection{Pre-Liquefaction Shear Wave Velocity}

Shear wave velocity of the soil sample was estimated using a procedure similar to that outlined in Seismic Cone Downhole Procedure to Measure Shear Wave Velocity (Butcher et al., 2005). A $46 \mathrm{~cm}$ long, $9 \mathrm{~cm} \times 9 \mathrm{~cm}$ block was placed at the top of the soil. Approximately $950 \mathrm{~N}$ were applied to the block. The block was then struck with a rubber mallet on one side, and then the other (Figure 50). The accelerometers were used to detect the shear wave propagating through the soil profile. The first major cross-over of these "butterflied" shear waves was used as the "reference" arrival of the shear

wave. Using accelerometers are different depths in the sample, the shear wave velocity was estimated by taking the vertical distance between accelerometers and dividing it by the difference in the time of reference arrival.

The measured shear wave velocity of the sample is approximately 200 $\mathrm{m} / \mathrm{sec}$. Shear wave velocity was measured without the overburden assembly, likely resulting in lower measured shear wave velocity than that present during cyclic testing. 


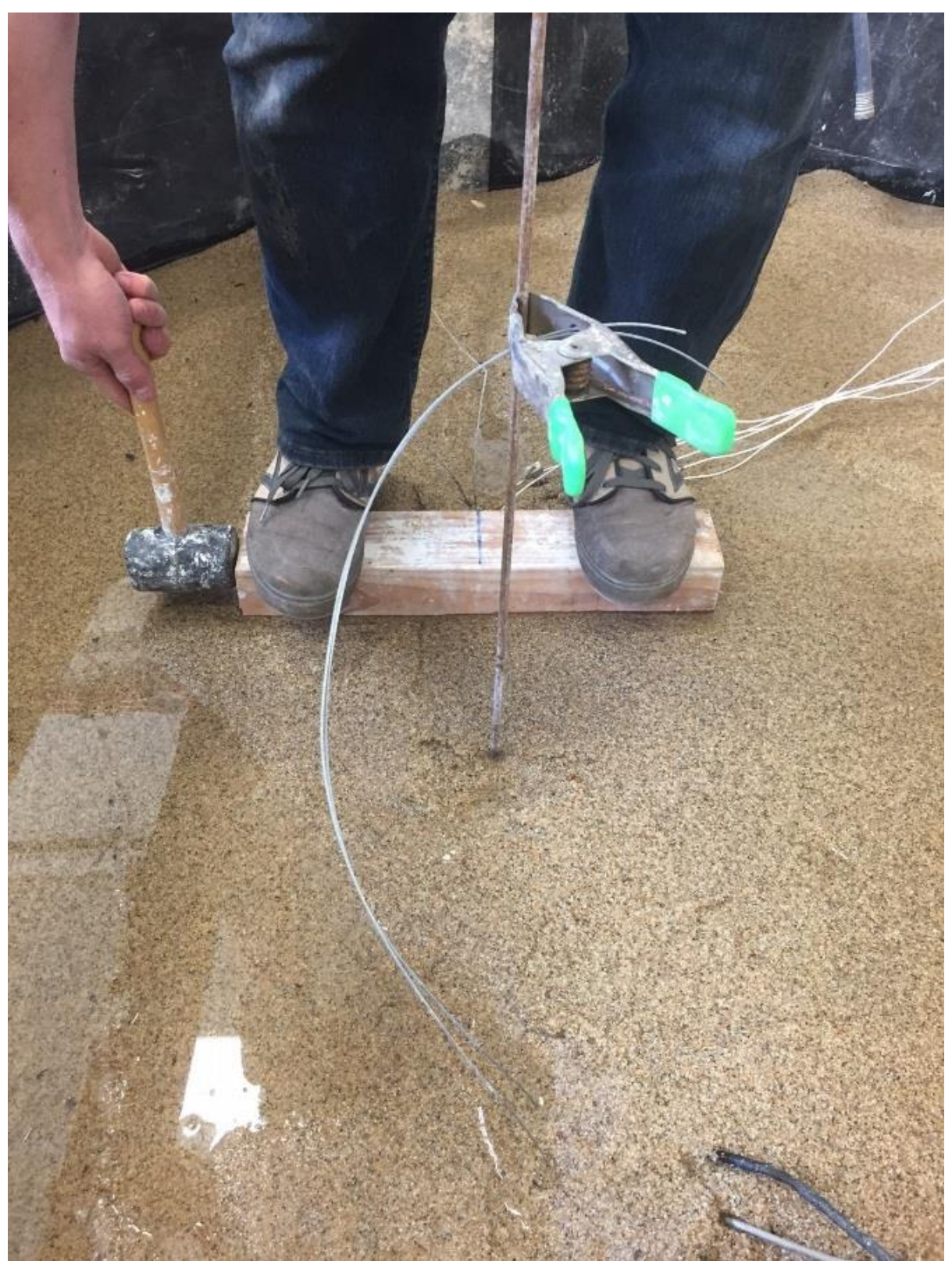

Figure 50: Shear Wave Velocity Testing 


\subsubsection{Initial Cone Penetration Test Sounding (CPT_1.1)}

An initial CPT sounding was performed in the soil sample prior to the first cyclic test. The cone penetrometer was pushed to a depth of $90 \mathrm{~cm}$ below the soil surface. The overburden assembly provided a virtual overburden of $31.8 \mathrm{kPa}$ during this sounding. 


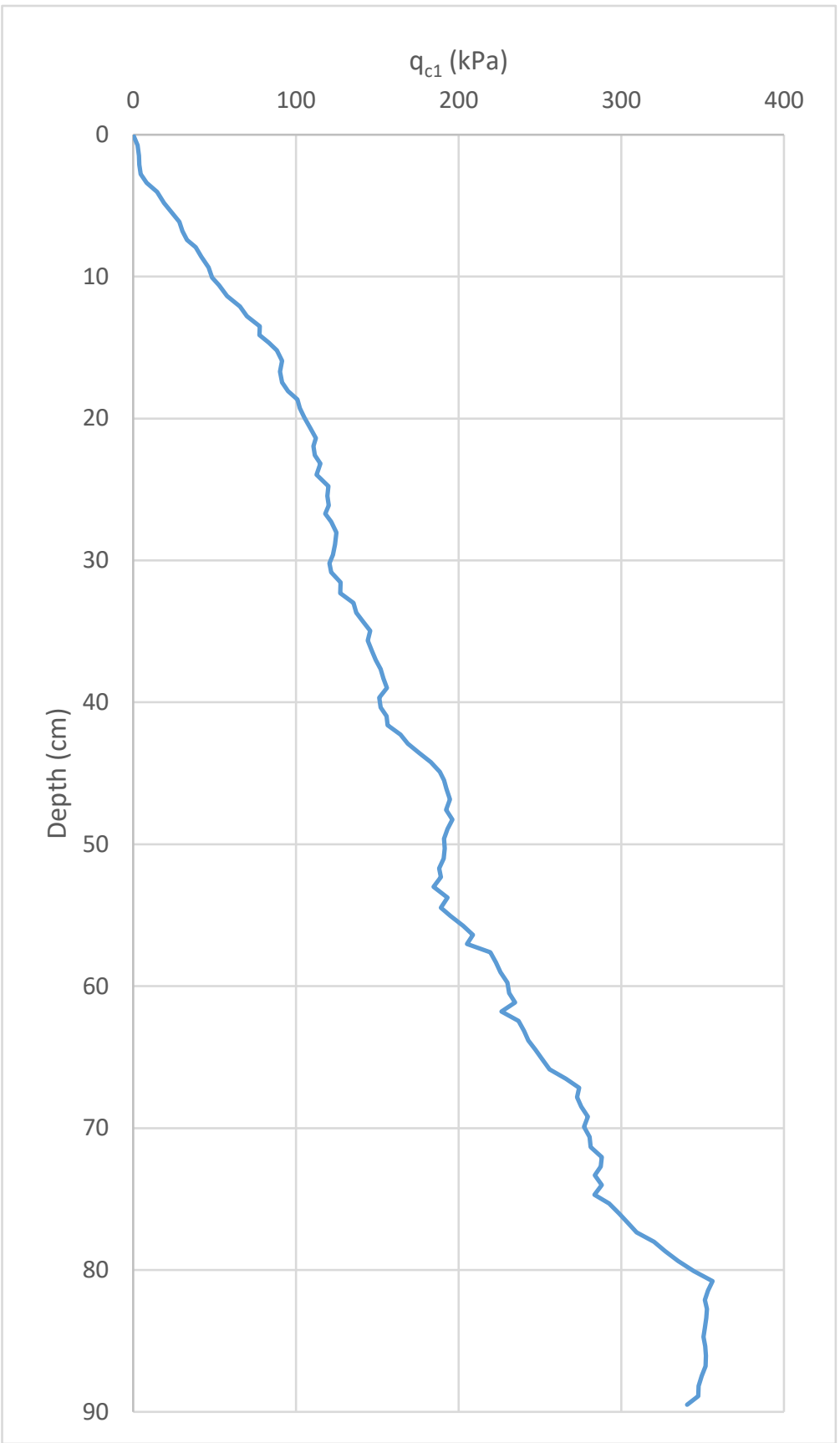

Figure 51: CPT 1.1 Corrected Tip Resistance 


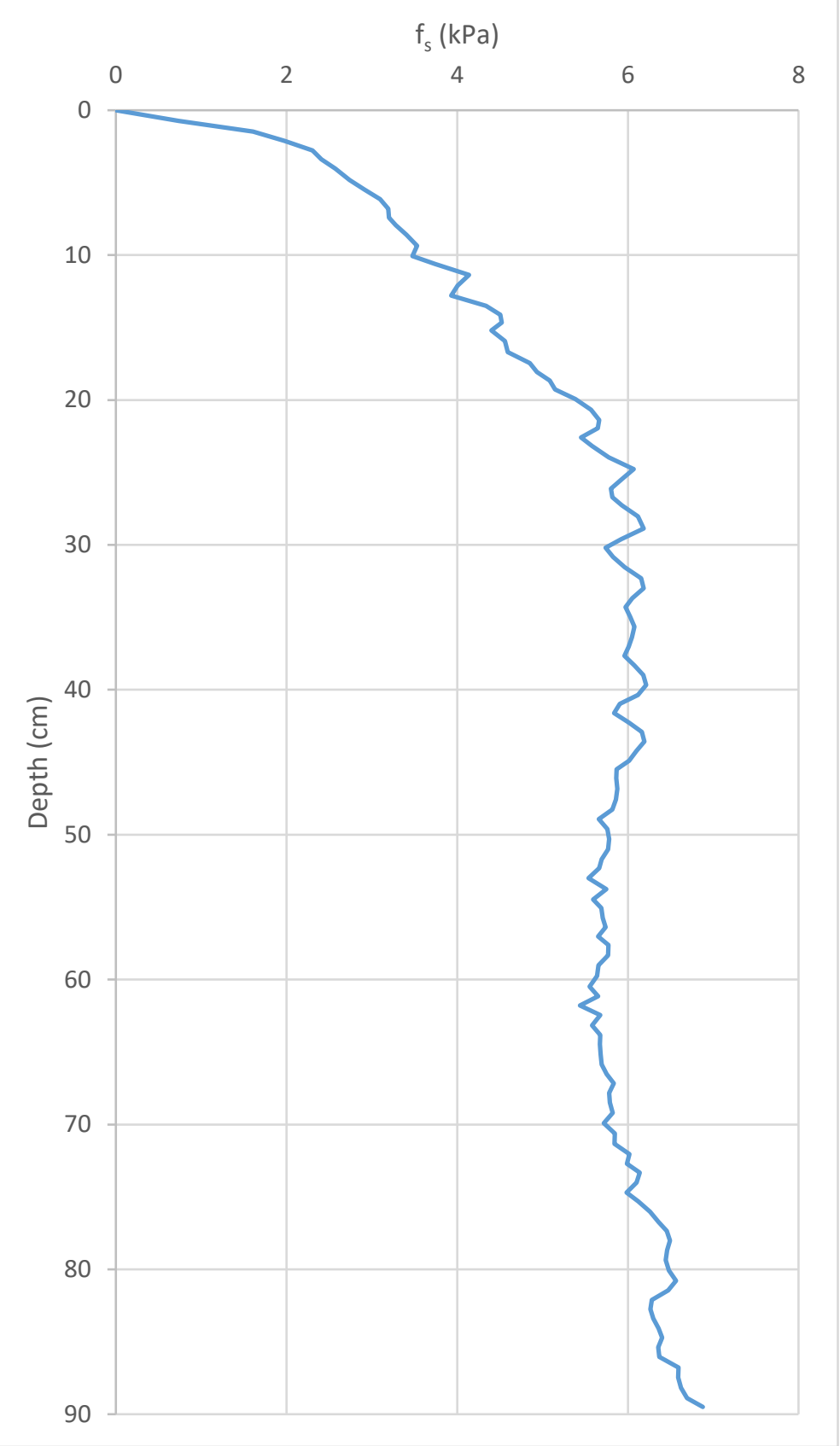

Figure 52: CPT 1.1 Sleeve Friction 


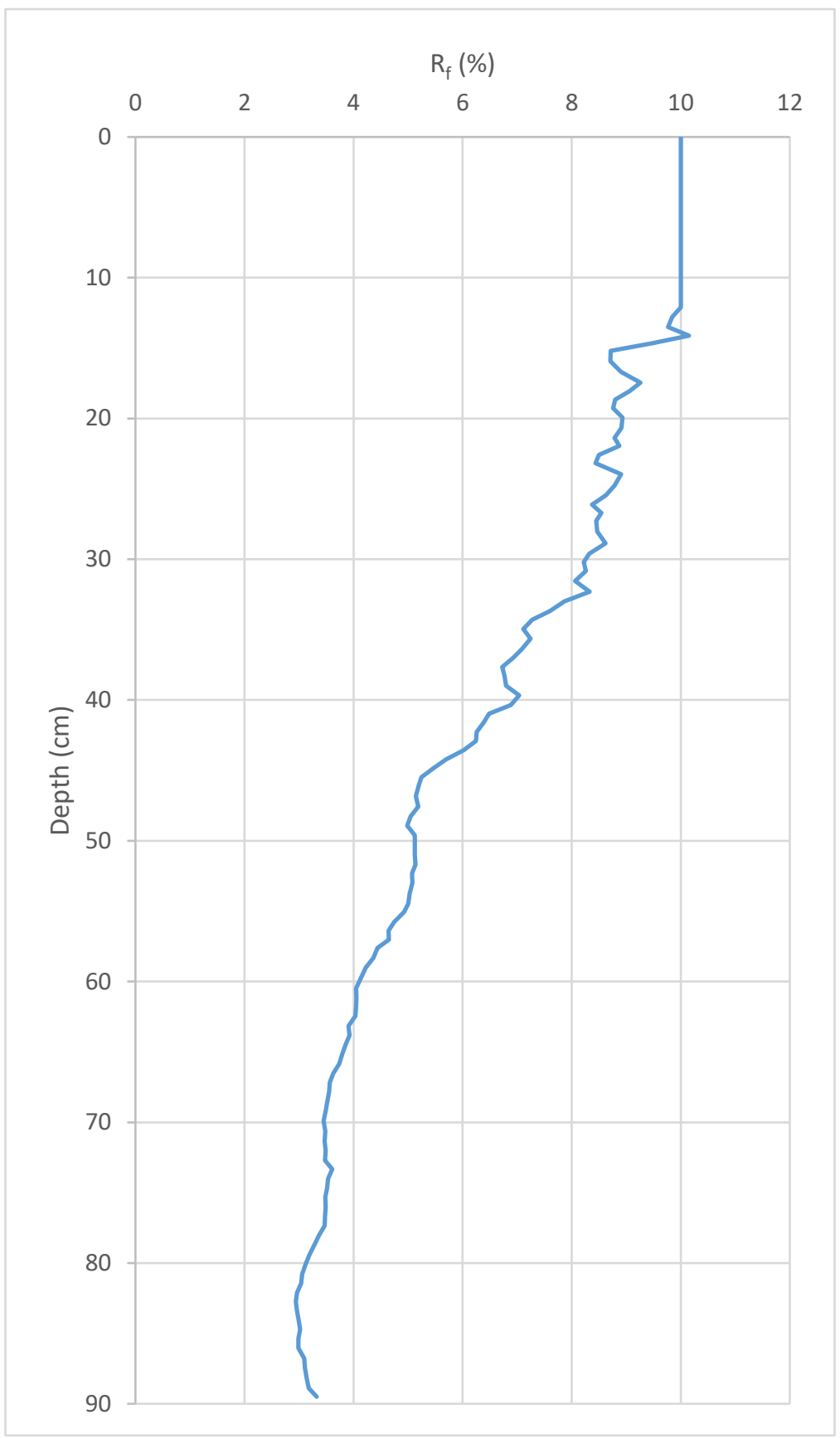

Figure 53: CPT 1.1 Friction Ratio 


\subsubsection{Cyclic Test 1.1}

A testing frequency of $8.0 \mathrm{~Hz}$ was run for 122 cycles (15.3 seconds). An output from the table control during the shaking can be seen in Figure 54. "Control" in the figure is the true table accelerations while "profile" is the input motion. As can be seen in the figure, the transfer function used for this setup created a response very similar to the input.

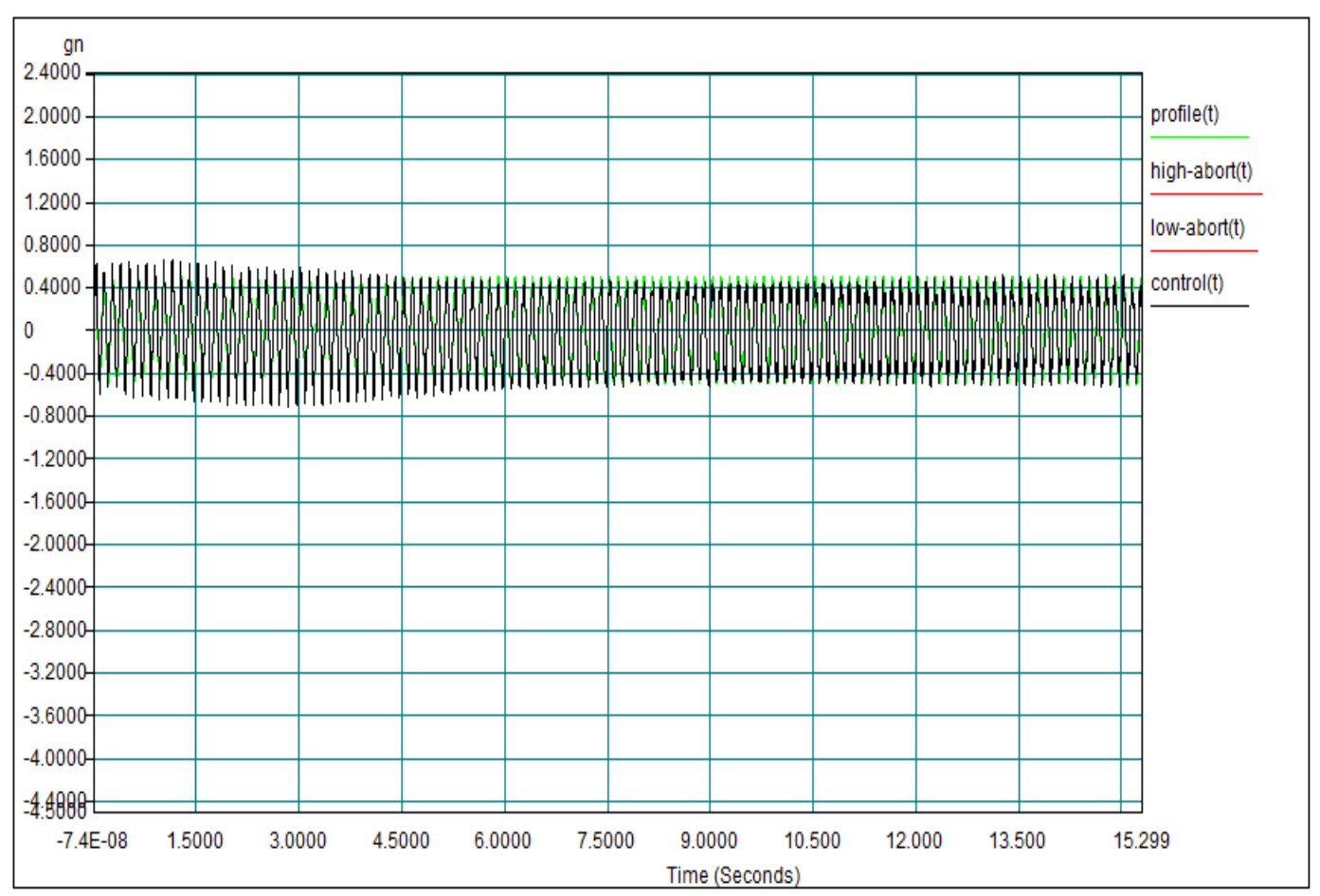

Figure 54: Shake Table Control Output

From visual observation, the sample liquefied almost instantaneously as motion started. There was a failure with the DAQ system during this test and many sensors did not record data during the motion. The DAQ system did not record pore pressures, bucket displacement, and accelerations during this test. 
One T-bar was lifted during this cyclic test. The lifting began approximately 2 seconds after shaking began. The load required to lift the $T$ bar was measured at a rate of $600 \mathrm{~Hz}$ and a graph of the pressure on the T-bar vs. Depth can be seen in Figure 55.

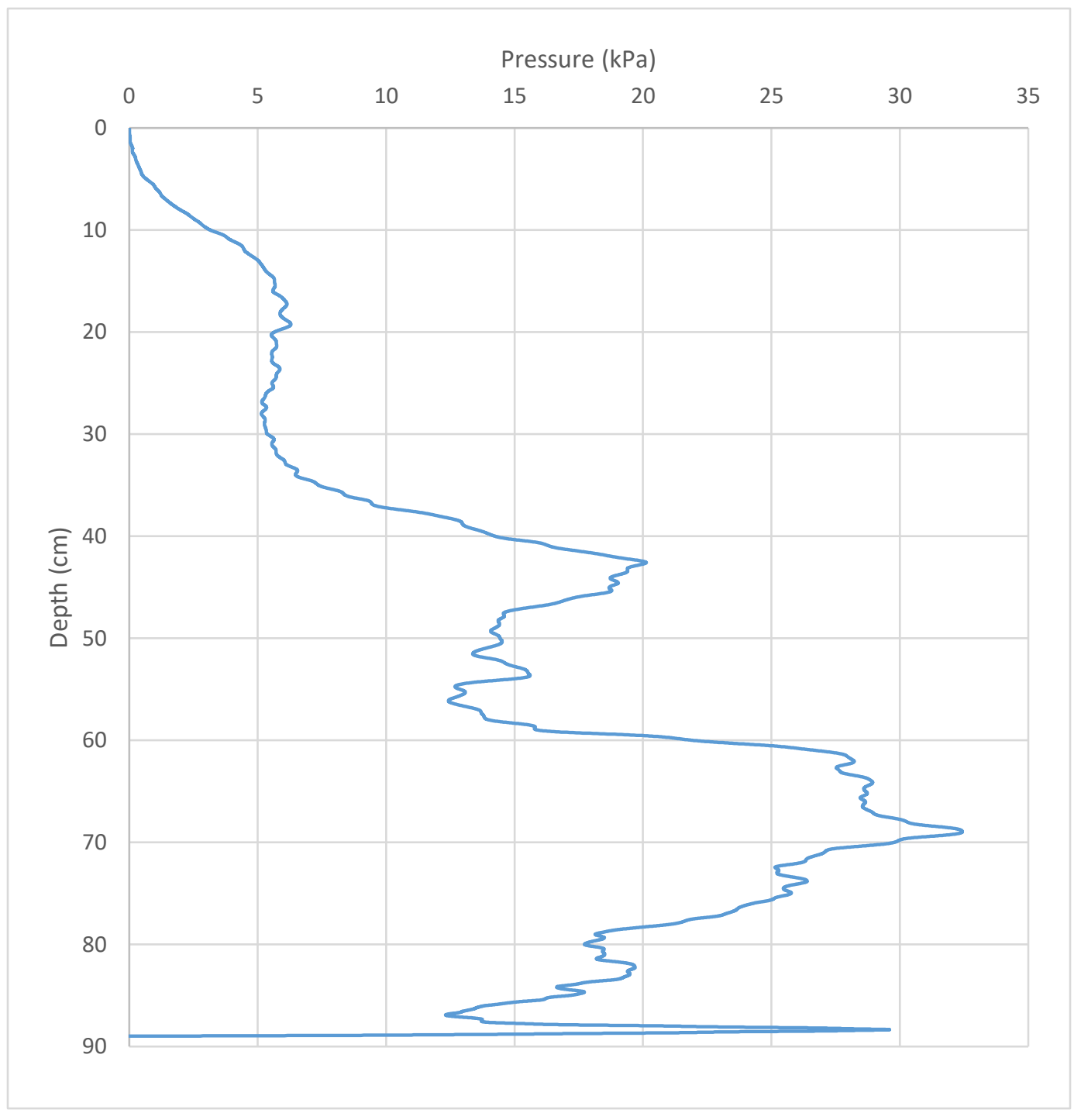

Figure 55: Cyclic Test 1.1 T-bar Pullout Pressure

After the shaking was finished, $18 \mathrm{~cm}$ of saturated sand ejecta and an additional $21.5 \mathrm{~cm}$ of water filled the annular space of the bucket top. The overburden pressure dropped $8.4 \mathrm{kPa}$ to $23.4 \mathrm{kPa}$. 
The bucket displaced laterally during the first cyclic test that resulted in a pure shear strain of $16.1 \%$ (Figure 56). The bucket was tied off to an anchor to resist any further deformations in the direction perpendicular to the shaking motions.

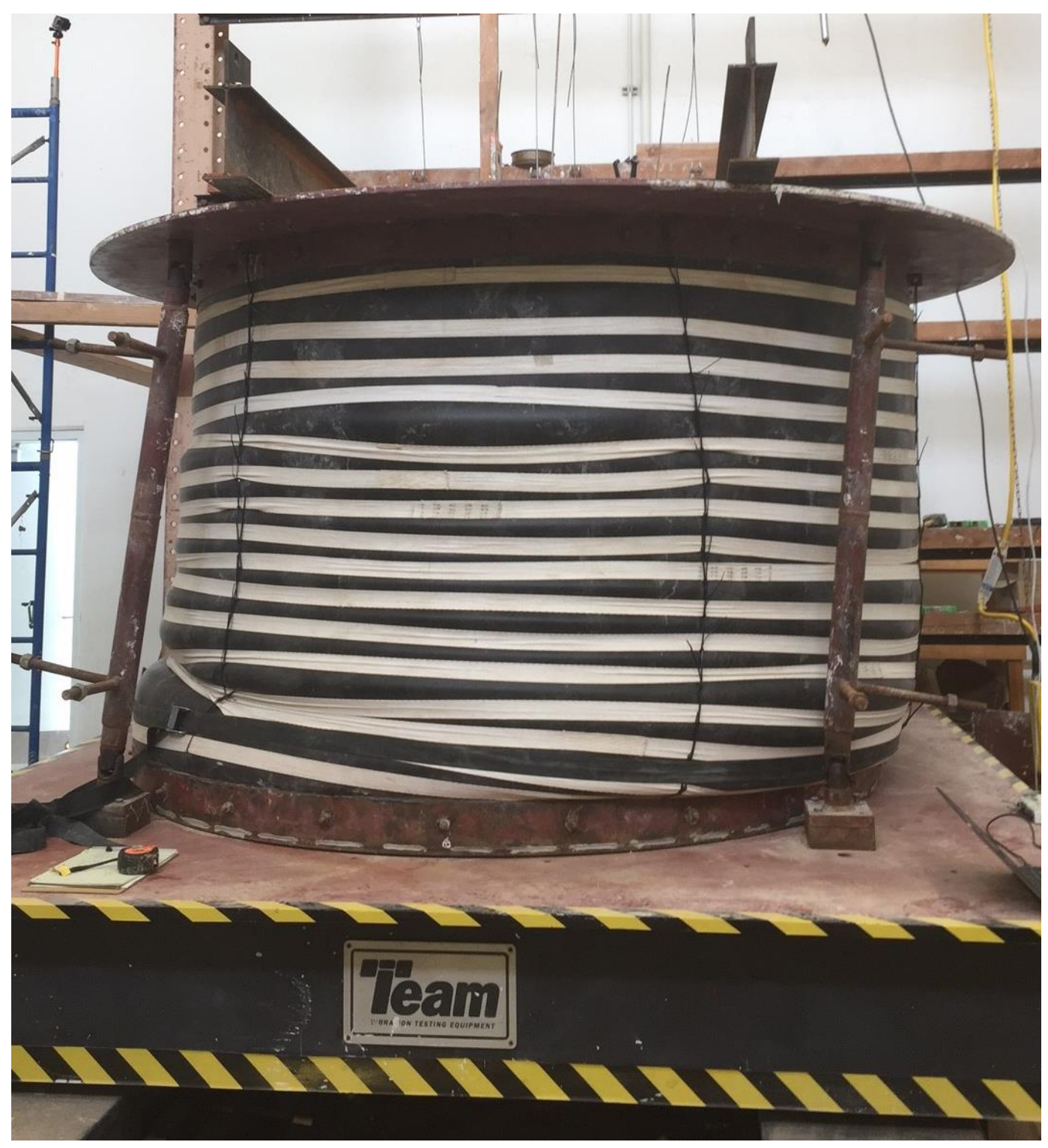

Figure 56: Displaced Bucket After Cyclic Test 1.1 


\subsubsection{CPT_1.2}

A CPT sounding was performed after the first cyclic test to categorize any change in soil stiffness and structure. The cone was pushed to a depth of $64 \mathrm{~cm}$ before initial refusal. An additional $95 \mathrm{~kg}$ of driving mass was added to the cone penetrometer which drove the cone to a depth of $73 \mathrm{~cm}$ before reaching refusal. 


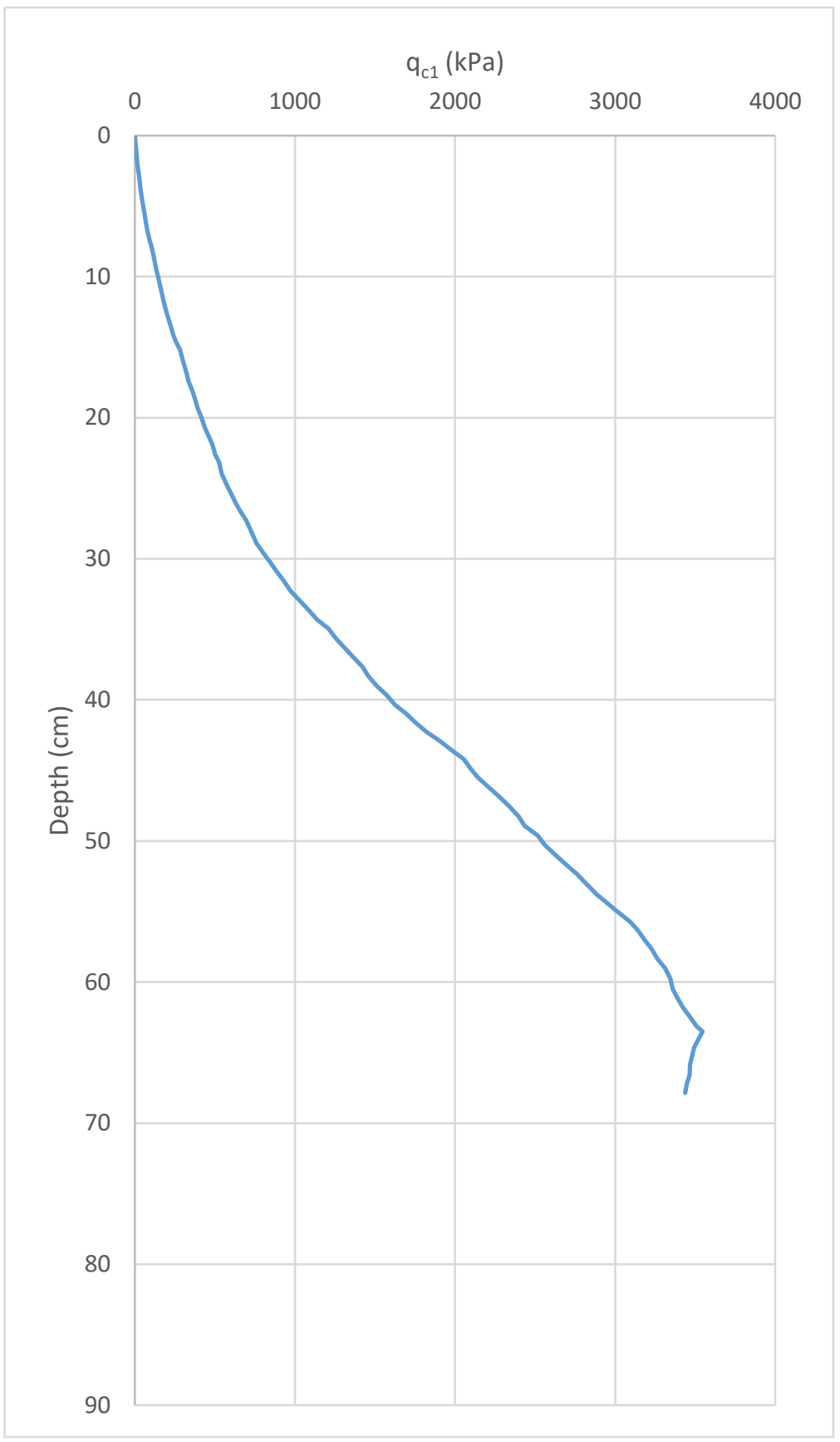

Figure 57: CPT 1.2 Corrected Tip Resistance 


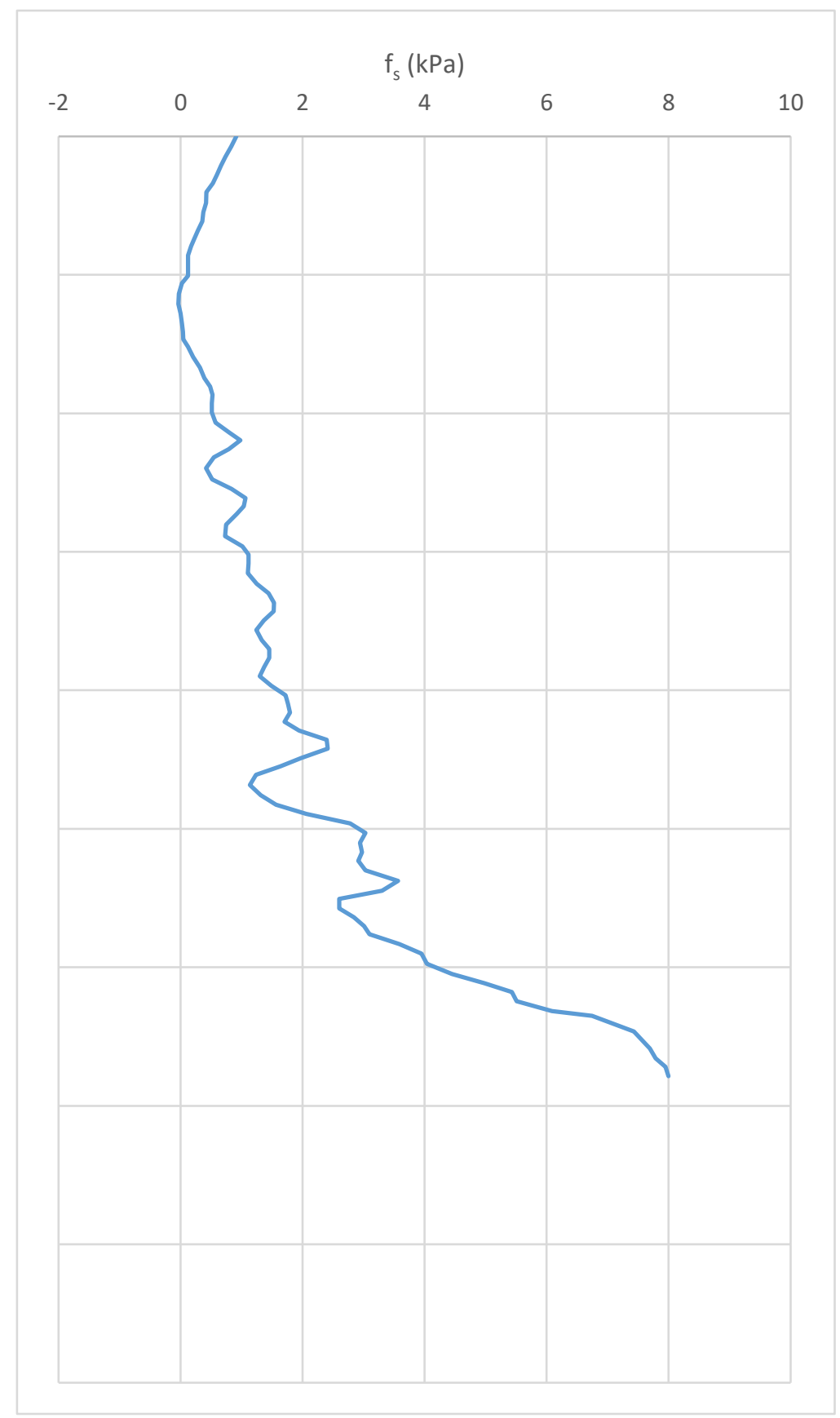

Figure 58: CPT 1.2 Sleeve Friction 


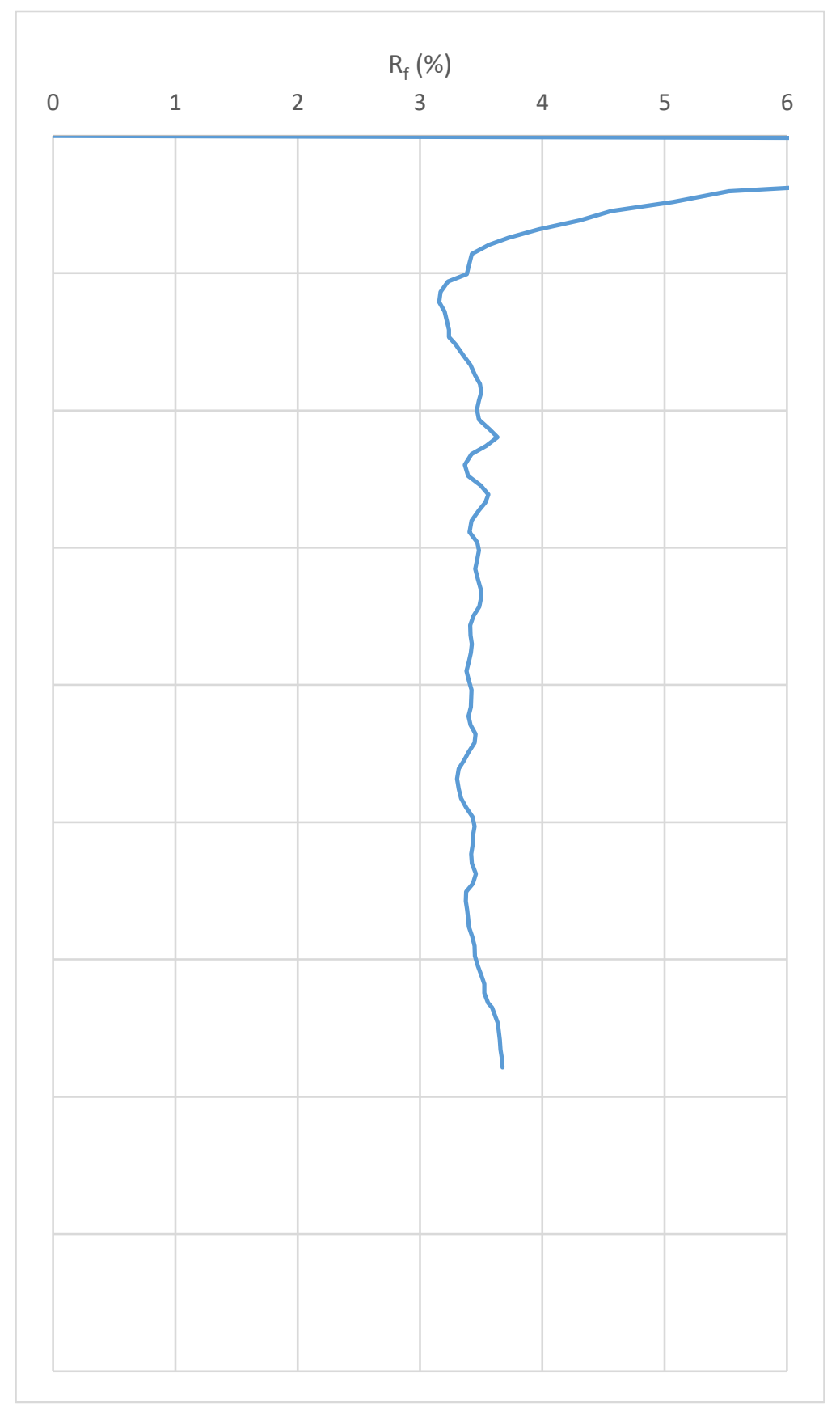

Figure 59: CPT 1.2 Friction Ratio 


\subsubsection{Cyclic Test 1.2}

A second cyclic test was run at the same parameters as Cyclic Test 1 with approximately $23.4 \mathrm{kPa}$ of effective overburden. The DAQ system failed to record displacements and the load cell measurements for this test. Excess pore pressures were successfully recorded during this test. Excess pore pressures rose immediately upon shaking, but never reached an excess pore pressure ratio of 1.0 . The excess pore pressures generated during shaking can be seen in Figure 60. 


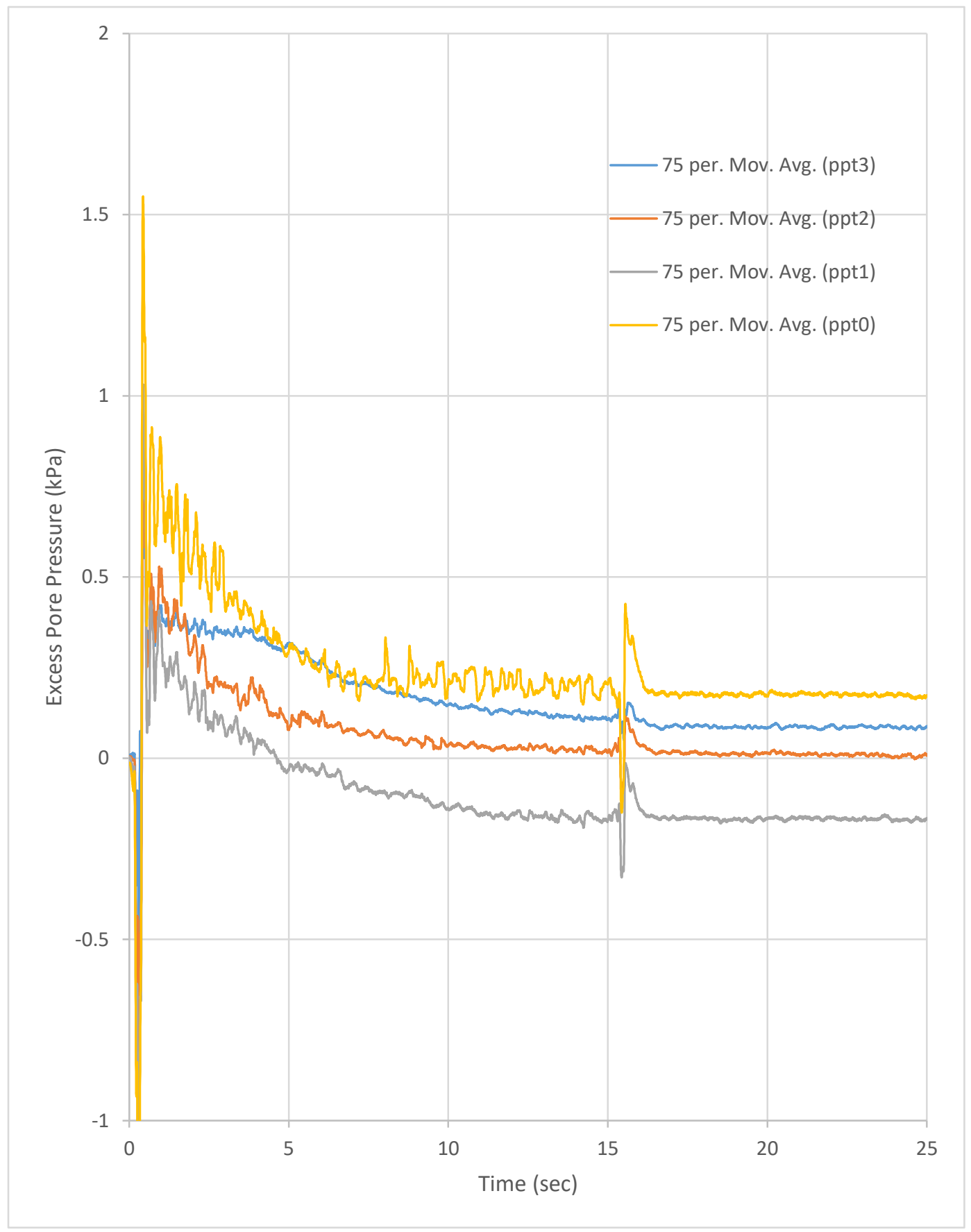

Figure 60: Cyclic Test 1.2 Excess Pore Pressures 


\subsubsection{Cyclic Test 1.3}

A third cyclic test was performed with the same parameters as the previous two. The T-bar pullout pressure can be seen in Figure 61. After shaking finished, the overburden pressure dropped to approximately $22.6 \mathrm{kPa}$.

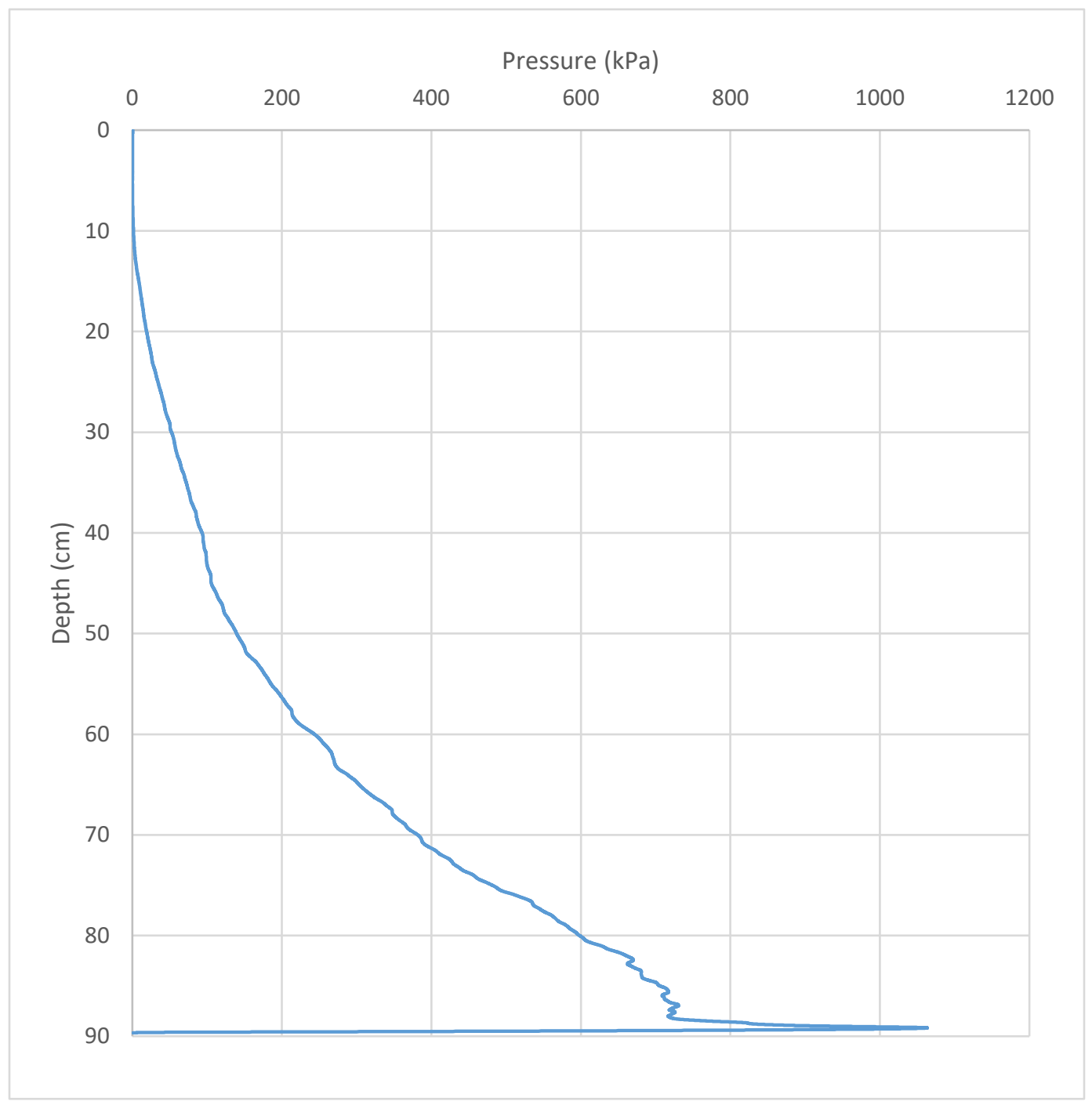

Figure 61: Cyclic Test 1.3 T-Bar Pullout Pressure 


\subsubsection{CPT_1.3}

A CPT sounding was performed after the third cyclic test. The cone was pushed with an additional $95 \mathrm{~kg}$ of driving mass to a depth of $63 \mathrm{~cm}$ before refusal.

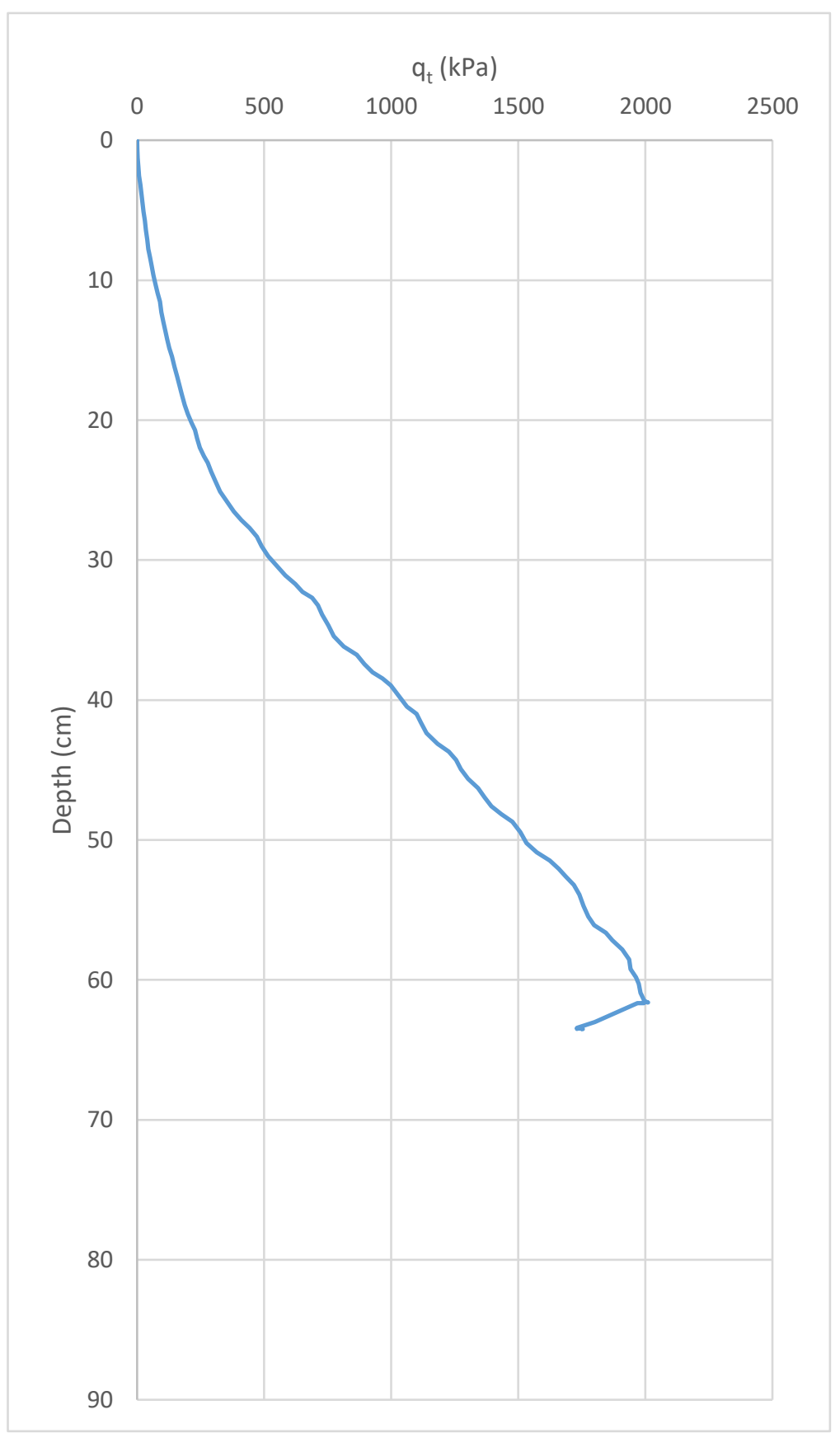

Figure 62: CPT 1.3 Corrected Tip Resistance 


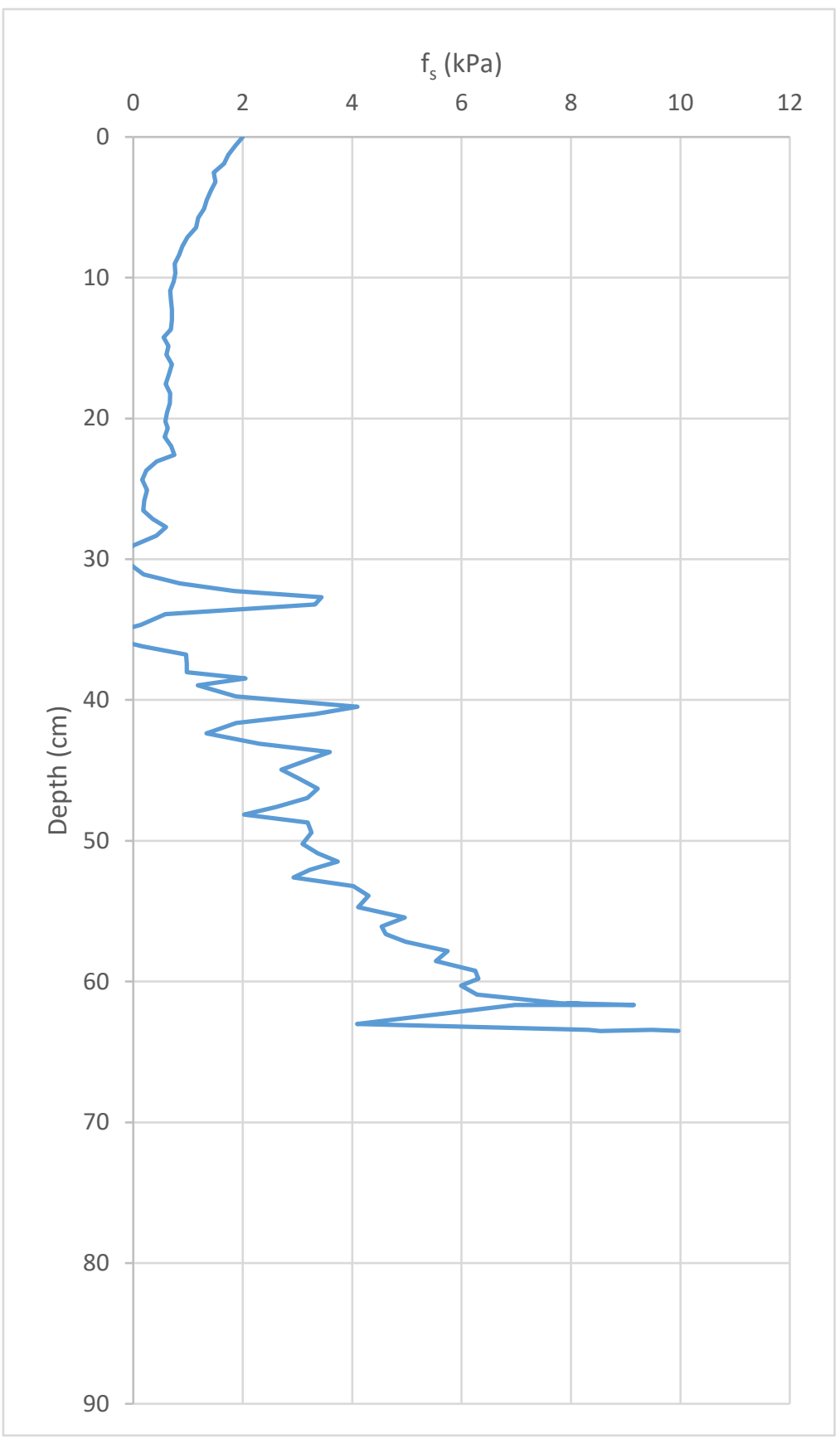

Figure 63: CPT 1.3 Sleeve Friction 


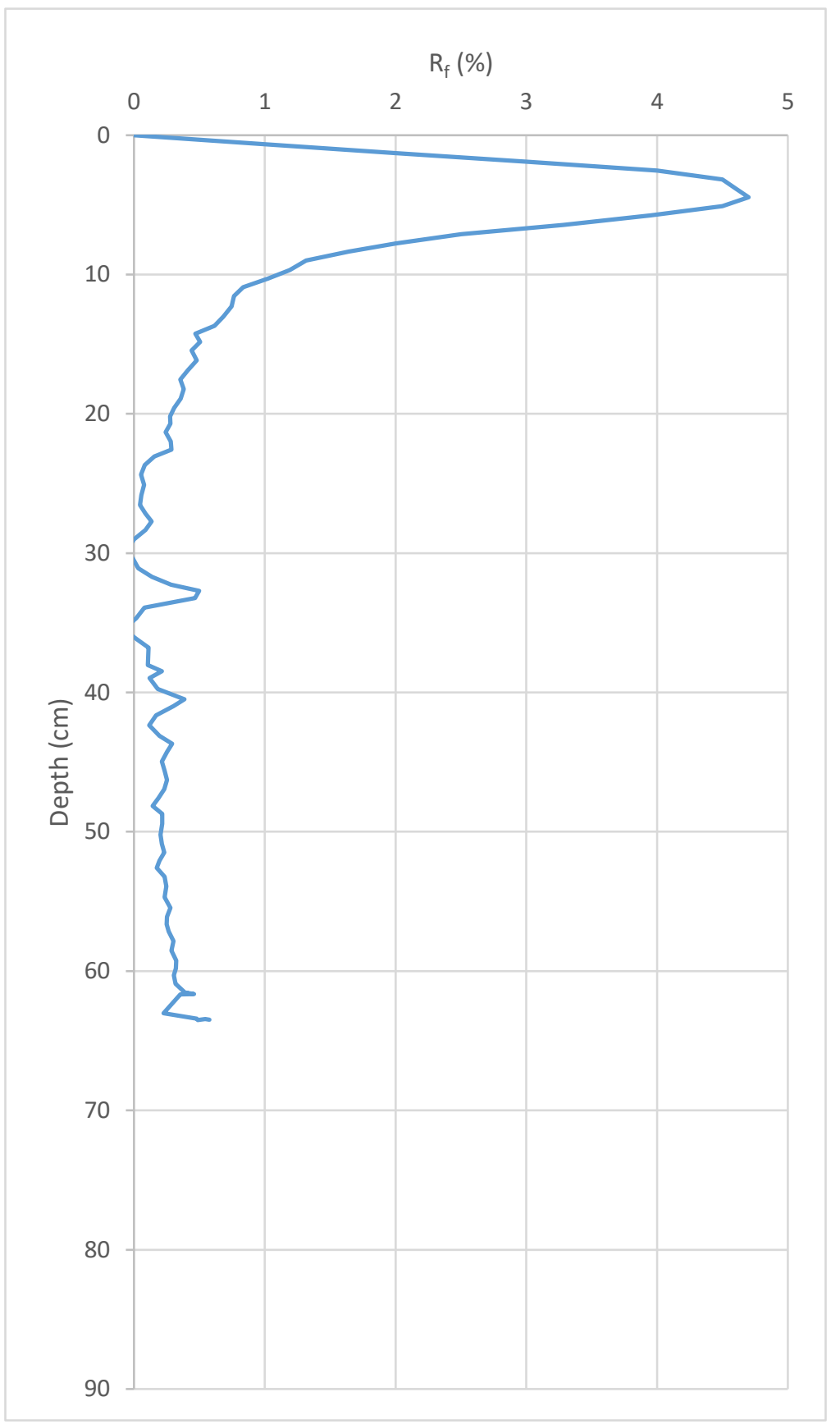

Figure 64: CPT 1.3 Friction Ratio 


\subsection{Setup 2}

After the first round of cyclic testing, the sand was removed from the specimen and was placed into sunlight to reduce the moisture content. The sand was then redeposited into the flexible walled testing apparatus following the method described in Chapter 4. The resulting soil column had a relative density of approximately $34.6 \%$ and a shear wave velocity of approximately $200 \mathrm{~m} / \mathrm{sec}$. The overburden assembly was pressurized to an approximate overburden pressure of $27.6 \mathrm{kPa}$.

\subsubsection{CPT_2.1}

An initial pre-liquefaction CPT sounding was performed on the second specimen. The CPT cone was driven a depth of $90 \mathrm{~cm}$. 


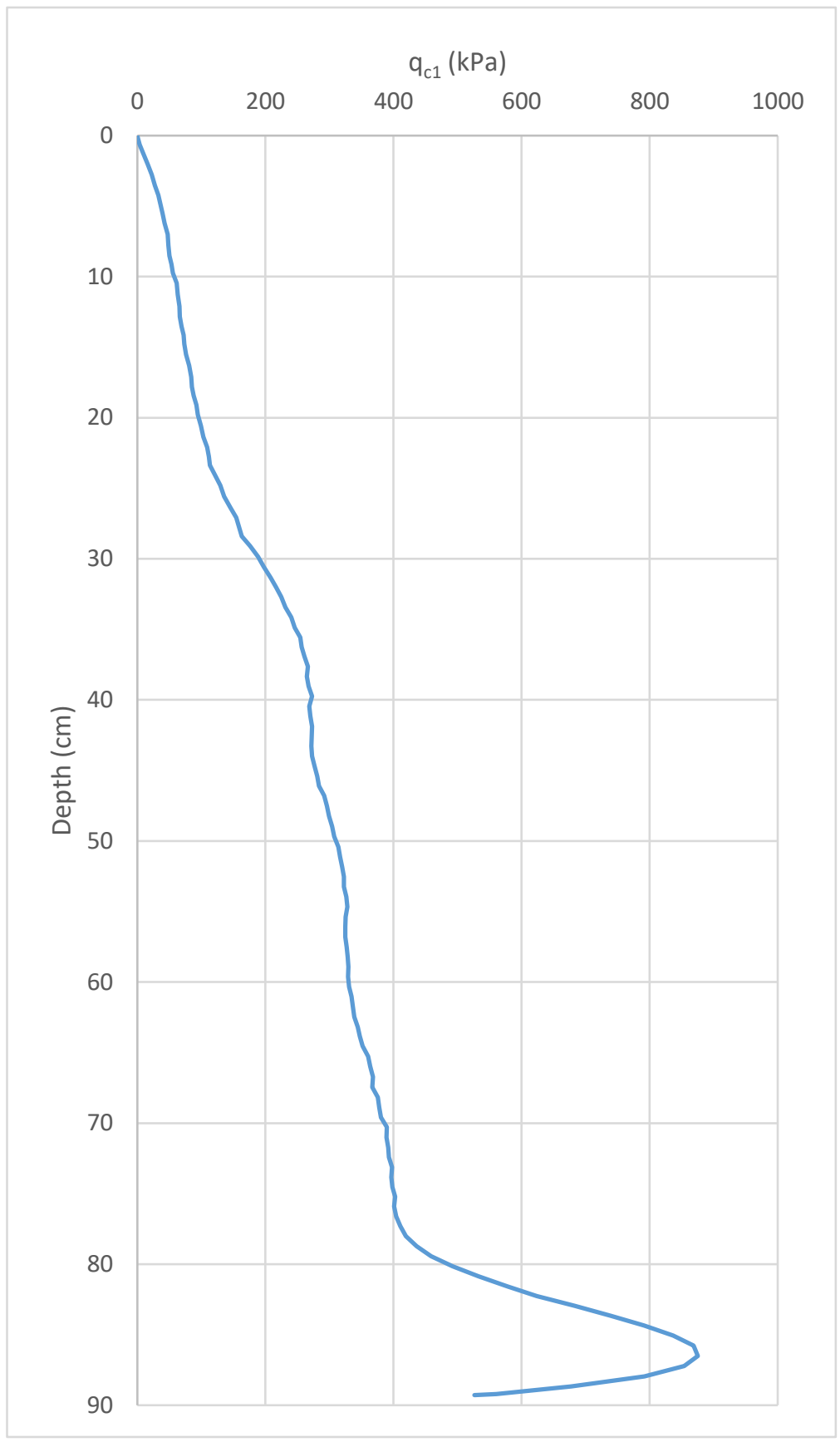

Figure 65: CPT 2.1 Corrected Tip Resistance 


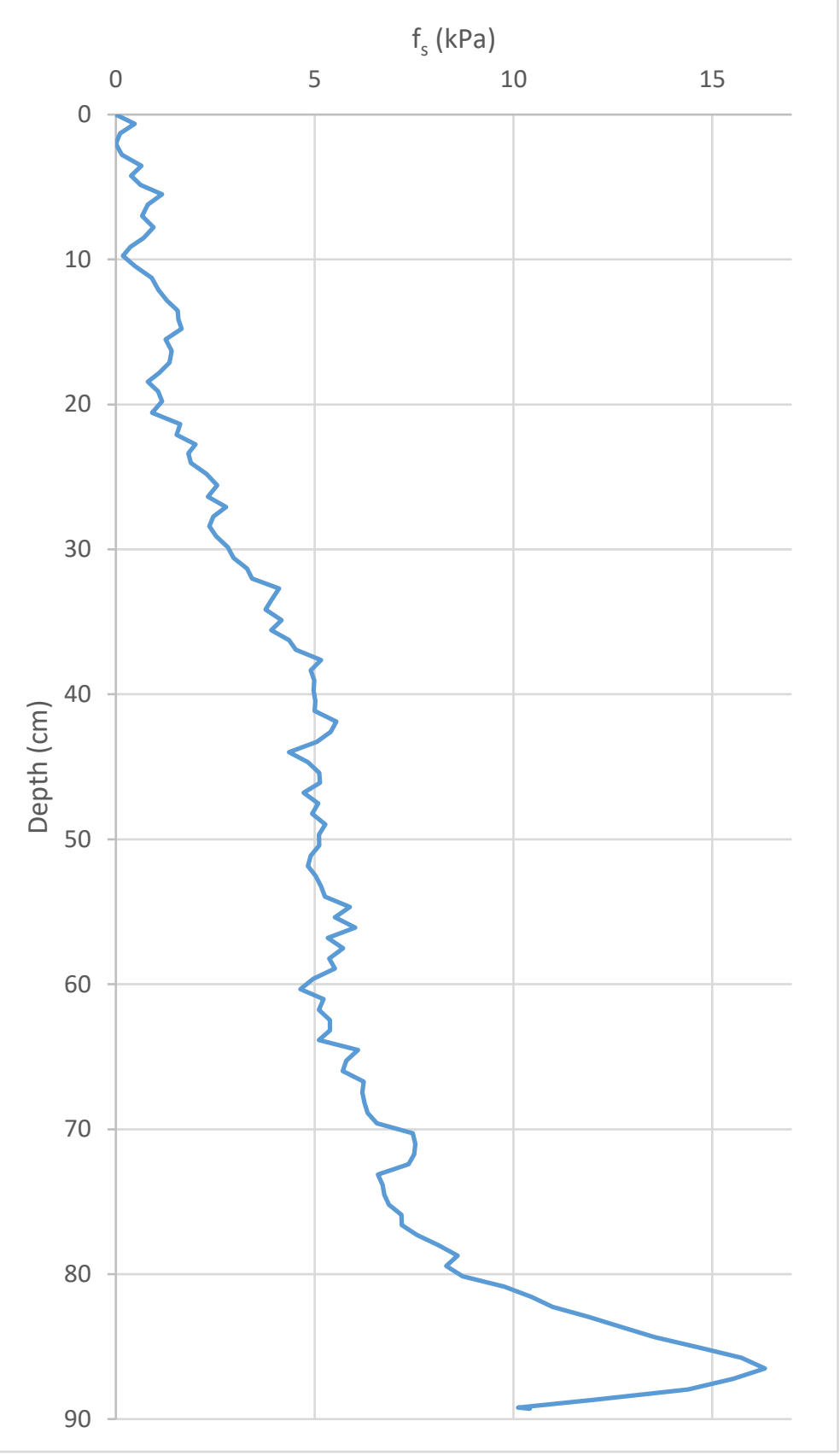

Figure 66: CPT 2.1 Sleeve Friction 


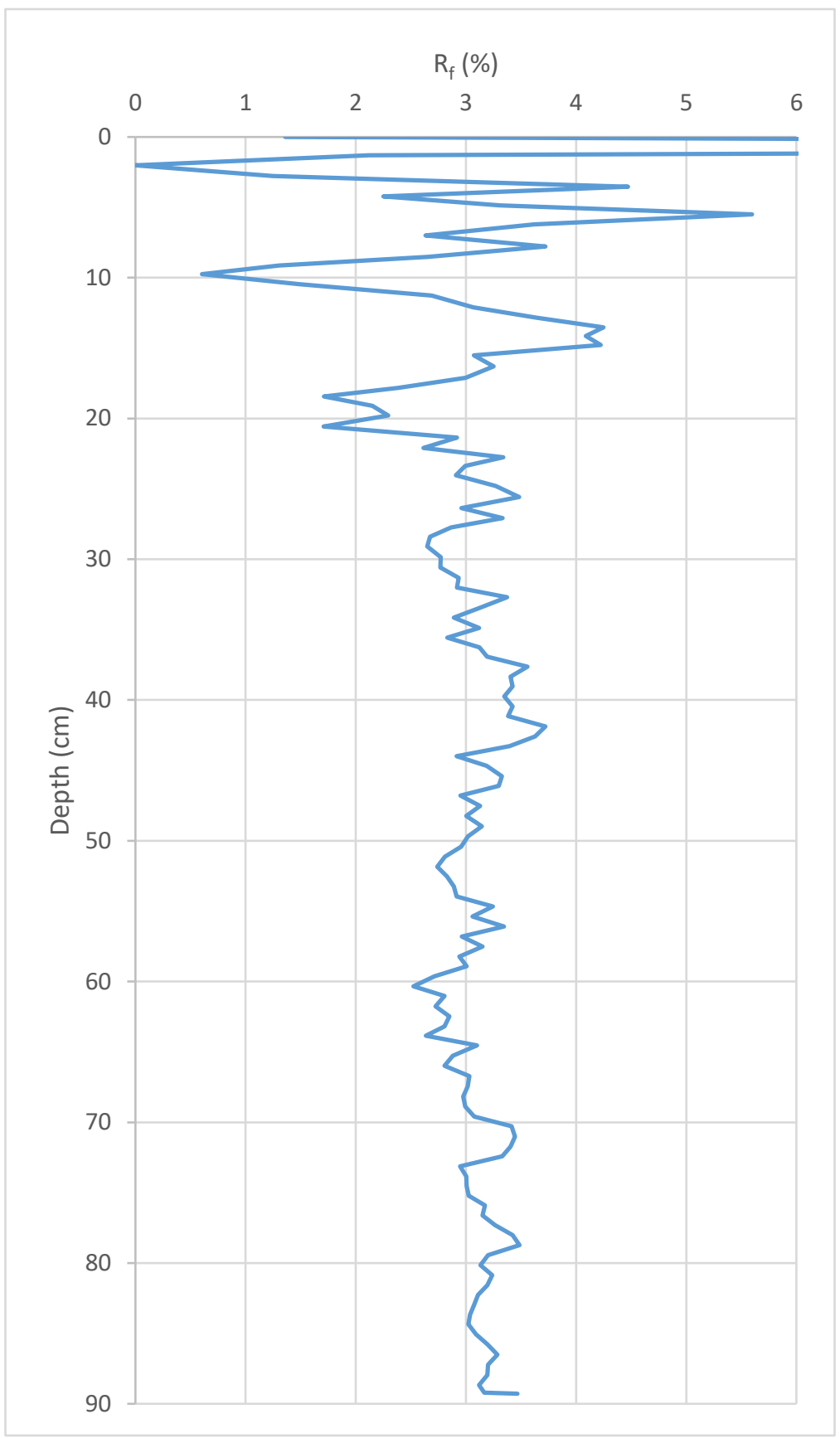

Figure 67: CPT 2.1 Friction Ratio 


\subsubsection{Cyclic Test 2.1}

Almost immediately upon shaking, the soil column experienced large liquefaction induced displacements. T-bar pullout loads were measured during the cyclic shaking motion (Figure 68). The pullout pressures measured may be influenced by the large displacements. The T-bar was not pulled completely vertically. Therefore, additional friction could have developed between the bar and top plate of the overburden assembly which would have influenced the readings of the load cell.

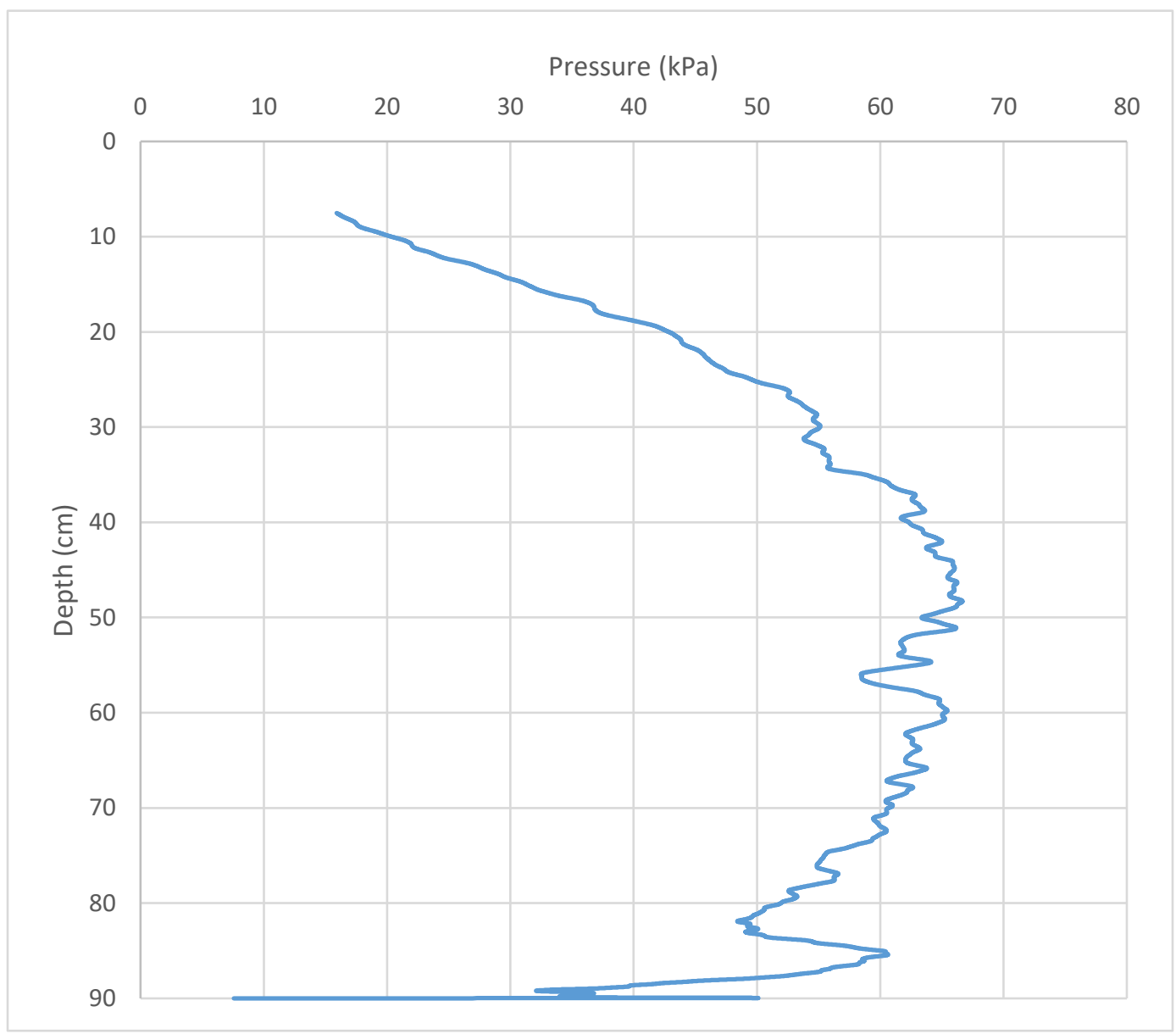

Figure 68: Cyclic Test 2.1 T-bar Pullout Pressure 
The excess pore pressures recorded by the transducers can be seen in Figure 69. Upon completion of the shaking, the soil column experienced a pure shear strain of roughly $41 \%$ (Figure 70 ).

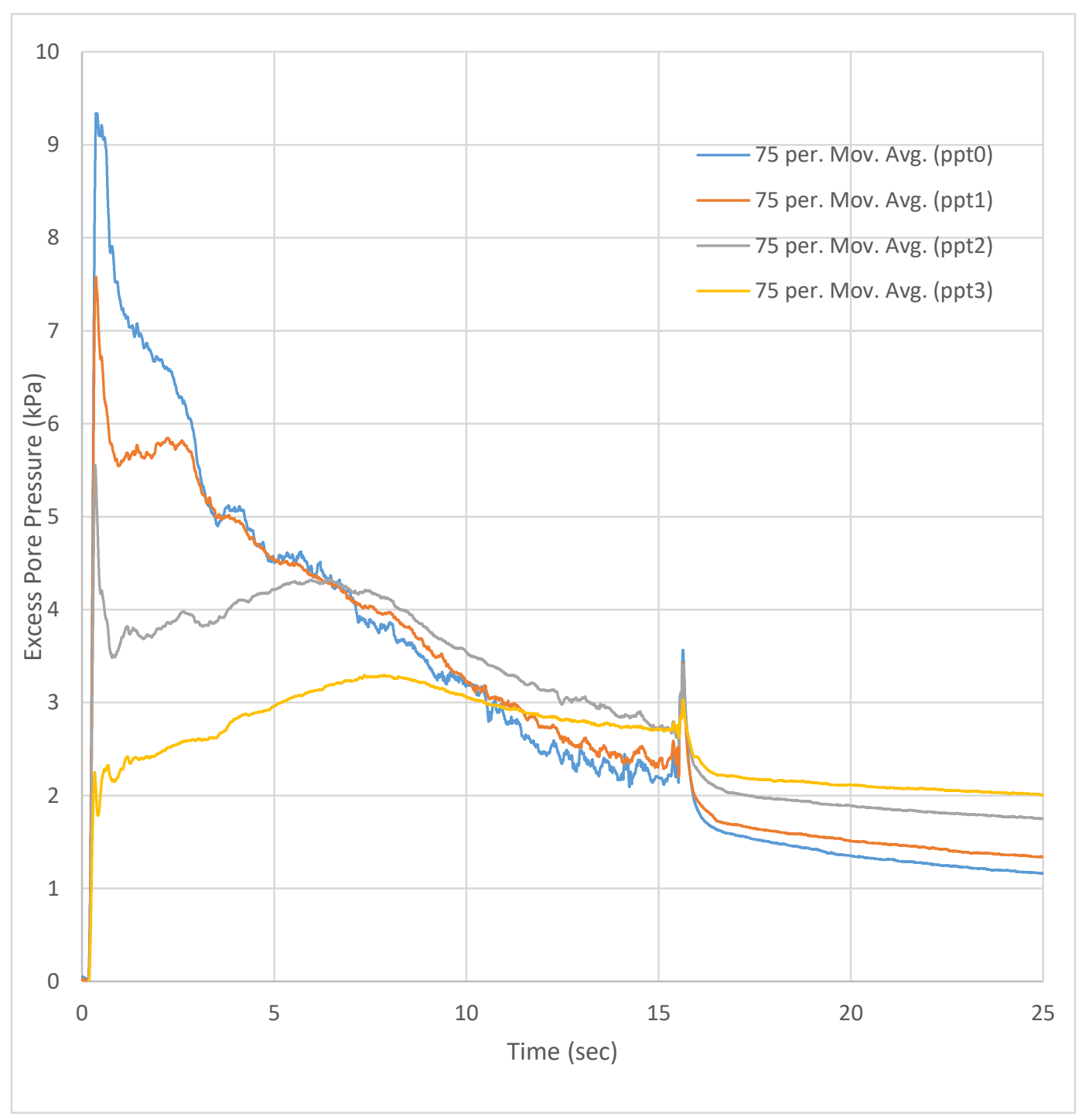

Figure 69: Cyclic Test 2.1 Excess Pore Pressures 


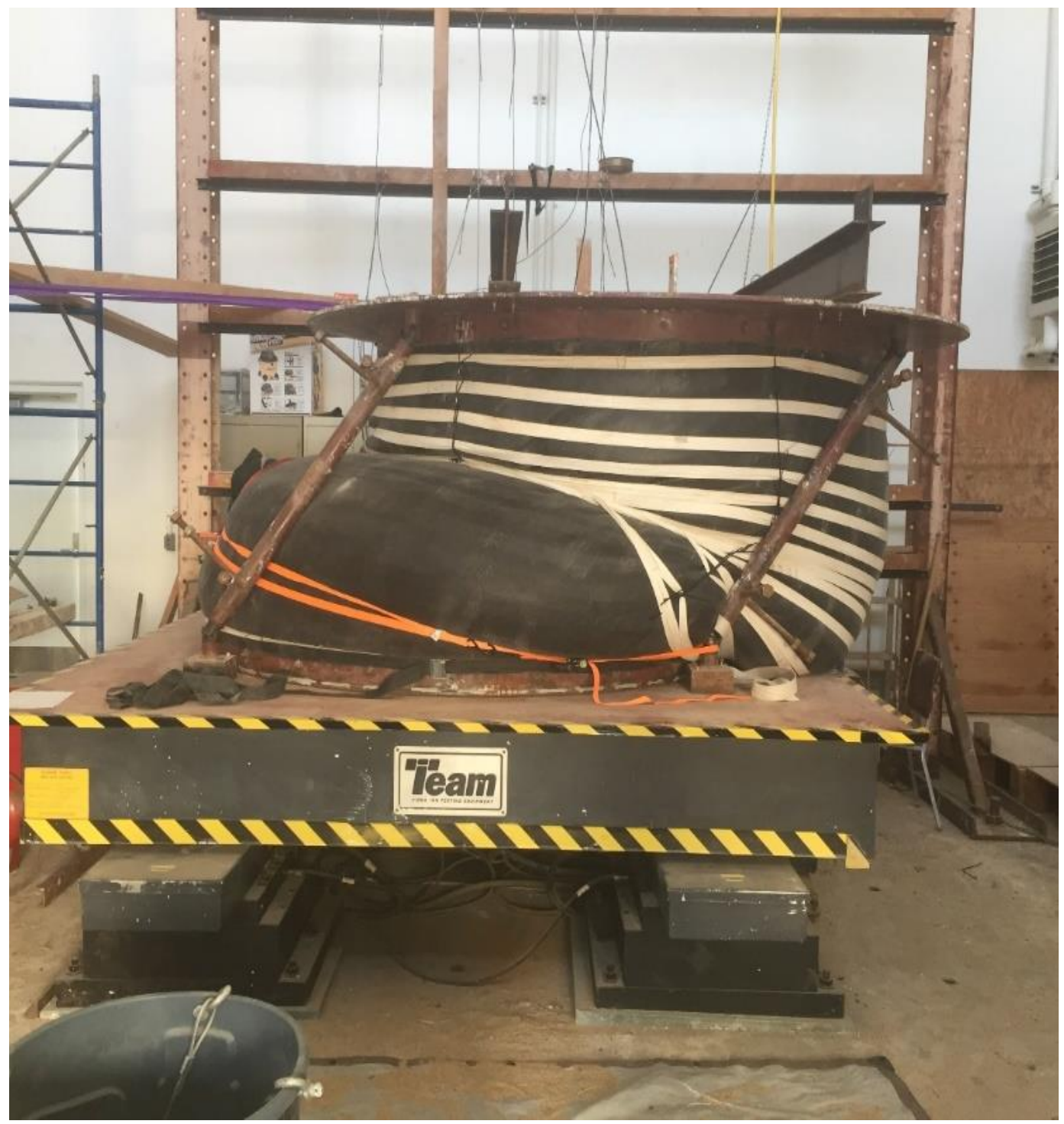

Figure 70: Displaced Bucket After Cyclic Test 2.1 


\subsubsection{CPT_2.2}

A post-liquefaction CPT sounding was performed on the sample. The CPT cone was driven a depth of $72 \mathrm{~cm}$ before refusal.

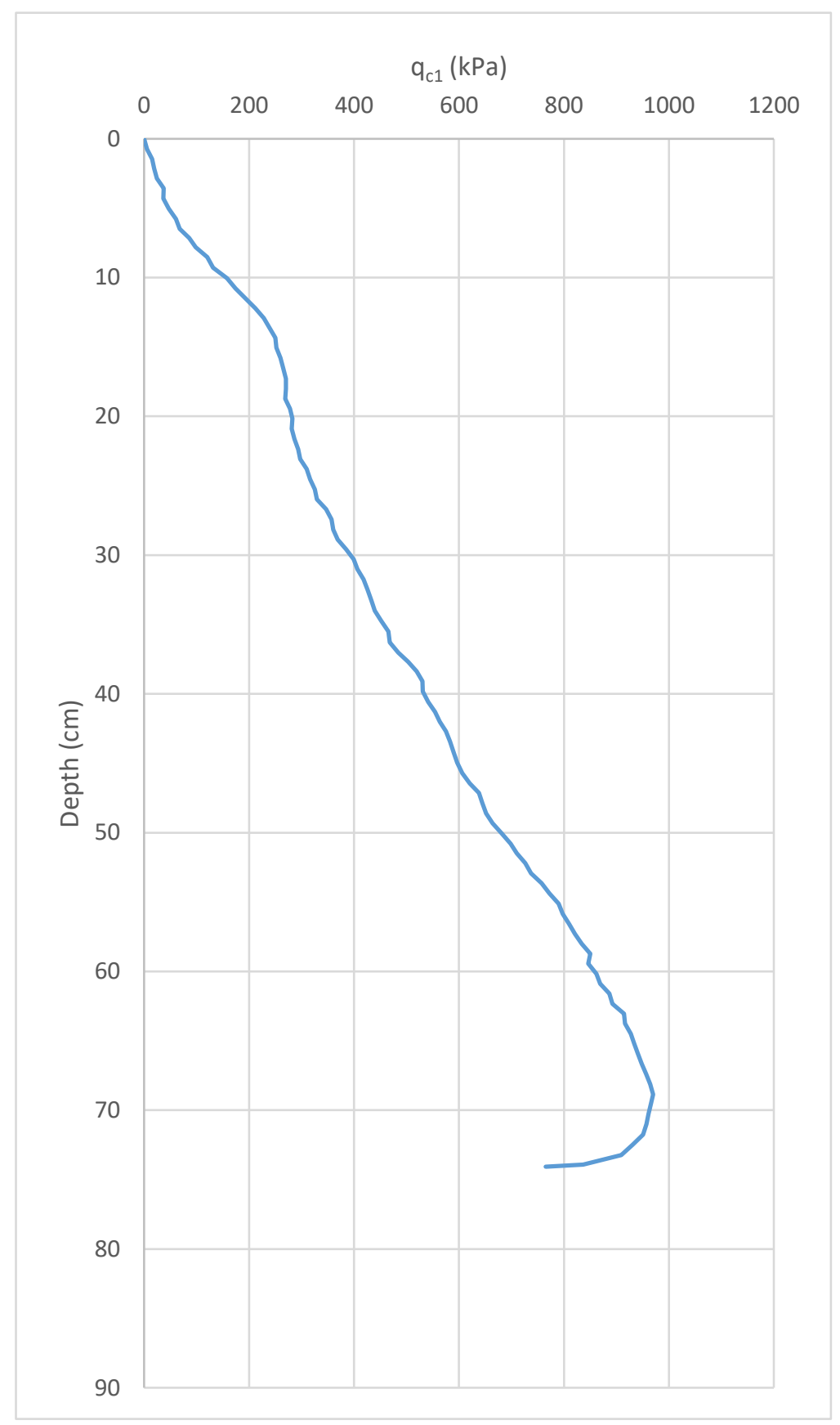

Figure 71: CPT 2.2 Corrected Tip Resistance 


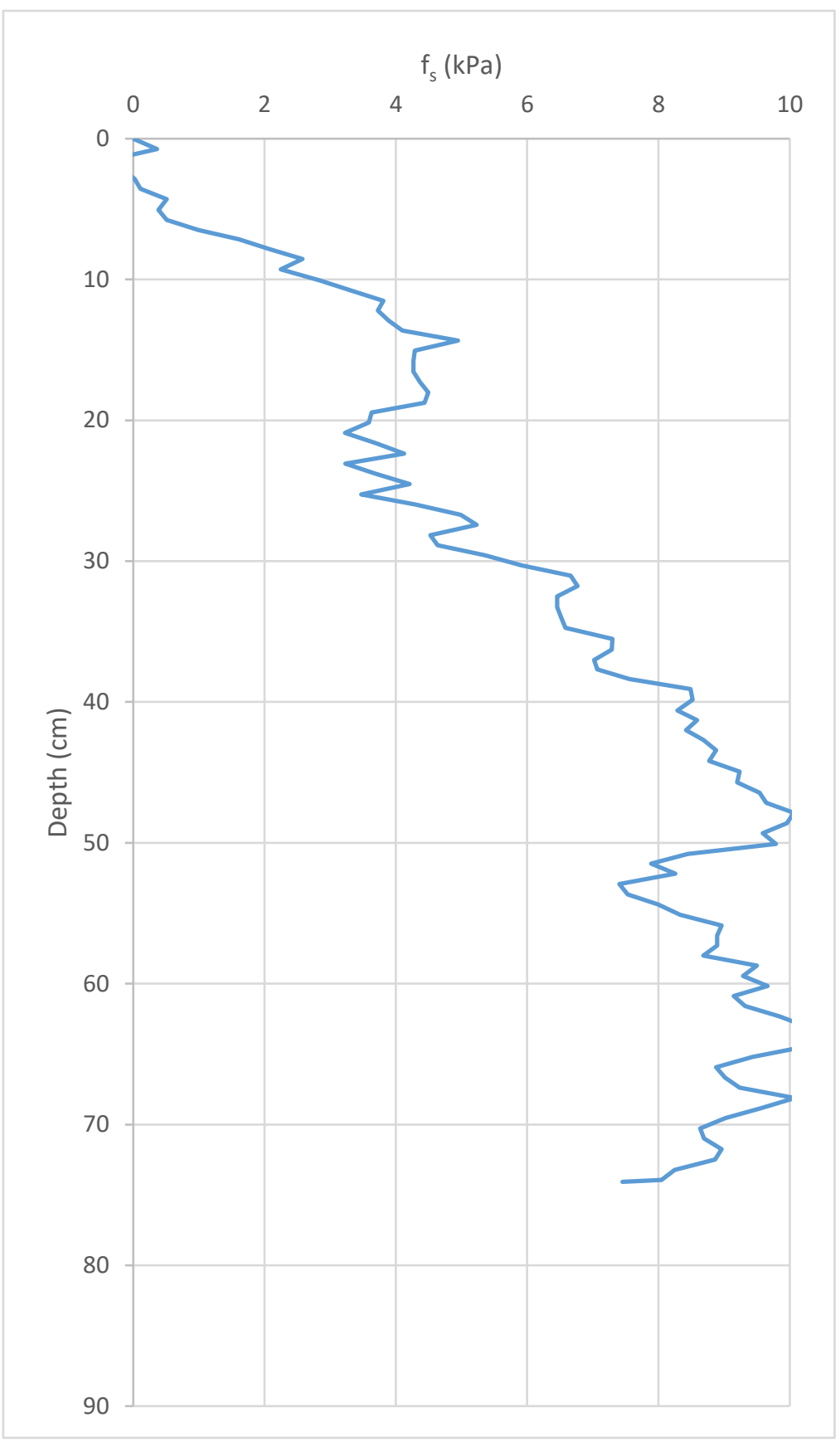

Figure 72: CPT 2.2 Sleeve Friction 


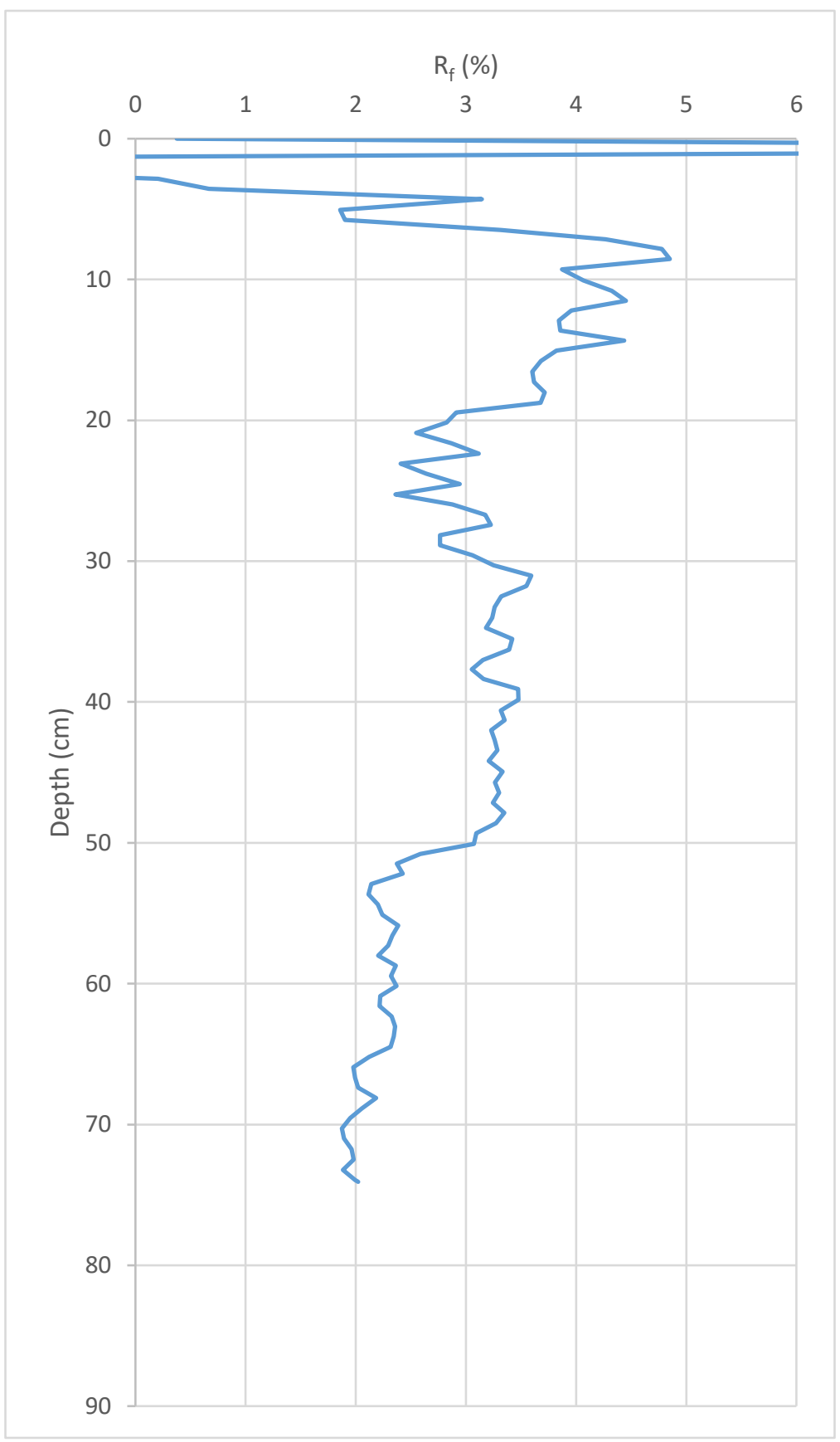

Figure 73: CPT 2.2 Friction Ratio 


\subsubsection{Cyclic Test 2.2}

Prior to cyclic test 2.2, the bucket was tied off to an anchor to prevent further lateral deformations perpendicular to the shaking motion. A T-bar pullout was performed during the cyclic shaking (Figure 74). Similar to cyclic test 2.1 , the results of this pullout test may be influenced by a pullout angle that was not vertical, and potential friction between the T-bar rod and top plate of the overburden assembly. The T-bar was pulled approximately $50 \mathrm{~cm}$, to a final depth of $40 \mathrm{~cm}$, during the test. The sample laterally displaced such that the rubber membrane came in contact with one of the vertical supports of the top ring of the assembly. The membrane became sandwiched between this support and the bottom plate of the overburden assembly, causing a separation to develop in the membrane. This separation prevented any further testing because water and sand began pouring out of the separation. 


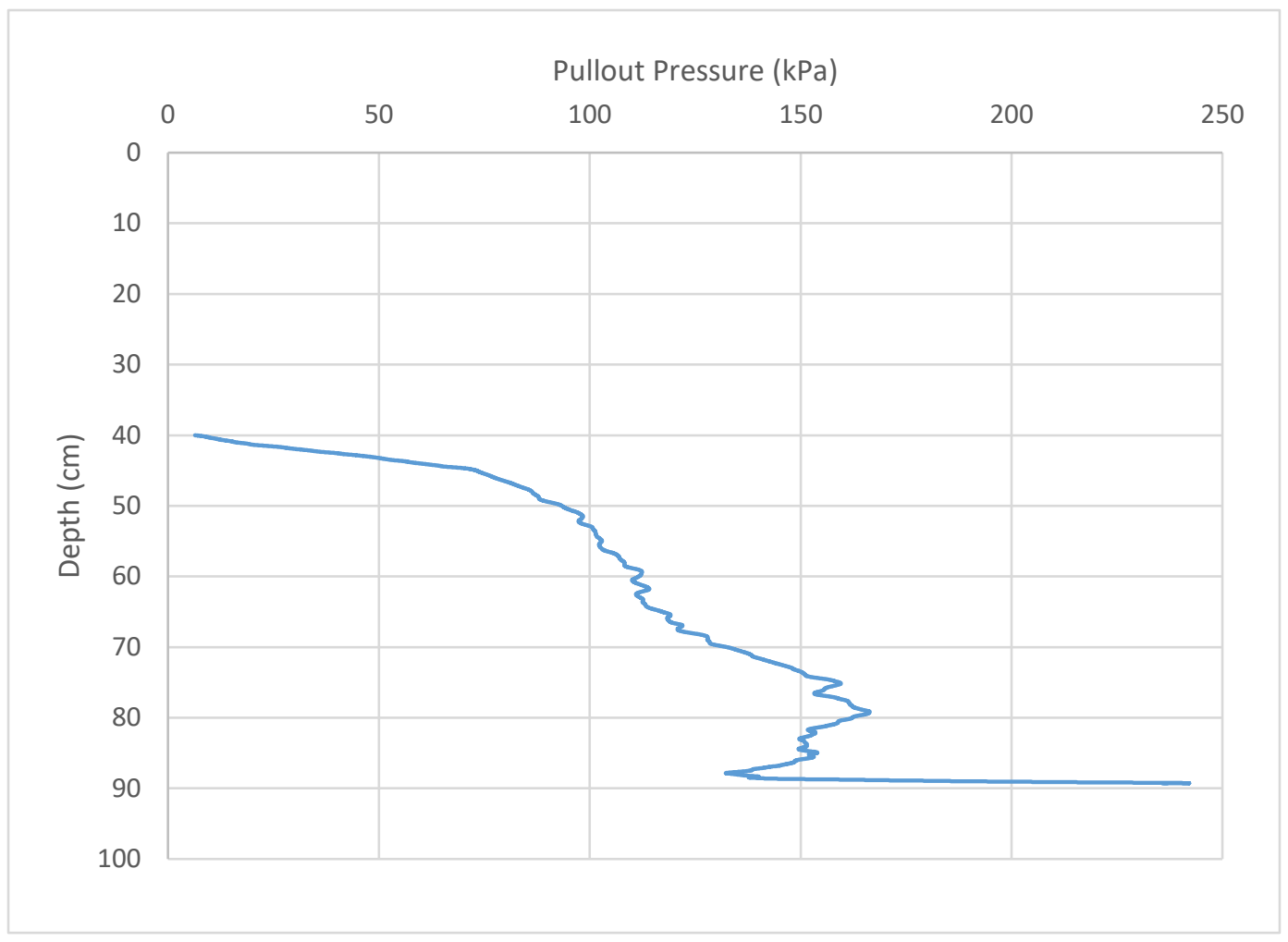

Figure 74: Cyclic Test 2.2 T-bar Pullout Pressure 


\subsubsection{CPT_2.3}

A final CPT push was performed in the sample after Cyclic Test 2.2. This CPT was driven to a depth of $66 \mathrm{~cm}$ before refusal.

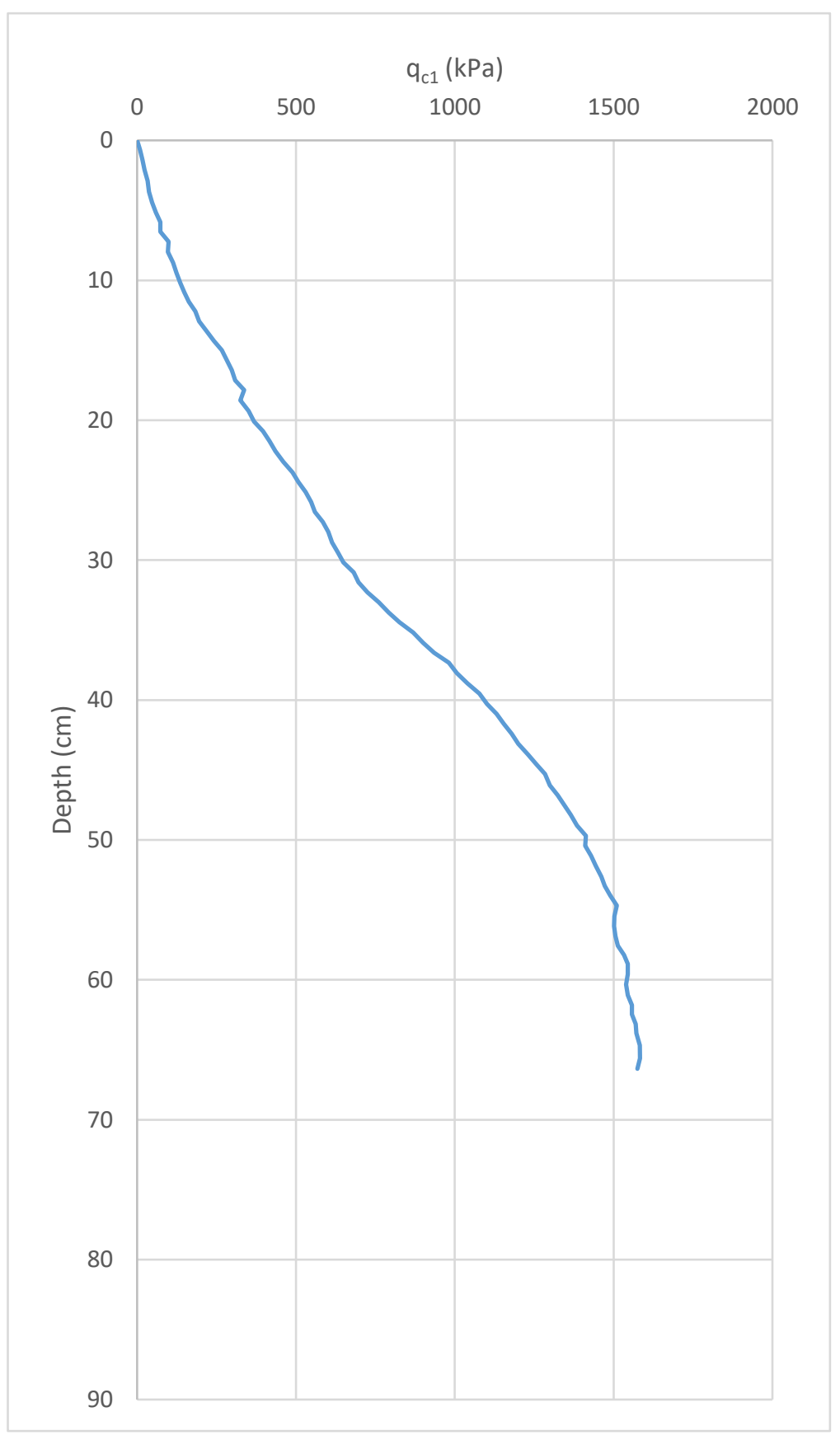

Figure 75: CPT 2.3 Corrected Tip Resistance 


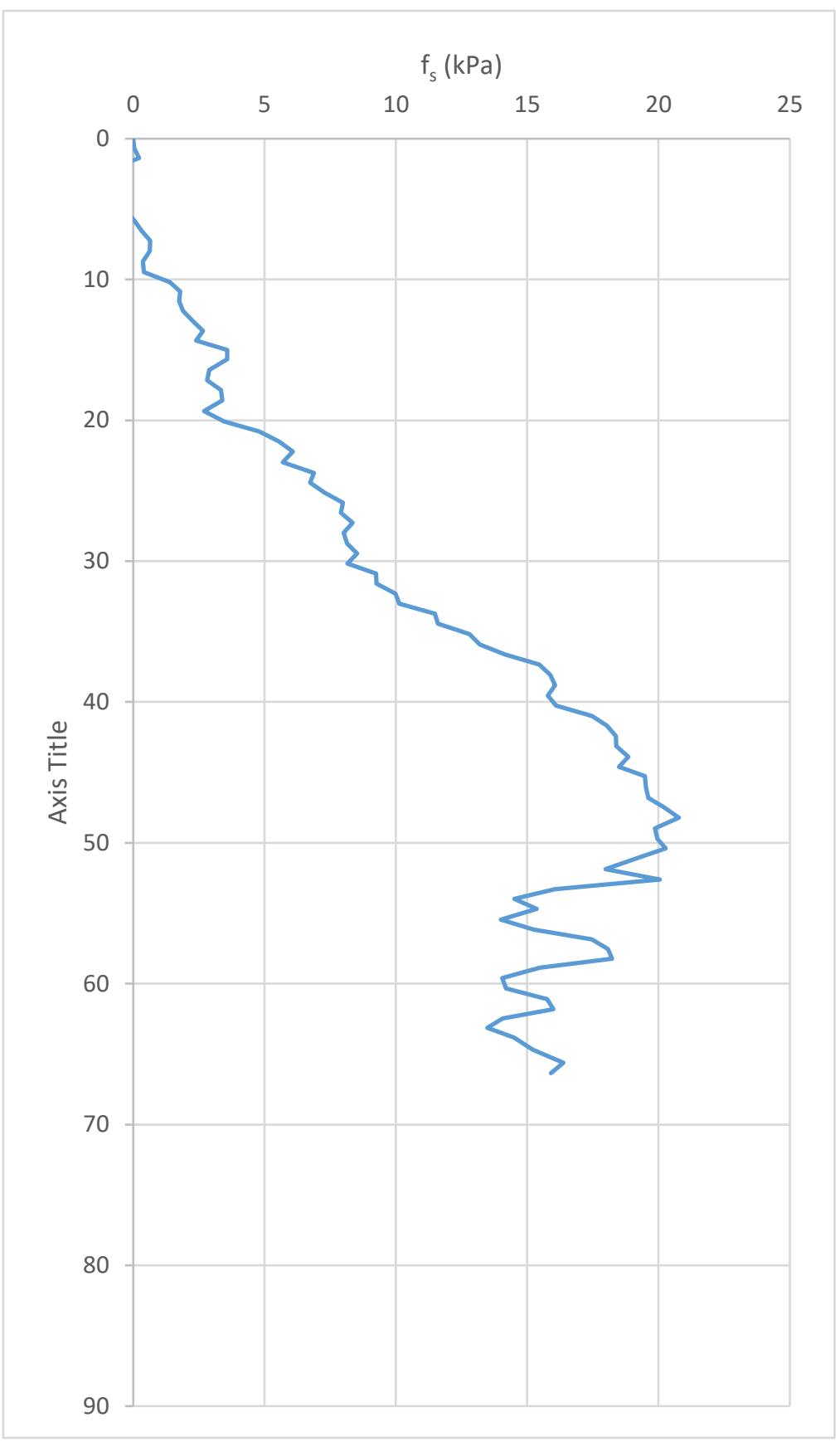

Figure 76: CPT 2.3 Sleeve Friction 


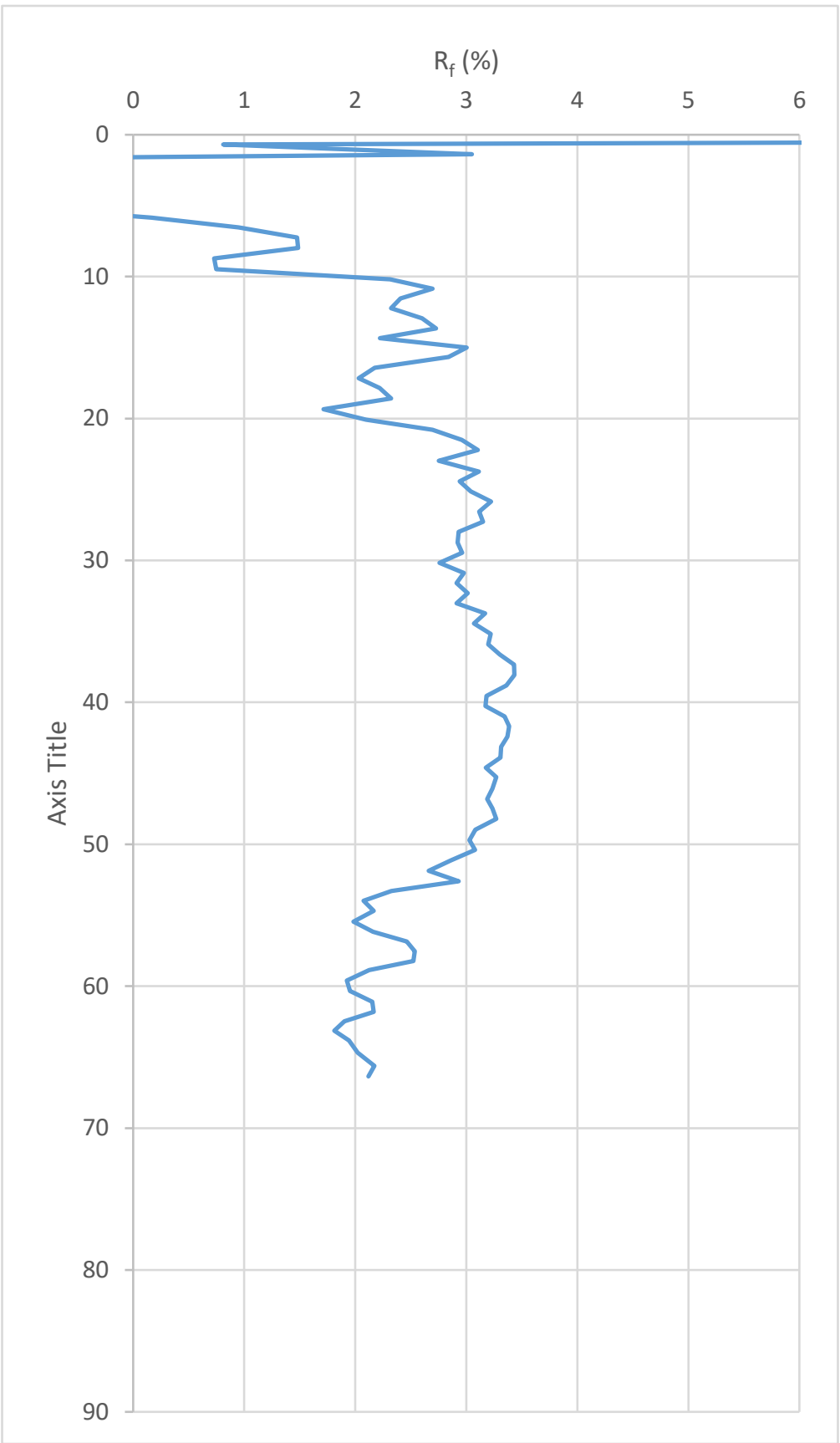

Figure 77: CPT 2.3 Friction Ratio 


\section{CHAPTER 6 RESULTS}

This chapter presents analysis and results of the data presented in the previous chapter. A summary of the data recorded by the data acquisition system is presented. Summaries of the CPT and T-bar results are shown. Observation of excess pore water pressure gives insight into pore pressure dissipation is shown. A discussion of the liquefied soils response to the input motion is provided. Estimates of liquefied residual strength are calculated and compared to previous correlations with index tests.

\subsection{Data Acquisition}

As described in the previous section, the data acquisition system failed to record all sensors during the testing. Table 3 shows which channels of the data acquisition were stored for each test.

Table 3: Data Acquisition Summary

\begin{tabular}{|l|c|c|c|c|c|c|c|c|c|c|c|c|c|c|c|c|c|c|c|}
\hline Test & acci1 & acci2 & acci3 & acci4 & acc1 & acct2 & acct3 & acct4 & accv1 & accv4 & atab & DTG1 & DTG2 & DTG3 & PPT0 & PPT1 & PPT2 & PPT3 & LC7 \\
\hline 1.1 & & $\mathbf{X}$ & & $\mathbf{X}$ & & & $\mathbf{X}$ & & & $\mathbf{X}$ & $\mathbf{X}$ & & & & & & & & $\mathbf{X}$ \\
\hline 1.2 & & $\mathbf{X}$ & $\mathbf{X}$ & $\mathbf{X}$ & $\mathbf{X}$ & $\mathbf{X}$ & $\mathbf{X}$ & & & $\mathbf{X}$ & $\mathbf{X}$ & & & & $\mathbf{X}$ & $\mathbf{X}$ & $\mathbf{X}$ & $\mathbf{X}$ & \\
\hline $\mathbf{1 . 3}$ & & $\mathbf{X}$ & $\mathbf{X}$ & $\mathbf{X}$ & $\mathbf{X}$ & $\mathbf{X}$ & $\mathbf{X}$ & & & $\mathbf{X}$ & $\mathbf{X}$ & $\mathbf{X}$ & $\mathbf{X}$ & $\mathbf{X}$ & $\mathbf{X}$ & $\mathbf{X}$ & $\mathbf{X}$ & $\mathbf{X}$ & $\mathbf{X}$ \\
\hline $\mathbf{2 . 1}$ & & $\mathbf{X}$ & $\mathbf{X}$ & $\mathbf{X}$ & $\mathbf{X}$ & $\mathbf{X}$ & $\mathbf{X}$ & $\mathbf{X}$ & & $\mathbf{X}$ & $\mathbf{X}$ & $\mathbf{X}$ & $\mathbf{X}$ & $\mathbf{X}$ & $\mathbf{X}$ & $\mathbf{X}$ & $\mathbf{X}$ & $\mathbf{X}$ & $\mathbf{X}$ \\
\hline $\mathbf{2 . 2}$ & & $\mathbf{X}$ & $\mathbf{X}$ & $\mathbf{X}$ & & $\mathbf{X}$ & $\mathbf{X}$ & $\mathbf{X}$ & & $\mathbf{X}$ & $\mathbf{X}$ & & & & $\mathbf{X}$ & $\mathbf{X}$ & $\mathbf{X}$ & $\mathbf{X}$ & $\mathbf{X}$ \\
\hline
\end{tabular}




\subsection{CPT Summary}

A summary of the normalized tip resistance $\left(q_{c 1}\right)$ of all CPT tests performed on the full-scale specimen can be seen in Figure 78.

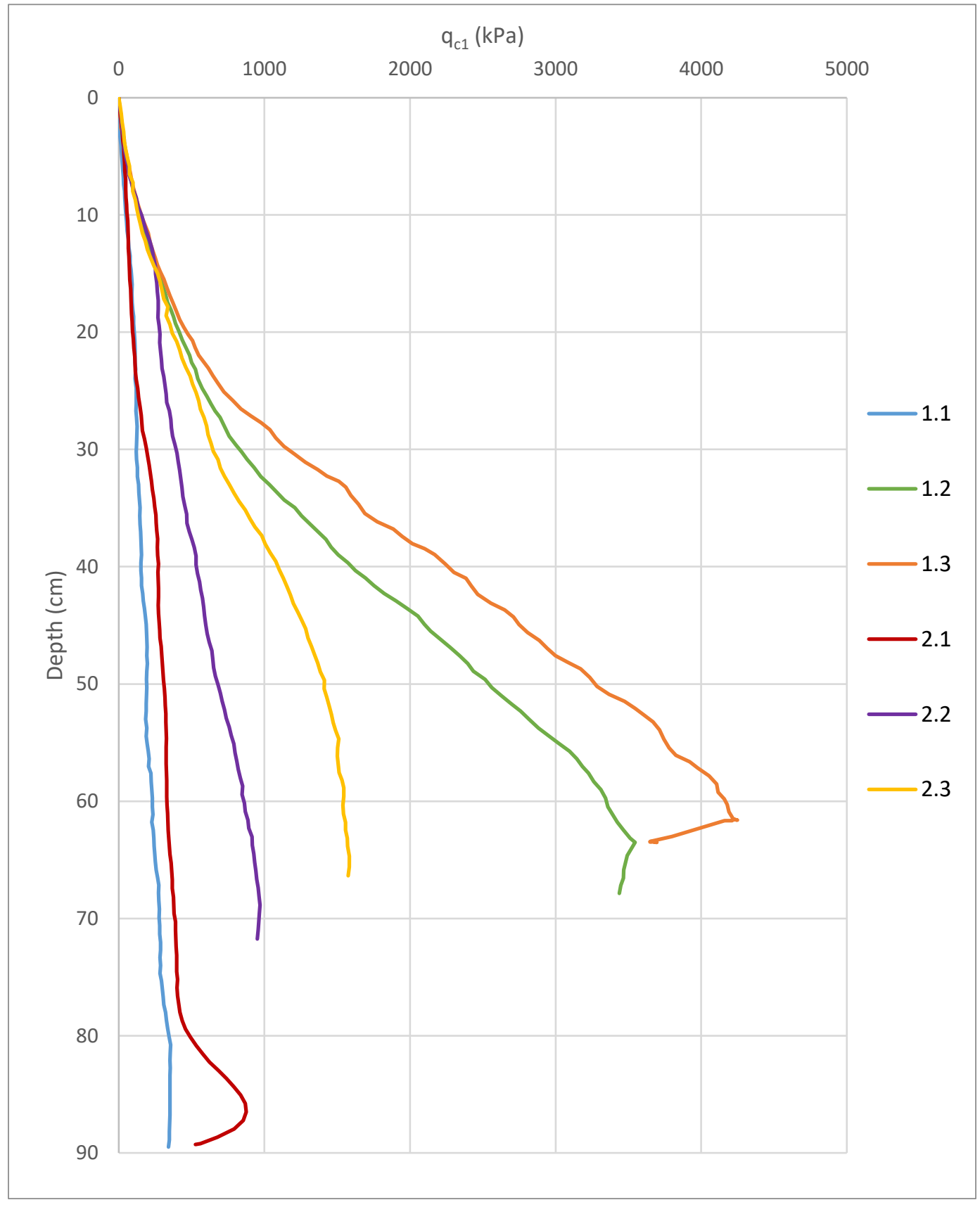

Figure 78:CPT Summary 
The CPT comparisons show that the specimen created for both sets of testing were similar in properties before shaking, with the specimen created before the second set of testing being slightly denser than the first. As expected, CPT Tip Resistance at depth increased with each successive test, showing that void redistribution had occurred. Presumably, void redistribution caused the deeper section of the sand matrix to densify as pore pressures dissipated.

\subsection{T-Bar Penetrometer Summary}

A summary of the pullout pressure calculated from the T-bar pullout tests recorded can be seen in Figures 79 and 80 . Similar to the CPT summary, The T-bar pullout pressures at depth increased with each successive test. This increase in pullout pressure is caused by the densification of soil postliquefaction. 


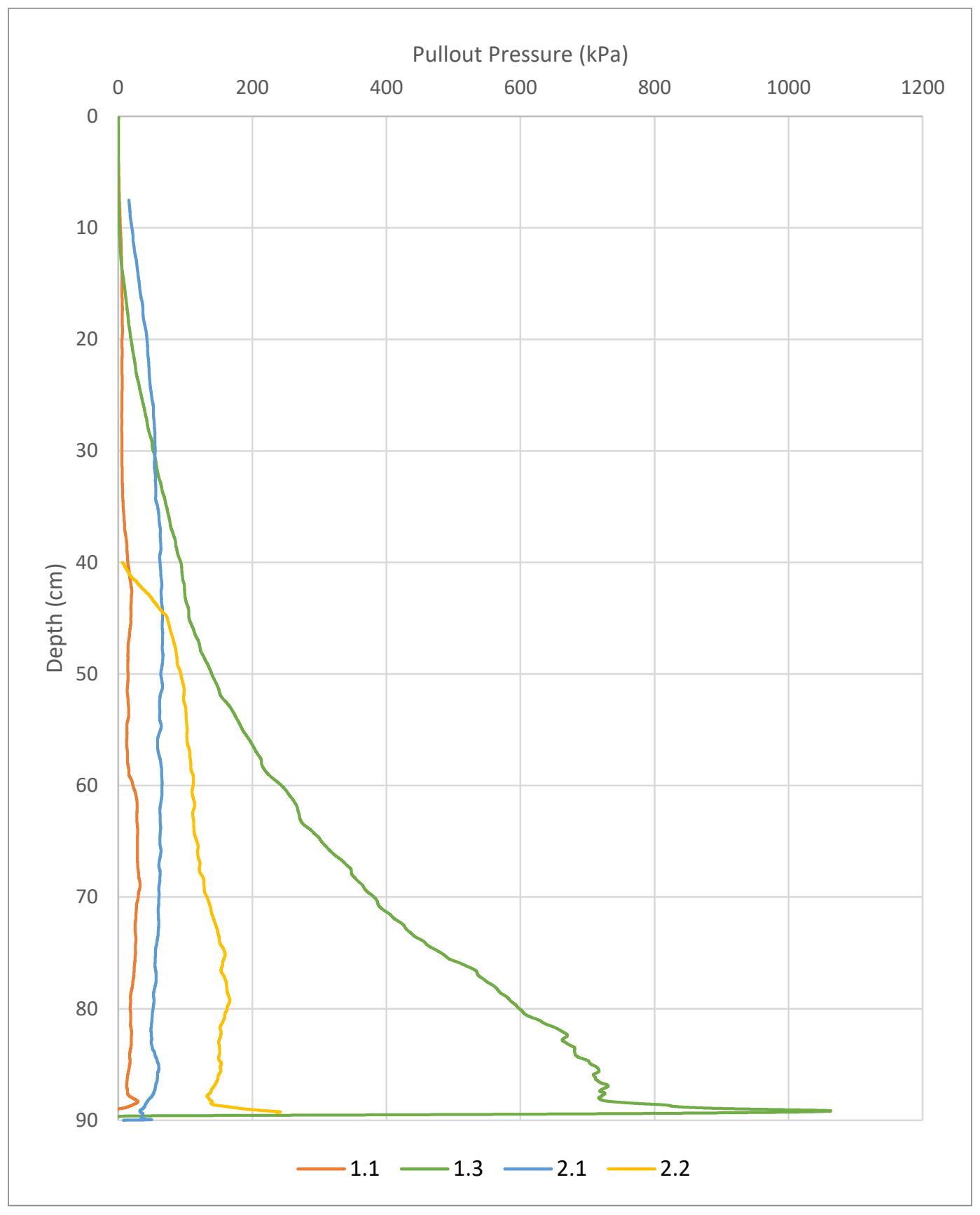

Figure 79: T-bar Pullout Pressure Summary 


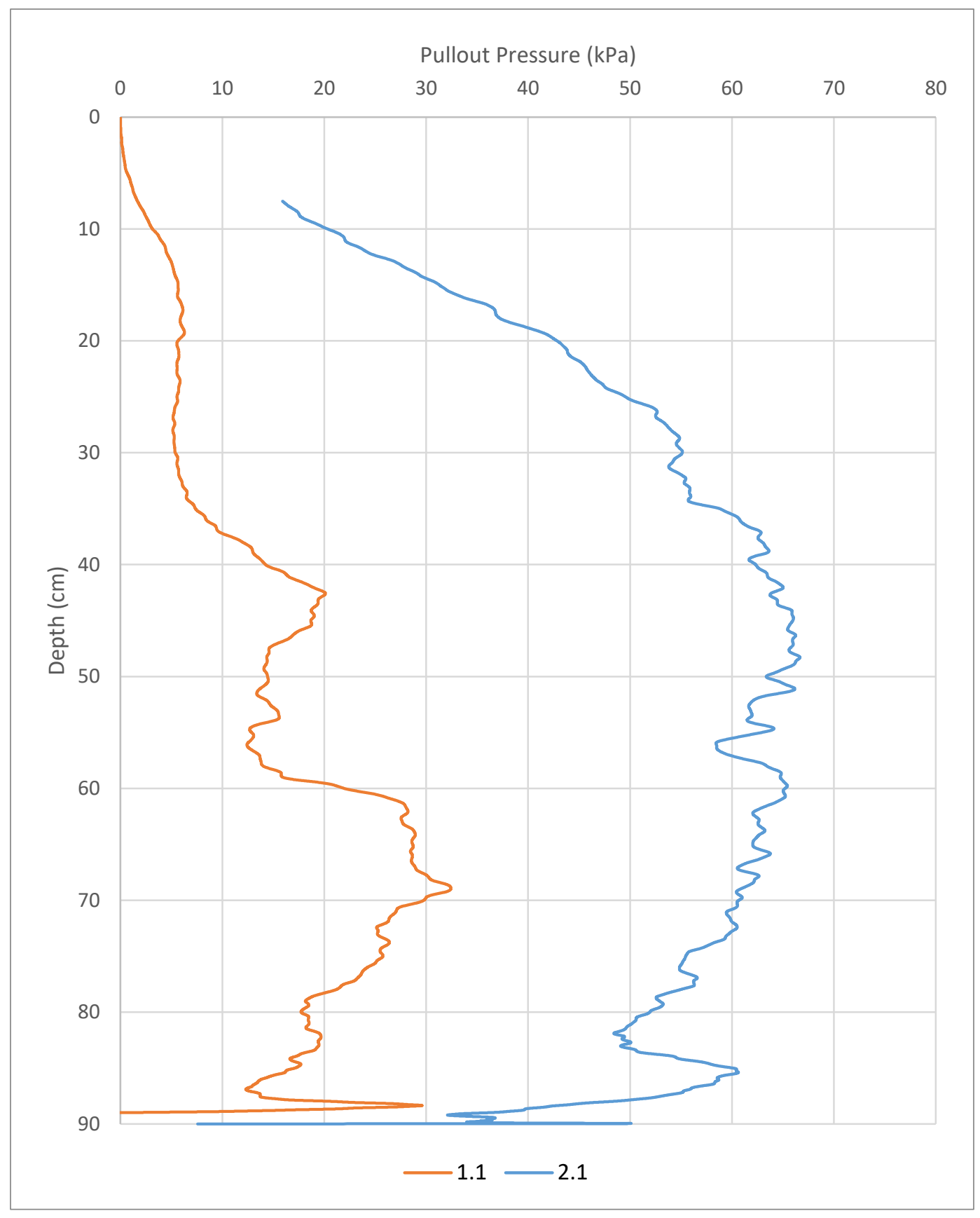

Figure 80: T-bar Pullout Pressure Cyclic Tests 1.1 and 2.1 


\subsection{Pore Pressure Dissipation}

Excess pore pressures developed immediately upon shaking. Figure 81 (Cyclic Test 2.1) shows that pore pressure dissipation began at the bottom of the sample and propagated upwards. Excess pore pressures in the bottom sensor (ppt0) began to dissipate almost immediately after developing.

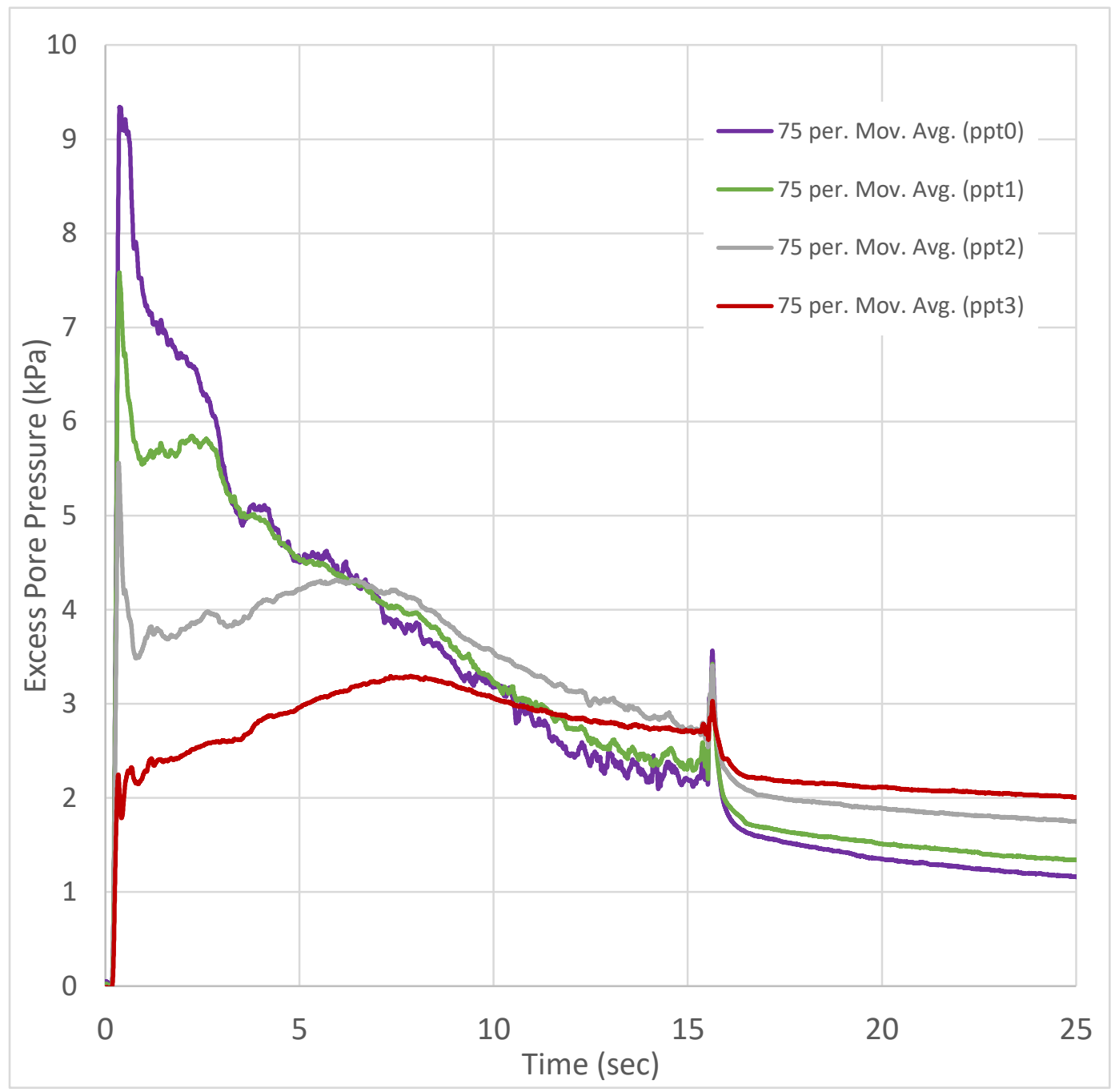

Figure 81: Cyclic Test 2.1 Excess Pore Pressures 


\subsection{Liquefied Soil Effects on Motion}

Law et al. (1997) showed that high frequency components of earthquake motions can be filtered out by liquefied soils. They showed that liquefied soils can greatly reduce the seismic energy of the input motion transmitted to the ground surface.

A summary of selected accelerations recorded during Cyclic Test 2.1 can be seen in Figure 82 . The recorded accelerations began lower than the input motion. Then, as shaking continued, accelerations of the sand specimen began to increase from the bottom of the specimen upwards.

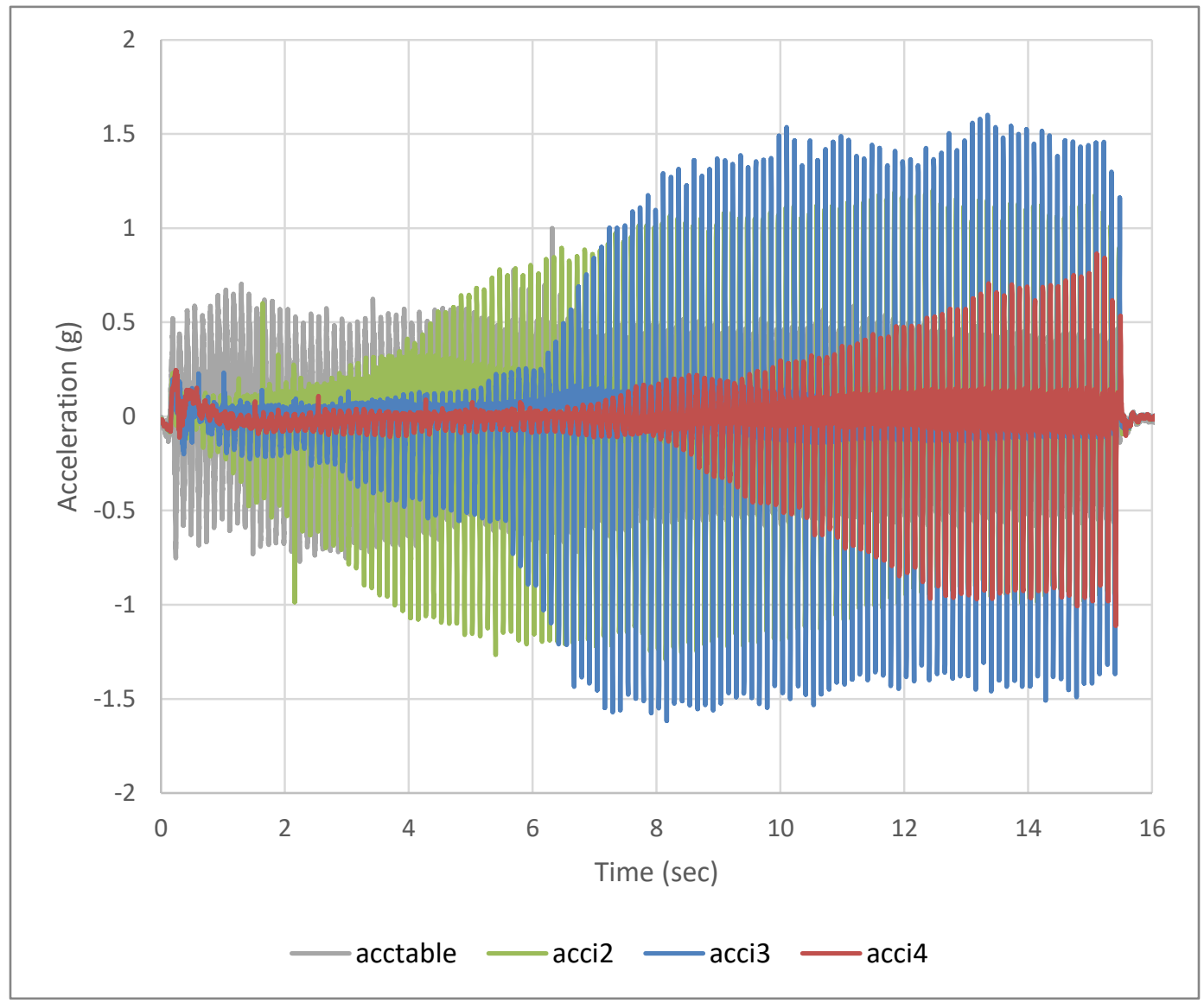

Figure 82: Cyclic Test 2.1 Accelerations 
The liquefied soil's reduced shear modulus reduced the energy transmitted through the soil fabric. Then as shaking continued and void redistribution occurred, the accelerations of the sand specimen grow higher than the input motion. This is likely caused by the increase in shear modulus that occurs with void redistribution. The cyclic cycle of this test did not continue long enough for the accelerations to reach a steady state. A comparison of the excess pore pressures generated and accelerations during Cyclic Test 2.1 can be seen in Figure 83. 


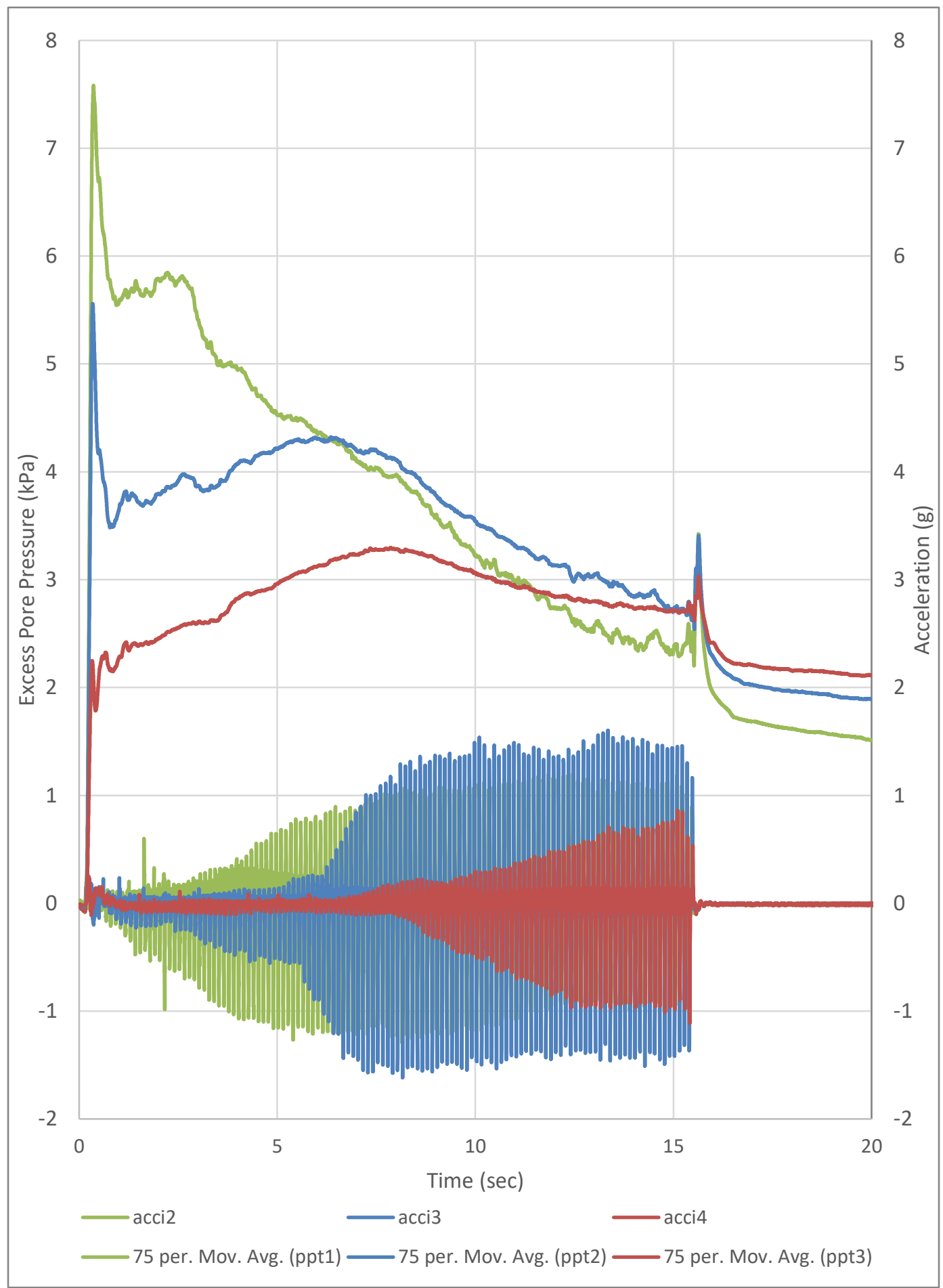

Figure 83: Comparison of Excess Pore Pressures and Accelerations (Cyclic Test 2.1) 


\subsection{Liquefied Residual Strength Estimation}

Randolph and Houlsby (1984) developed closed-form solutions, using classical plasticity theory, for the limiting pressure acting on a circular pile moving laterally through soil. Meymand (1998) further expanded on their research and developed the flowing equation:

$$
S_{u}=\frac{P}{N_{b} * D}
$$

Where $\mathrm{S}_{u}$ is undrained shear strength; $\mathrm{P}$ is force per unit length acting on the cylinder; $\mathrm{N}_{\mathrm{b}}$ is bar factor; and $\mathrm{D}$ is diameter of the cylinder. A bar factor $(\mathrm{Nb})$ of 10.5 is used in this research as suggested by Randolph and Houlsby (1984). 


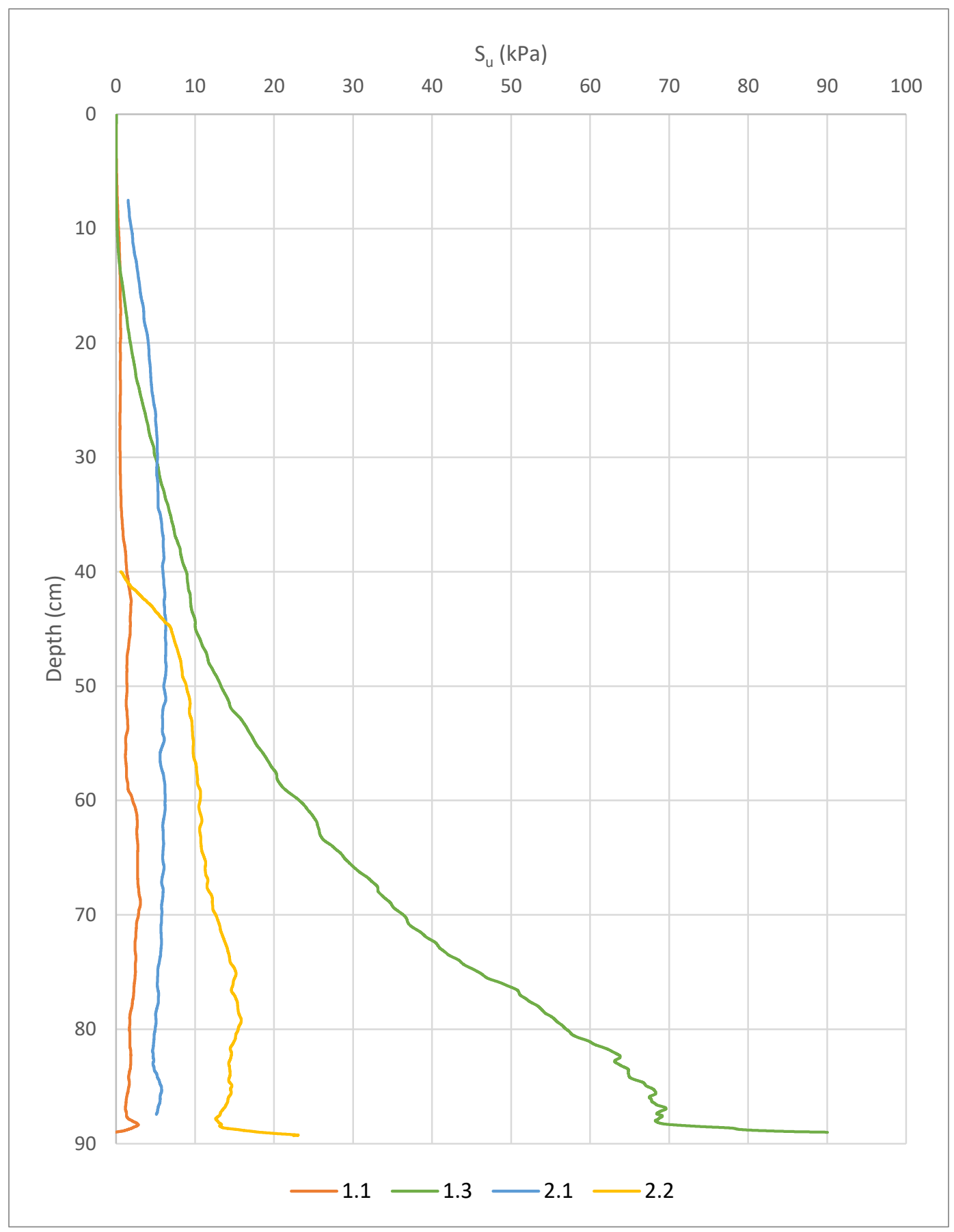

Figure 84: $\mathrm{S}_{u}$ Calculated from T-bar Pullout Test Summary 


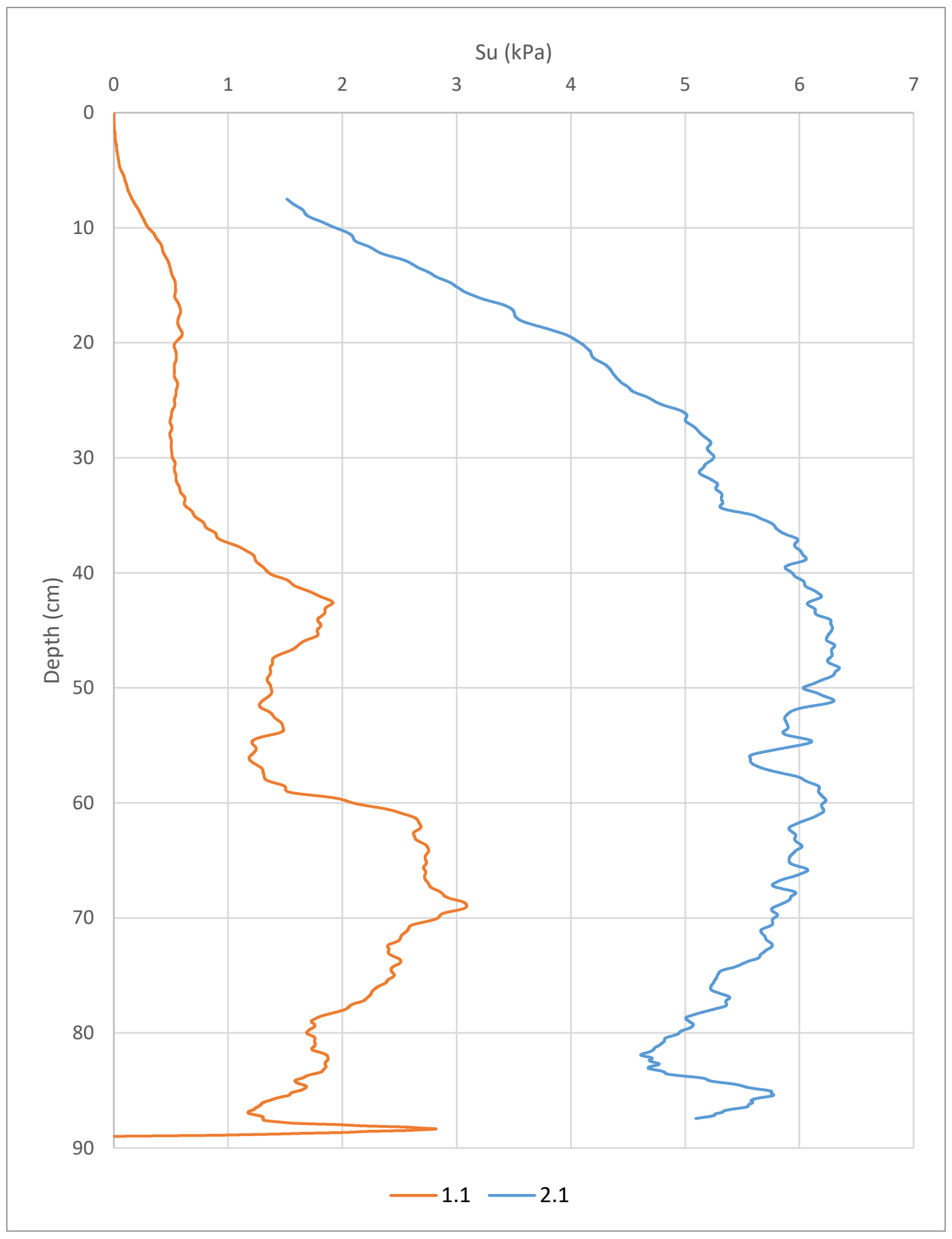

Figure 85: Comparison of $\mathrm{Su}$ Calculated from T-bar Pullout Test Cyclic Tests 1.1 and 2.1 


\subsubsection{Cyclic Test 1.1}

The liquefied strength ratio from Cyclic Test 1.1 was calculated by dividing the $S_{u}$ estimated from the T-bar pullout by the vertical effective stress. A graph of the liquefied strength ratio and normalized CPT tip resistance, $q_{\mathrm{c} 1}$, can be seen in Figure 86.

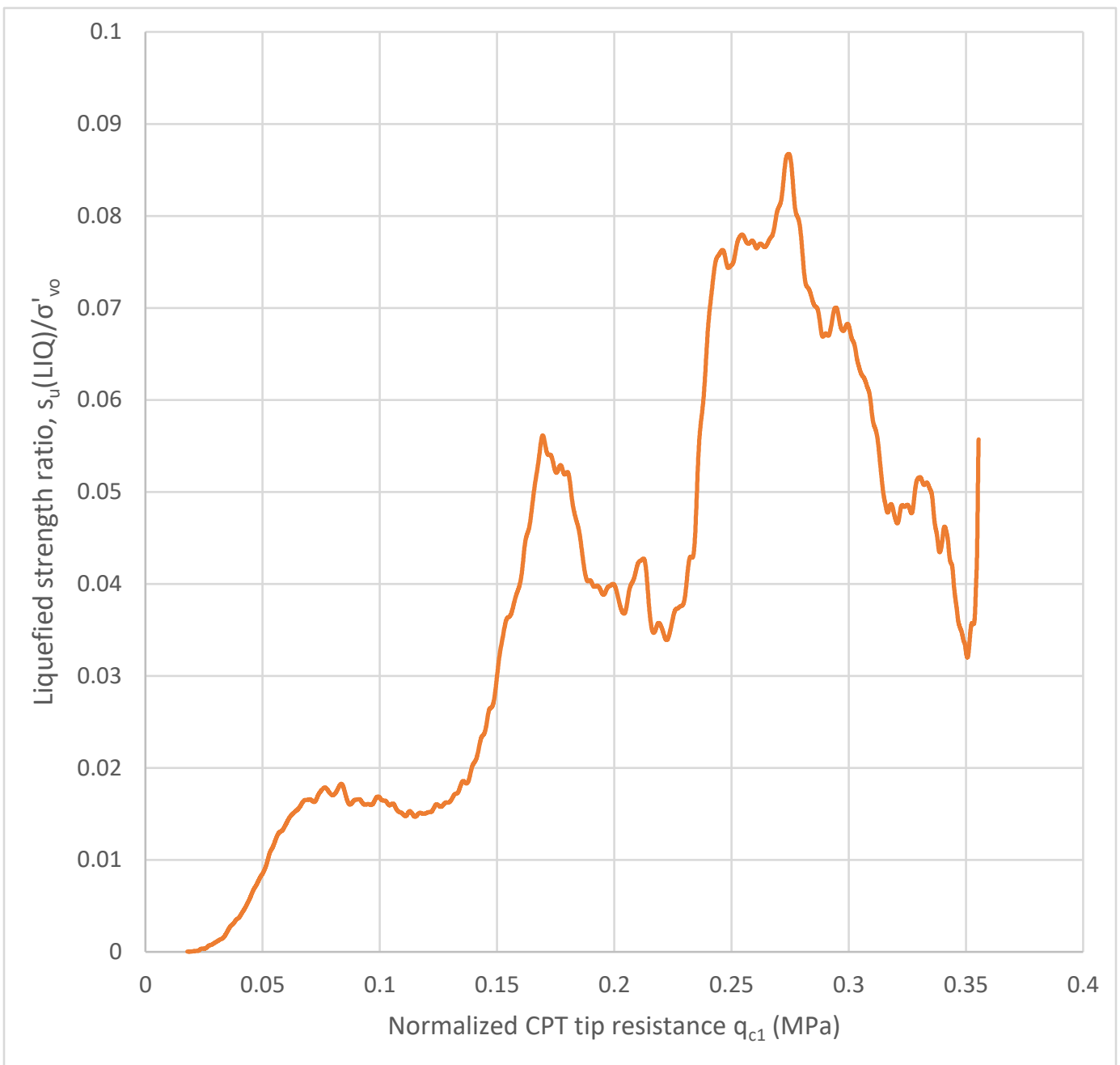

Figure 86: Cyclic Test 1.1 Liquefied Strength Ratio vs. Normalized CPT Tip Resistance 
A comparison of the results of Cyclic Test 1.1 to Olson and Stark (2003) can be seen in Figure 87.

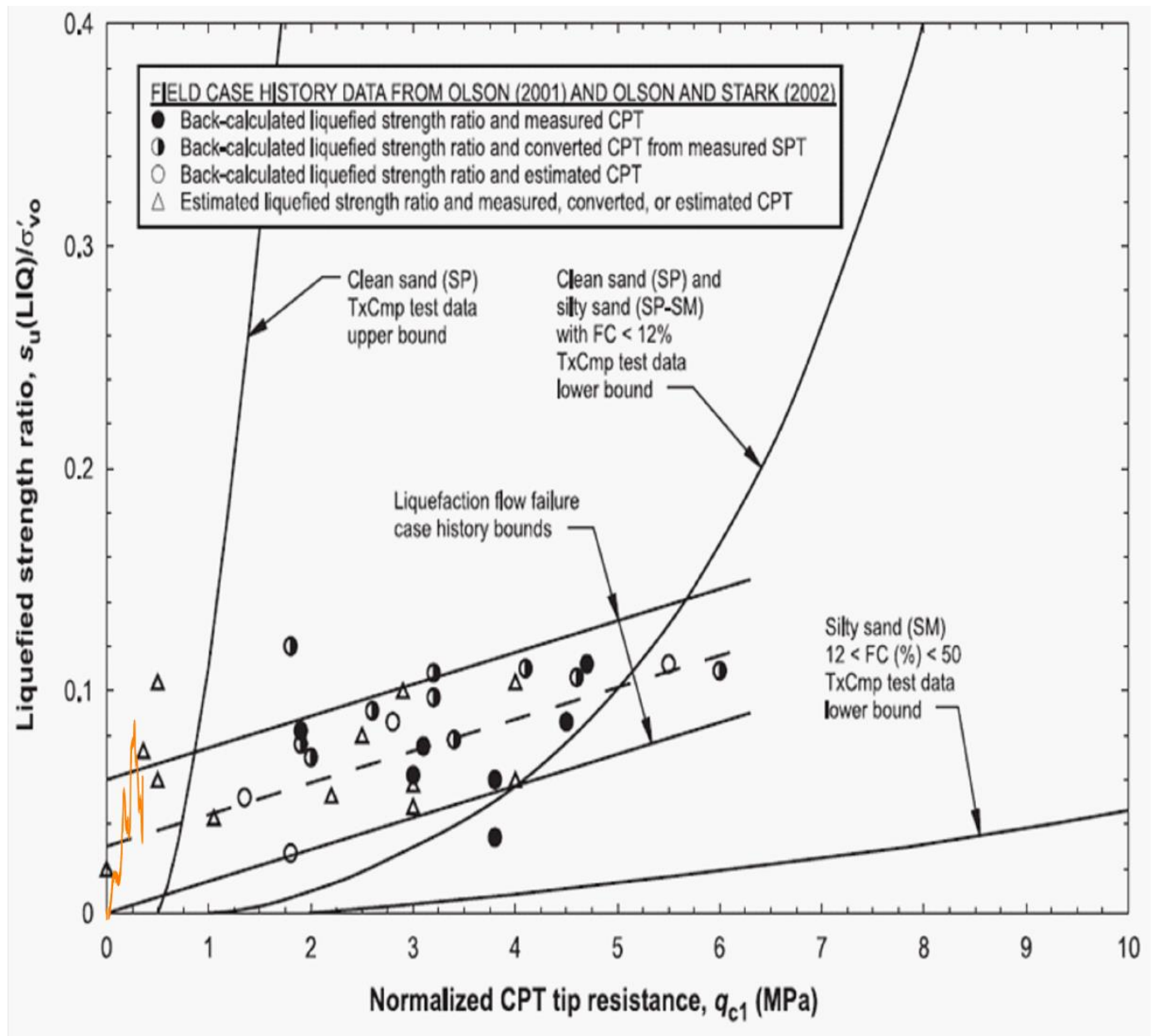

Figure 87: Comparison of Cyclic Test 1.1 Results to Olson and Stark (2003) 


\subsubsection{Cyclic Test 2.1}

As discussed previously, the Residual Strength $\left(\mathrm{S}_{\mathrm{u}}\right)$ calculated from the Tbar pullout during Cyclic Test 2.1 could have been influenced by additional friction between the T-bar and top plate of the flexible-walled testing apparatus. This increase in friction would overestimate the liquefied strength ratio for this test. The liquefied strength ratio from Cyclic Test 2.1 was calculated by dividing the $\mathrm{Su}_{\mathrm{u}}$ estimated from the T-bar pullout by the vertical effective stress. A graph of the liquefied strength ratio and normalized CPT tip resistance, $q_{c 1}$, can be seen in Figure 88 .

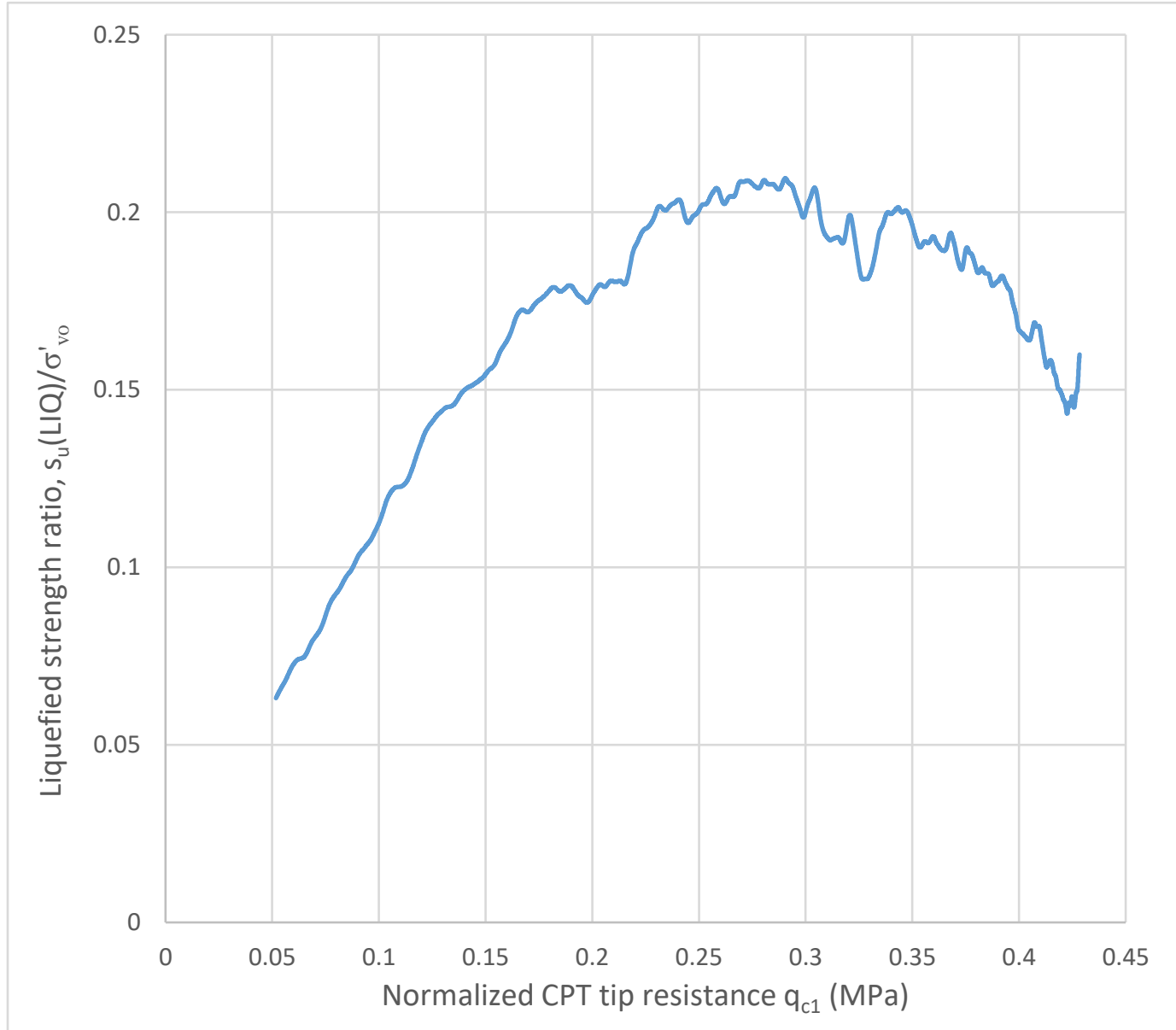

Figure 88: Cyclic Test 2.1 Liquefied Strength Ratio vs. Normalized CPT Tip Resistance 
A comparison of the results of Cyclic Test 2.1 to Olson and Stark (2003)

can be seen in Figure 89.

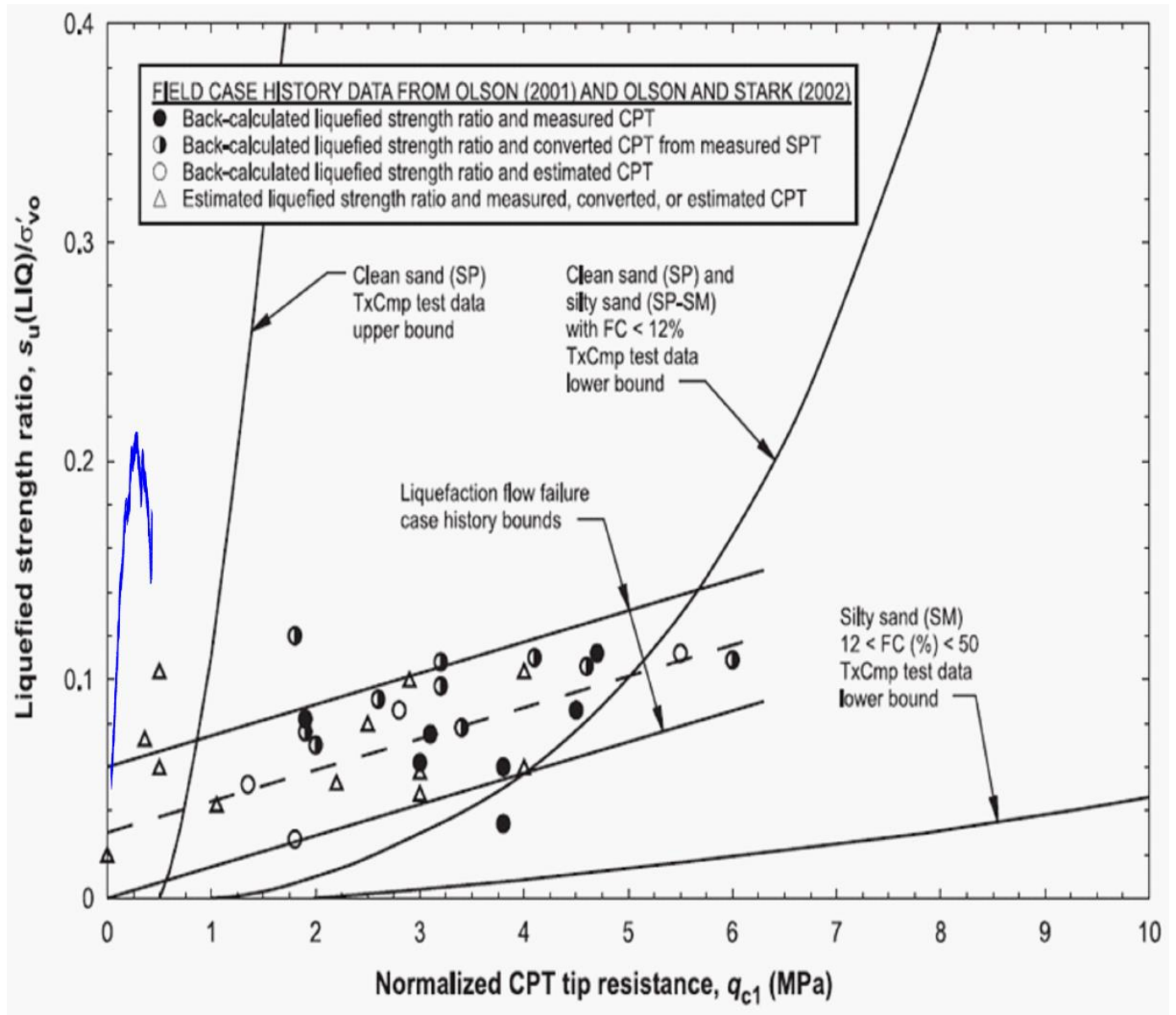

Figure 89: Comparison of Cyclic Test 2.1 Results to

Olson and Stark (2003) 


\section{CHAPTER 7 CONCLUSIONS AND RECOMMENDATIONS FOR FUTURE RESEARCH}

The full-scale cyclic simple shear tests and index testing performed in this study provide a progression in both laboratory and field testing for liquefaction. CPT index test data provided pre- and post- liquefaction index data for comparison to field tests and allowed for observation of the effect repeated liquefaction has on sand. T-bar penetrometer pullout tests provided estimates of liquefied residual strength during cyclic testing. Pore pressure recordings were used to directly observe the occurrence of liquefaction and show the dissipation of excess pore pressures as void redistribution occurs. Acceleration time-histories were used to show liquefaction's effect on how seismic energy propagates through soil layers.

\subsection{Data Acquisition}

The data acquisition system in the Parsons Geotechnical Laboratory experienced many issues and failures throughout this research. A more reliable system that could record all channels of input data at higher frequencies would greatly enhance and refine the data obtained in future research. 


\subsection{Overburden Measurement}

The development of an accurate measurement of the overburden assembly's effect on effective stress would allow for more accurate corrected CPT Tip Resistance $\left(\mathrm{q}_{\mathrm{c} 1}\right)$ and normalized residual strength estimations.

\subsection{Shear-Wave Velocity Measurement}

An efficient method of testing shear wave velocity while the overburden pressure assembly is installed and pressurized would improve the results of this research. The measurements of $V_{s}$ between each test would allow for additional comparisons to field index test data.

\subsection{Flexible walled testing container}

At the completion of testing, the rubber membrane of the flexible walled testing apparatus was destroyed beyond repair and disposed of. For future testing, a similar membrane with additional lateral stiffness may be beneficial. Additional lateral stiffness would increase resistance to the lateral deformations observed in this research. However, careful consideration of the effects an increased boundary stiffness would have on the sand specimen and its seismic response. 


\section{REFERENCES}

Andrus, R.D., Stokoe, K.H., (2000). Liquefaction Resistance of Soils from Shear-Wave Velocity. J. Geotech. Geoenvion. Eng., 126(11), 10151025.

ASTM D4253 - 14: Standard Test Methods for Maximum Index Density and Unit Weight of Soils Using a Vibratory Table. (2014, December 15), West Conshohocken, Pa: ASTM International.

ASTM D4254 - 14: Standard Test Methods for Minimum Index Density and Unit Weight of Soils and Calculation of Relative Density. (2014, December 15), West Conshohocken, Pa: ASTM International.

ASTM D5778 - 12: Standard Test Method for Electronic Friction Cone and Piezocone Penetration Testing of Soils. (2012, January 1), West Conshohocken, Pa: ASTM International.

Boulanger, R.W., and Seed, R.B., (1995). Liquefaction of sand under bidirectional monotonic and cyclic loading. Journal of Geotechnical Engineering, ASCE, 121(12), 870-878.

Butcher, A.P., Campanella, R.G., Kaynia, A.M., Massarsch, K.R., (2005). Seismic Cone Downhole Procedure to Measure Shear Wave Velocity - A Guide Prepared by ISSMGE TC10: Geophysical Testing in Geotechnical Engineering. London: International Society for Soil Mechanics and Geotechnical Engineering.

Cetin, K.O., Der Kiureghian, A., and Seed, R.B., (2002). Probabilistic Models for the Initiation of Seismic Soil Liquefaction. Structural Safety, 24, pp. 67-82. 
Crosariol, V. A. (2010). Scale Model Shake Table Testing of Underground Structures in Soft Clay. San Luis Obispo, Ca: Cal Poly Digital Commons.

Davis, A. P., Jr., Poulos, S. J., and Castro, G., (1988). Strengths back figured from liquefaction case histories. 2nd Int. Conf. on Case Histories in Geotechnical Engineering, St. Louis, MO, 1693-1701.

Davis, A.P., Jr., Poulos, S.J., and Castro, G., (1988), Strengths Back Figured from Liquefaction Case Histories. $2^{\text {nd }}$ Int. Conf. on Case Histories in Geotechnical Engineering, St. Louis, MO, 1693-1701.

de Alba, P., and Ballestero, T. P., (2006). Residual strength after liquefaction: A rheological approach. Soil Dyn. Earthquake Eng., 26(2-4), 143-151.

DeJong, J.T., Yafrate, N.J., DeGroot, D.J., (2011). Evaluation of Undrained Shear Strength Using Full-Flow Penetrometers. J. Geotech. Geoenviron. Eng., 137(1), 14-26.

Dewoolkar, M., Hargy, J., Anderson, I., de Alba, P., Olson, S.M., (2016). Residual and Postliquefaction Strength of a Liquefiable Sand. J. Geotech. Geoenviron. Eng., 2016, 142(2).

Hazirbaba, K., and Rathje, E.M., (2009). Pore Pressure Generation of Silty Sands due to Induced Cyclic Shear Strains, Journal of Geotechnical and Environmental Engineering, ASCE, 135(12), 1892-1905.

Idriss, I. M., and Boulanger, R. W., (2007). SPT- and CPT-based relationships for the residual shear strength of liquefied soils. Earthquake Geotechnical Engineering, 4th Int. Conf. on Earthquake Geotechnical Engineering_Invited Lectures, K. D. Pitilakis, ed., Springer, Netherlands, 1-22. 
Idriss, I. M., and Boulanger, R. W., (2008). Soil liquefaction during earthquakes. Earthquake Engineering Research Institute, Oakland, CA.

Ishihara, K., (1993). Liquefaction and flow failure during earthquakes. Geotechnique, 43(3), 351-415.

Jacobs, J.S., (2016). Full-Scale Shake Table Cyclic Simple Shear Testing of Liquefiable Soil. San Luis Obispo, Ca: Cal Poly Digital Commons.

Juang, C.H., Jiang, T., and Andrus, R.D., (2002). Assessing probabilitybased methods for liquefaction potential evaluation. Journal of Geotechnical and Geoenvironmental Engineering, 128(7): 580-589.

Kammerer, A.M., Pestana, J.M., and Seed, R.B., (2005). Behavior of Monterey 0/30 Sand Under Multidirectional Loading Conditions. Geomechanics, 154-173.

Kramer, S.L., Wang, C.H., (2015). Empirical Model for Estimation of the Residual Strength of Liquefied Soil. J. Geotech. Geoenviron. Eng., 2015, 141(9), 04015038.

Kuo, S., (2012). Scale Model Shake Table Testing of Shallow Embedded Foundations in Soft Clay. San Luis Obispo, Ca, Cal Poly Digital Commons.

Law, K.T., Song, Q., Fukue, M., (1997). Effects of Liquefaction on Seismic Ground Motion. In Proceedings of the International Conference on Soil Mechanics and Foundation Engineering, Hamburg, Germany, 695-698.

Meymand, P., (1998). Shaking table scale model tests of nonlinear soil-pile superstructure interaction in soft clay. Ph.D. Disseration, University of California, Berkeley. 
Mitchell, J. K., and Tseng, D. J., (1990). Assessment of liquefaction potential by cone penetration resistance. Proc., H. Bolton Seed Memorial Symp. Duncan, J. M. BiTech, Vancouver, Canada, 335350.

Moss, R. E. S., Seed, R. B., Kayen, R. E., Stewart, J. P., Kiureghian, A. D., and Cetin, K. O., (2006). CPT-based probabilistic and deterministic assessment of in situ seismic soil liquefaction potential. J. Geotech. Geoenviron. Eng., 132(8), 1032-1051.

Moss, R.E.S., and Crosariol, V.A. (2013). Scale Model Shake Table Testing of an Underground Tunnel Cross Section in Soft Clay. Earthquake Spectra: November 2013, Vol. 29, No. 4, 1413-1440.

Moss, R.E.S., (2003). CPT-Based Probabilistic Assessment of Seismic Soil Liquefaction Initiation. Ph.D. thesis, University of California at Berkeley.

Motamed, R., and Towhata, I., (2010). Shaking Table Model Tests on Pile Groups behind Quay Walls Subjected to Lateral Spreading. J. Geotech. Geoenviron. Eng., 2010, 136(3), 477-489.

National Academies of Sciences, Engineering, and Medicine. (NAE). (2016). State of the Art and Practice in the Assessment of Earthquake-Induced Soil Liquefaction and Its Consequences. Washington, DC: The National Academies Press.

Noche, R., (2013). Scale Model Shake Table Testing of Seismic Earth Pressures in Soft Clay. San Luis Obispo, Ca: Cal Poly Digital Commons.

Olson, S. M., and Stark, T. D., (2002). Liquefied strength ratio from liquefaction flow failure case histories. Can. Geotech. J., 39(3), 629647. 
Olson, S. M., and Stark, T. D., (2003). Use of laboratory data to confirm yield and liquefied strength ratio concepts. Can. Geotech. J., 40(6), 1164-1184.

Poulos, S.J., Castro, G., and France, J.W., (1985). Liquefaction evaluation procedure. J. Geotechnical Eng., ASCE 111(6), 772-91.

Randolph, M.F. and Houlsby, G.T., (1984). The limiting pressure on a circular pile loaded laterally in cohesive soil. Geotechnique, 34(4), 613-623.

Robertson, P. K., and Campanella, R. G., (1985). Liquefaction potential of sand using the CPT. J. Geotech. Eng., 111(3), 384-403.

Robertson, P.K., and Wride, C.E., (1998). Evaulating cyclic liquefaction potential using the cone penetration test, Canadian Geotechnical J., 35(3), 442-59.

Seed, H. B., and de Alba, P., (1986). Use of SPT and CPT tests for evaluating the liquefaction resistance of sands. Proc., In Situ '86, ASCE, New York, 281-302.

Seed, H. B., and Idriss, I. M., (1971). Simplified procedure for evaluating soil liquefaction potential. J. Soil Mech. Found. Div., 97(9), 12491273.

Seed, H.B., (1987). Design Problems in Soil Liquefaction. J. Geotech. Geoenviron. Eng., 113(8), 827-845.

Seed, H.B., and Idriss, I.M., (1971). Simplified procedure for evaluating soil liquefaction potential. J. Soil Mechanics and Foundations Div., ASCE 97(SM9), 1249-273.

Seed, R.B., and Harder, L.F., (1990). SPT-Based Analysis of Cyclic Pore Pressure Generation and Undrained Residual Strength. Proc., $\mathrm{H}$. 
Bolton Seed Memorial Symp., Vol. 2, BiTech Publishing, Richmond, BC, Canada, 351-76.

Seed, R.B., Cetin, K.O., Moss, R.E., Kammerer, A.M., Wu, J., Pestana, J.M., et al., (2003). Recent Advances in Soil Liquefaction Engineering: a Unified and Consistent Framework. University of California, Berkeley: Earthquake Engineering Research Center.

Shibata, T., and Teparaska, W., (1988). Evaluation of liquefaction potential of soils using cone penetration testing. Soils Found., 28(2), 49-60.

Stanton, K., (2013). Investigation of Parameters Influencing Reverse Fault Rupture Propogation to the Ground Surface. San Luis Obispo, Ca: Cal Poly Digital Commons.

Stark, T. D., Olson, S. M., Kramer, S. L., and Youd, T. L., (1998). Shear strength of liquefied soils. Proc., National Science Foundation Workshop on Post-Liquefaction Shear Strength of Granular Soils, Univ. of Illinois at Urbana-Champaign, Urbana, IL.

Stark, T.D., and Mesri, G., (1992). Undrained shear strength of sands for stability analysis. J. Geotechnical Eng. Div., ASCE 118(11), 1727747.

Stark, T.D., and Olson, S.M., (1995). Liquefaction resistance using CPT and field case histories. J. Geotechnical Eng., ASCE 121(12), 856-69.

Stewart, D.P., and Randolph, M.F., (1991). A new site investigation tool for the centrifuge. In Proceedings of the International Conference on Centrifuge Modelling, Centrifuge '91, Boulder, Colo., 13-14 June 1991. Balkema, Rotterdam, the Netherlands. 531-538.

Stewart, D.P., and Randolph, M.F., (1994). T-Bar Penetration Testing in Soft Clay. J. Geotech. Eng., 120(12), 2230-2235. 
Suzuki, Y., Tokimatsy, K., Taya, Y., and Kubota, Y., (1995). Correlation between Cpt data and dynamic properties of in situ frozen samples. in Proceedings, $3^{\text {rd }}$ International Conference on Recent Advances in Geotechnical Earthquake Engineering and Soil Dynamics, Vol. I, St. Louis, MO.

Toprak, S., Holzer, T.L., Bennett, M.J., and Tinsley, J.C., III., (1999). CPTand SPT-based probabilistic assessment of liquefaction. in Proceedings, $7^{\text {th }}$ U.S.-Japan Workshop on Earthquake Resistant Design of Lifeline Facilities and Countermeasures against Liquefaction, Seattle, August, Multidisciplinary Center for Earthquake Engineering Research, Buffalo, NY, pp. 69-86.

Towhata, I., Vargas-Monge, W., Orense, R.P., Yao, M., (1999). Shaking table tests on subgrade reaction of pipe embedded in liquefied subsoil. Soil Dynamics and Earthquake Engineering 18, 1999, 347361.

Weber, J.P. (2015). Engineering Evaluation of Post-Liquefaction Strength. University of California, Berkeley.

Wride, C.E., McRoberts, E.C., and Robertson, P.K., (1999). Reconsideration of case histories for estimating undrained shear strength in sandy soils. Canadian Geotechnical J., 36, 907-33.

Yoshimine, M., Robertson, P.K., and (Fear) Wride, C.E. (1999). Undrained shear strength of clean sands to trigger flow liquefaction. Can. Geotech. J., 36, pp. 891-906.

Youd, T. L., Idriss, I.M., Andrus, R.D., Marcuson, W.F., (2001). Liquefaction resistance of soils: Summary report from the 1996 NCEER and 1998 NCEER/NSF workshops on evaluation of liquefaction resistance of soils. J. Geotech. Geoenviron. Eng., 127(10), 817-833. 


\section{APPENDIX A: T-bar Penetrometer Testing}

\section{T-bar Measurements}

To measure the liquefied residual or undrained strength of the liquefied soil we used T-bar pullout tests that measure the flow resistance of the liquefied sample during shaking. T-bar tests have been popularized by Stewart and Randolf (1994) and others for measuring strength of clays and calcareous sands in the lab and the field. At Cal Poly, researchers have used T-bar tests in prior soil-structure-interaction experiments on this shake table to measure the undrained strength of clay soils (Moss and Crosariol, 2013). For this current test the T-bars were deployed in the same manner but for measuring the resistance while the Monterey sand was in a liquefied state. Other tabletop and centrifuge experiments measuring the residual strength of liquefied soil were initiated by de Alba and Ballestero, (2006) using a sphere, and continued by Dewoolkar et al., (2016) using a stamp-type pullout. The utility of simple geometries like a sphere, cylinder, or stamp is that they offer a theoretical basis for the physical measurements.

\section{Theoretical, Numerical, and Experimental Background}

As discussed above, T-bar (Fig 1) pullouts have been found to be a simple experimental means of measuring the flow characteristics of material around a small cylinder. 


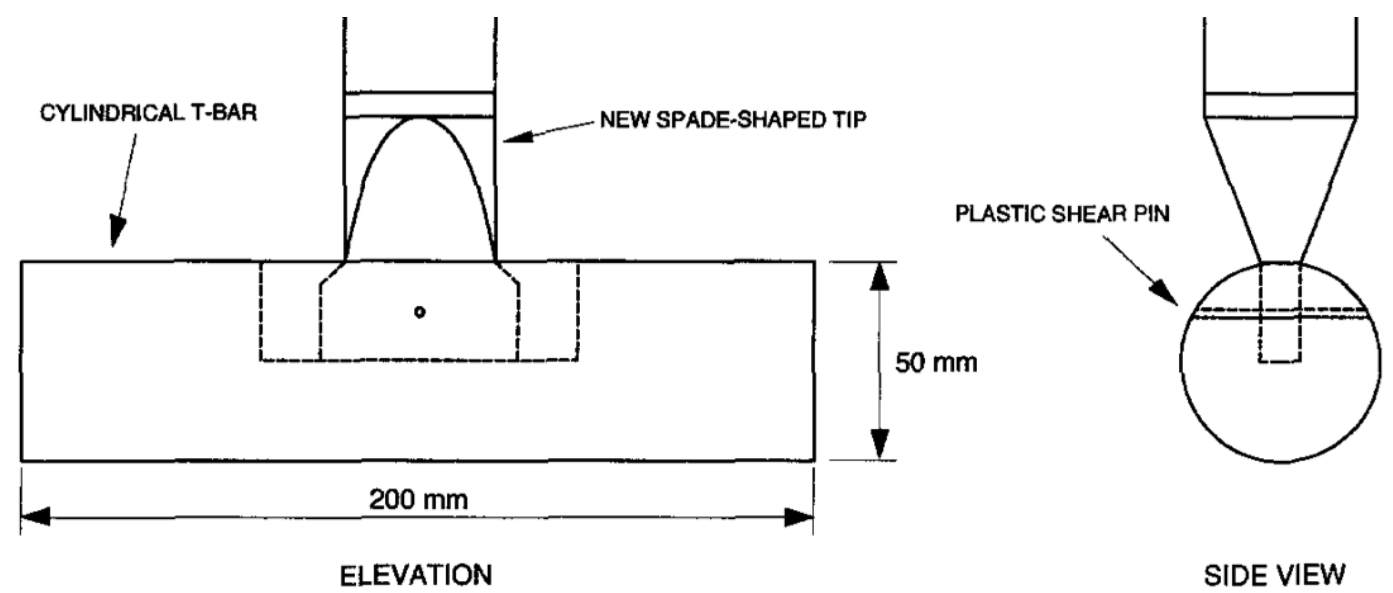

Figure 90 Schematic of T-bar equipment to be used to measure the undrained residual strength of liquefied soil, from Stewart and Randolf (1994).

From a soils perspective this problem has been analyzed primarily looking at undrained clays. A cylinder can be quantified using a plasticity solution (among others) for the limiting pressure, as described in Randolf and Houlsby, 1984. If we assume that the soil closes fully behind the passing cylinder so that there is no gap ("creeping flow"), the solution results in a simple expression with a semi-theoretical factor:

$$
P / s_{u} d=N_{b} \quad \text { Equation } 1
$$

where $P$ is the force per unit length acting on the cylinder, $s_{u}$ is the undrained strength of the soil, $d$ is the cylinder diameter, and $N_{b}$ is the bar factor. The analytical value of the bar factor varies as a function of the surface roughness of the cylinder but is between the bounds of 11.94 for rough cylinders and 9.14 for smooth cylinders. End areas of the cylinder are neglected treating it as an infinitely long bar, which amounts to $10 \%$ of the overall cylinder area. 
From a fluids perspective this problem has been analyzed extensively under many different flow conditions. If we are interested in very slow flow so that conditions are laminar (Reynolds number, $R_{e}<5$ ) then we can treat the fluid as viscoplastic (i.e., Bingham plastic) as shown in Figure 2. The characteristic of a non-Newtonian fluid like a Bingham plastic is that it has some limiting yield strength followed by a strain rate dependent shear strength. This behavior is typically explained in a physical manner stating that the fluid has particles that provide some limiting stress threshold.

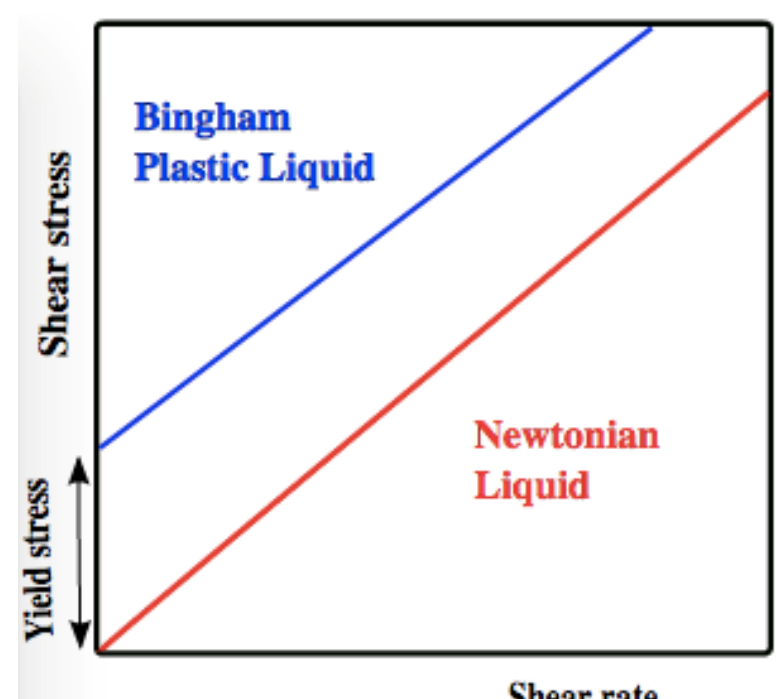

Shear rate

Figure 91. Schematic of Newtonian vs. Non-Newtonian fluid response to the rate of shearing (strain rate).

Tokpavi et al., (2008) evaluated this flow condition around a cylinder using a numerical solution and found that their results for a rough cylinder agreed perfectly $\left(N_{b}=11.94\right)$ with the plastic solution by Randolf and Houlsby (1984). [Note: in fluid mechanics literature the factor is termed the drag coefficient $C_{d}$. We will use the symbol $N_{b}$ here to be consistent with geotechnical literature; $N_{b}=C_{d}$ ] Tokpavi et al., (2009) then conducted a 
detailed physical experiment to compare to the numerical results and found the measured factor was higher than the numerical/theoretical results (in the range of 13.5 to 12.0 ) as a function of the Bingham number, but converged to 12 as the fluid became more non-Newtonian. The Bingham number $\left(B_{n}\right)$ is a dimensionless parameter that when it is equal to zero describes a Newtonian fluid and when it is equal to infinity describes an unyielding solid. The experimental results approached the theoretical/numerical results as the Bingham number approached 40 .

\section{References}

de Alba, P., and Ballestero, T. P. (2006). "Residual strength after liquefaction: A rheological approach." Soil Dyn. Earthquake Eng., 26(2-4), 143-151.

Dewoolkar, M., Hargy, J., Anderson, I., de Alba, P., and Olson, S.M. (2016) "Residual and Postliquefaction Strength of a Liquefiable Sand." J. Geotech. Geoenviron. Eng., 142(2): 04015068.

Jacobs, J.S. (2016) "Full-Scale Shake Table Cyclic Simple Shear Testing of Liquefiable Soil." Thesis in partial fulfillment of MS degree in Civil and Environmental Engineering, California Polytechnic State University, January: http://digitalcommons.calpoly.edu/theses/1527/.

Moss, R. E. S. and Crosariol, V. (2013). "Shake table testing to quantify seismic soil-structure- interaction of underground structures." Earthquake Spectra, 29(4) pp. 1413-1440. 
Randolph, M. G., and Houlsby, G. T. (1984). "The limiting pressure on a circular pile loaded laterally in cohesive soil." Geotechnique, London, England, 34(4), 613-623.

Stewart, D.P., and Randolph, M.F. (1994) "T-Bar Penetraiton Testing in Soft Clay.” J. Geotech. Engrg., 120(12): 2230-2235.

Tokpavi, D., L., Magnin, A., and Jay, P. (2008). "Very slow flow of Bingham viscoplastic fluid around a circular cylinder." Journal of Non-Newtonian Fluid Mechanics, 154, 65-76.

Tokpavi, D., L., Jay, P., Magnin, A., and Jossic, L. (2009). "Experimental study of the very slow flow of a yield stress fluid around a circular cylinder." Journal of Non-Newtonian Fluid Mechanics, 164, 35-44. 